RENATA ELAINE PARAIZO LEITE

\title{
Determinação de elementos traço no encéfalo de idosos em
} diferentes estados cognitivos

Tese apresentada à Faculdade de Medicina da Universidade de São Paulo para obtenção do título de Doutor em Ciências

Área de concentração: Patologia

Orientador: Prof. Dr. Wilson Jacob Filho

São Paulo 
Dados Internacionais de Catalogação na Publicação (CIP)

Preparada pela Biblioteca da

Faculdade de Medicina da Universidade de São Paulo

Creprodução autorizada pelo autor

\section{Leite, Renata Elaine Paraizo}

Determinação de elementos traço no encéfalo de idosos em diferentes estados cognitivos / Renata Elaine Paraizo Leite. -- São Paulo, 2009.

Tese(doutorado)--Faculdade de Medicina da Universidade de São Paulo.

Departamento de Patologia.

Área de concentração: Patologia.

Orientador: Wilson Jacob Filho.

Descritores: 1.Elementos 2.Encéfalo 3.Idoso 4.Envelhecimento 5.Cognição 6.Doença de Alzheimer

USP/FM/SBD-283/09 


\section{DEDICATÓRIA}

Aos meus pais

Que renunciaram a muito para priorizar minha educação. Apoiaram minha decisão de deixar o aconchego de nosso lar na pequena cidade do interior para viver a quase $700 \mathrm{~km}$ de distância para realização desta tese de doutoramento. Entenderam minha ausência no período em que estive não a 700, mas sim a $7.000 \mathrm{~km}$ de distância, para realização de meu doutorado-sanduíche em Boston. O orgulhoso que sentem ao falar do meu trabalho é fonte de inspiração!

\section{À minha irmã Paula}

Facilitadora e incentivadora da boa alimentação e prática de atividade física. Extremamente bondosa e simpática, uma grande amiga na infância, adolescência e durante todo o processo de formação profissional, um exemplo de pessoa.

Aos meus irmãos Márcia e Marcelo e sobrinhos Fernanda, Denise e Gustavo

Pessoas com as quais os laços permanecem unidos apesar da distância. O abraço sincero a cada reencontro, as conversas, o carinho me enchem de alegria. Sinto muito orgulho de nossa família!

\section{Ao Ricardo Di Lazzaro Filho}

Tornou-se amigo por um interesse em comum: estudar o envelhecimento. Tornou-se, mais tarde, namorado por inúmeras razões: carinho, atenção, dedicação, apoio. Aquele que me traz alegria e que não canso de desejar ao meu lado! 


\section{AGRADECIMENTOS}

Às famílias que, mesmo em um momento de luto, consentiram em doar o tecido encefálico visando ajudar o próximo e colaborar com o desenvolvimento da ciência em nosso país.

Ao Prof. Dr. Carlos Augusto Pasqualucci pela supervisão no Programa de Aperfeiçoamento do Ensino da FMUSP, por constantemente estimular o trabalho em equipe e dedicar-se ao desenvolvimento do Grupo de Estudos em Envelhecimento Cerebral.

À Prof. Dra. Lea Grinberg, por me ensinar muito do que sei sobre o cérebro e por realizar a análise neuropatológica dos casos do presente estudo. Suas dicas e ensinamentos sobre neurociências foram fundamentais para realização deste trabalho e para minha formação.

À Dra Renata Ferretti, que colaborou de forma significativa para este trabalho por meio da aplicação rigorosa e organizada dos instrumentos de avaliação clínica.

Ao Dr José Marcelo Farfel pela colaboração com o Grupo de Estudo em Envelhecimento Cerebral e Laboratório de Fisiopatologia no Envelhecimento, fundamentais para o desenvolvimento deste trabalho. 
Ao Prof. Dr. Paulo Saldiva, Prof. Dr. Ricardo Nitrini e Prof. Dr. Sérgio Rosemberg pelos ensinamentos e incentivo.

À Ana Tereza di Lorenzo Alho e Kátia Cristina Oliveira pelo auxílio, de forma responsável e dedicada, com os diversos assuntos do Laboratório de Fisiopatologia no Envelhecimento.

À Edilaine Trampelli e Lívia Polichiso pela disponibilidade e prontidão no processamento e seleção dos casos utilizados no presente estudo e pelo valioso auxílio na organização do Laboratório de Fisiopatologia no Envelhecimento.

À todos os estagiários e ex-estagiários do Laboratório de Fisiopatologia no Envelhecimento que atuaram de forma dedicada na coleta, processamento e aplicação da entrevista clínica dos casos que compõem a casuística do Banco de Encéfalos Humanos do Grupo de Estudos em Envelhecimento Cerebral da FMUSP, utilizados no presente estudo. O trabalho desta equipe foi indispensável na viabilização deste trabalho!

À Dra Claudia Suemoto e Dra Mara Patrícia de Andrade que chegaram posteriormente para constituir nosso grupo, mas cuja participação e colaboração são muito importantes. 
À todos os funcionários técnicos, administrativos e médicos do Serviço de Verificação de Óbitos da Capital cuja colaboração foi imprescindível na realização deste trabalho.

À Sra Marta Crocci, pelo zelo e carinho com os integrantes do Laboratório de Fisiopatologia no Envelhecimento e pela responsabilidade e dedicação com os assuntos administrativos.

À Dra Elina Kikuchi e equipe da disciplina de Geriatria da FMUSP pela supervisão no estágio do Programa de Aperfeiçoamento do Ensino da FMUSP.

Aos Srs. Ruberval da Silva e aos funcionários da FMUSP César José de Oliveira, Reginaldo do Nascimento, Gerson Batista da Silva e Ana Luiza sempre solícitos e dispostos a auxiliar nos mais diversos assuntos relacionados ao desenvolvimento do Laboratório de Fisiopatologia no Envelhecimento.

À Dra. Carmen Diva Saldiva de André por me ensinar estatística e pelo imenso auxílio na análise dos dados do presente trabalho.

Ao amigo e professor de inglês Bill Presada pelo auxílio na preparação do resumo em inglês da presente tese e pela colaboração no aprimoramento do idioma nos meses que antecederam meu doutorado-sanduíche. 
À funcionária do departamento de Patologia, Liduvina Barros, pela eficiência e simpatia ao tratar dos assuntos da pós-graduação.

À Coordenação de Aperfeiçoamento de Pessoal de Nível Superior pela concessão das bolsas de estudo de doutorado no país e doutorado-sanduíche.

À Fundação de Amparo à Pesquisa do Estado de São Paulo, ao Conselho Nacional de Desenvolvimento Científico e Tecnológico, ao Instituto Israelita de Ensino e Pesquisa Albert Einstein, ao LIM 05 - FMUSP e Disciplina de Geriatria FMUSP pelo apoio financeiro. 


\section{AGRADECIMENTO ESPECIAL}

Ao meu orientador Prof. Dr. Wilson Jacob Filho

Por me receber, sem mesmo me conhecer, na porta da FMUSP e ouvir atenciosamente meus planos e aspirações, enquanto saboreávamos um café no quinto andar. A esta primeira hora de conversa se somaram inúmeras outras até a finalização deste trabalho. Este mestre, sempre muito atencioso e paciente, me orientou, compartilhou momentos de dúvida, apontou os erros, instigou-me a questionar, colaborou de forma significativa para meu amadurecimento.

Nestes cinco anos de convivência me tornei especialista em Gerontologia e aprendi muito sobre envelhecimento. Sua incansável orientação resultou não somente neste trabalho como também na certeza da carreira a ser seguida.

Sou sinceramente grata pelo privilégio de sua orientação e amizade.

\section{À Prof. Dra. Mitiko Saiki}

Excelente pesquisadora, que muito colaborou para o desenvolvimento deste trabalho e para meu desenvolvimento profissional. De forma encantadora, me ensinou muito sobre o método de irradiação com nêutrons e os elementos traço. Com ela também aprendi muito sobre organização e redação científica. Levarei sempre comigo seus ensinamentos. 


\section{SUMÁRIO}

\section{LISTA DE FIGURAS}

LISTA DE TABELAS

LISTA DE ABREVIATURAS, SIGLAS E SÍMBOLOS

RESUMO

\section{SUMMARY}

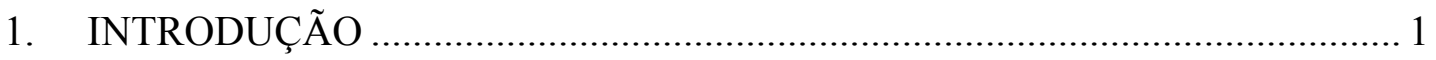

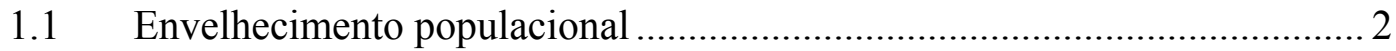

1.2 Envelhecimento da população no Brasil ..................................................... 3

1.3 O envelhecimento da população nos países em desenvolvimento................. 4

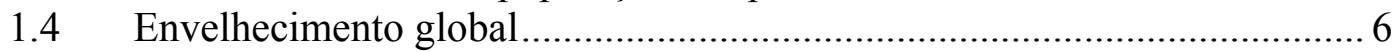

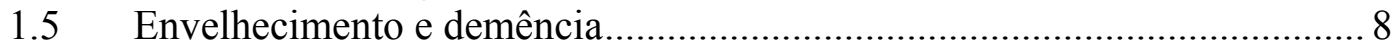

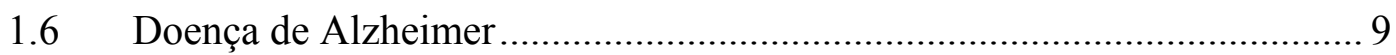

1.7 Presença de sinais neuropatológicos da DA e ausência de sintomas clínicos

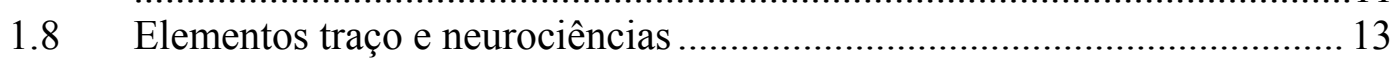

1.9 Método de análise por ativação com nêutrons ......................................... 17

1.10 Banco de encéfalos humanos do Grupo de Estudos em Envelhecimento

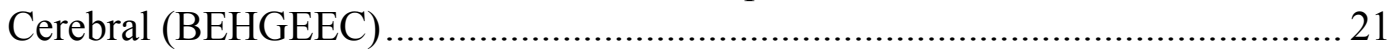

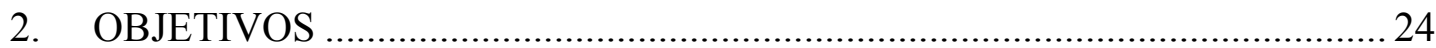

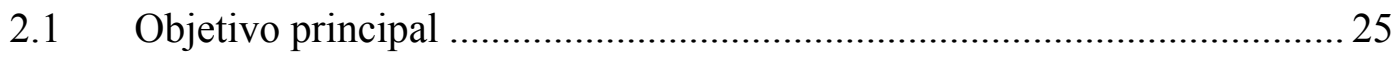

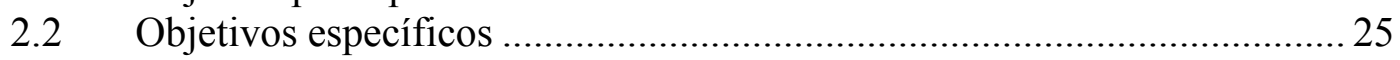

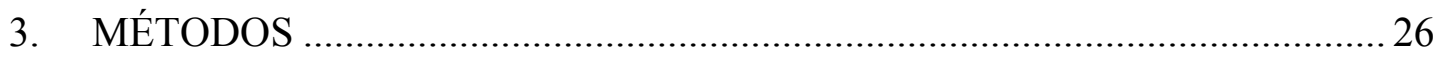

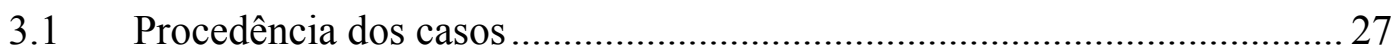

3.2 Características do BEHGEEC ............................................................... 27

3.3 Critérios de seleção de casos para o presente estudo ................................. 33

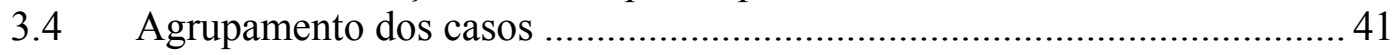

3.5 Obtenção e tratamento dos tecidos encefálicos para determinação de elementos pelo método de ativação com nêutrons ..................................................4 43

3.6 Procedimento para análise por ativação com nêutrons ............................. 44

3.7 Tratamento dos dados obtidos nas análises de tecidos cerebrais ...............46 46

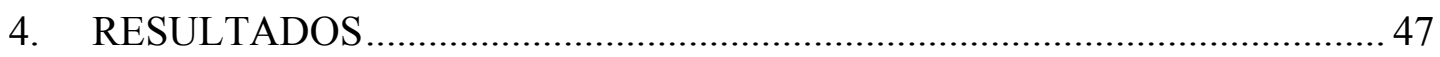

4.1 Caracterização dos grupos............................................................ 48

4.2 Comparação das médias das idades entre os grupos e entre os gêneros dos indivíduos

4.3 Comparação das concentrações médias dos elementos obtidos entre os grupos de indivíduos e entre regiões do encéfalo ................................................51

4.4 Comparação das concentrações de cada um dos elementos obtidos entre grupos de indivíduos 
4.5 Comparação das médias das concentrações entre grupos de indivíduos ... 60

4.6 Comparação das concentrações de cada um dos elementos entre região

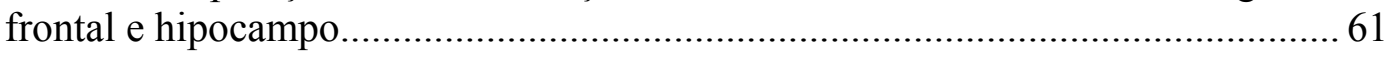

4.7 Determinação da concentração dos elementos nos materiais de referência

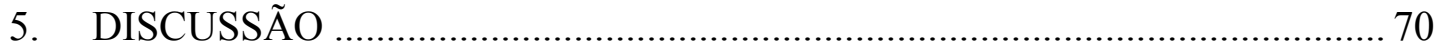

5.1 Rubídio, sódio e potássio na doença de Alzheimer.................................. 71

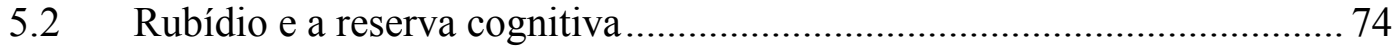

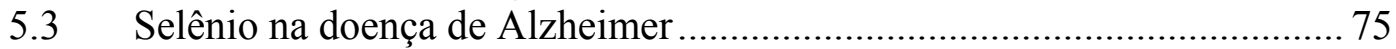

5.4 Ferro na Doença de Alzheimer ................................................................. 77

5.5 Zinco na doença de Alzheimer.................................................................. 78

5.6 Bromo na doença de Alzheimer........................................................... 79

5.7 Comparação entre concentrações de elementos presentes nas regiões

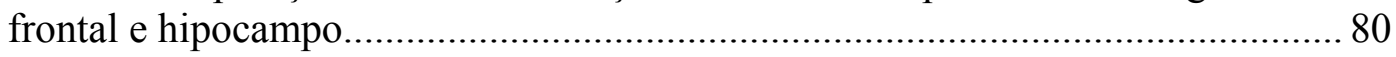

5.8 Considerações sobre a qualidade dos resultados analíticos ..................... 81

5.9 Terapias para DA envolvendo os elementos traço .................................... 84

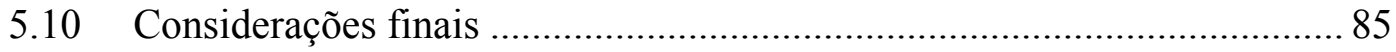

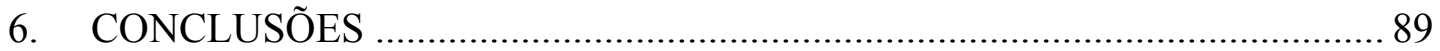

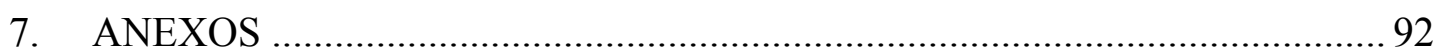

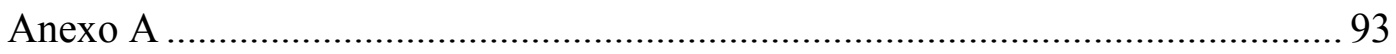

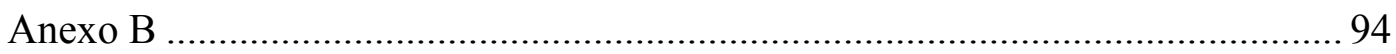

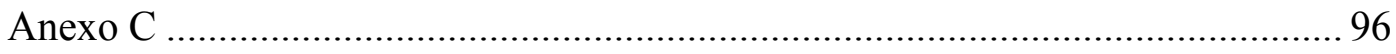

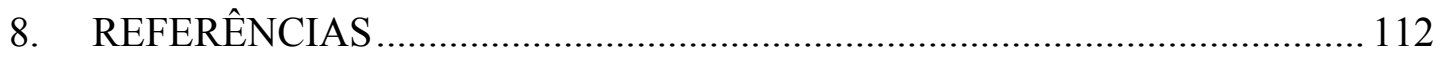




\section{LISTA DE FIGURAS}

Figura 01 - Representação gráfica da proporção de pessoas com 60 anos de idade ou mais em determinados países - 1990/1999.

Figura 02 - Pirâmide da população mundial em 2002 e em 2025 .............................. 7

Figura 03 - Ilustração do processo de formação de isótopos radioativos.................. 18

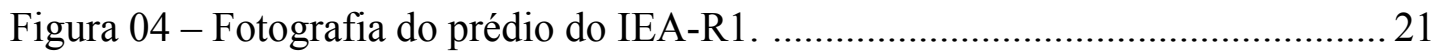

Figura 05 - Organograma representando a seleção de casos para o presente estudo. 35

Figura 06 - Classificação semiquantitativa de placas neuríticas.............................. 37

Figura 07 - Padrão de distribuição das alterações neurofibrilares.............................. 38

Figura 08 - Esquema representativo das áreas coletadas para determinação de elementos pelo método de ativação com nêutrons.

Figura 09 - Valores individuais e médios das concentrações de rubídio $(\mathrm{Rb})$ para grupos de indivíduos e regiões do encéfalo.

Figura 10 - Valores individuais e médios das concentrações de selênio (Se) para grupos de indivíduos e regiões do encéfalo. .................................................. 54

Figura 11 - Valores individuais e médios das concentrações de ferro $(\mathrm{Fe})$ para grupos de indivíduos e regiões do encéfalo.

Figura 12 - Valores individuais e médios das concentrações de zinco (Zn) para grupos de indivíduos e regiões do encéfalo.

Figura 13 - Valores individuais e médios das concentrações de bromo $(\mathrm{Br})$ para grupos de indivíduos e regiões do encéfalo.

Figura 14 - Valores individuais e médios das concentrações de sódio $(\mathrm{Na})$ para grupos de indivíduos e regiões do encéfalo.

Figura 15 - Valores individuais e médios das concentrações de potássio (K) para grupos de indivíduos e regiões do encéfalo.

Figura 16 - Valores individuais e médios das concentrações de rubídio $(\mathrm{Rb}) \mathrm{em}$ região frontal e hipocampo para cada um dos grupos de indivíduos. 
Figura 17 - Valores individuais e médios das concentrações de selênio (Se) em região frontal e hipocampo para cada um dos grupos de indivíduos.

Figura 18 - Valores individuais e médios das concentrações de ferro $(\mathrm{Fe})$ em região frontal e hipocampo para cada um dos grupos de indivíduos.

Figura 19 - Valores individuais e médios das concentrações de zinco (Zn) em região frontal e hipocampo para cada um dos grupos de indivíduos...........................6 65

Figura 20 - Valores individuais e médios das concentrações de bromo $(\mathrm{Br})$ em região frontal e hipocampo para cada um dos grupos de indivíduos. 66

Figura 21 - Valores individuais e médios das concentrações de sódio $(\mathrm{Na})$ em região frontal e hipocampo para cada um dos grupos de indivíduos. 67

Figura 22 - Valores individuais e médios das concentrações de potássio (K) em região frontal e hipocampo para cada um dos grupos de indivíduos. 68 


\section{LISTA DE TABELAS}

Tabela 01 - Proporção da população com mais de 65 anos residentes no Brasil, segundo a região geográfica - Ranking descendente

Tabela 02 - Tipos de tecidos coletados e seus respectivos procedimentos para amostragem - Banco de encéfalos do Grupo de Estudos em Envelhecimento Cerebral

Tabela 03 - Áreas imunocoradas e anticorpos usados rotineiramente no Banco de encéfalos do Grupo de Estudos em Envelhecimento Cerebral

Tabela 04 - Motivos de exclusão e número de casos excluídos do grupo de portadores de declínio cognitivo grave (CDR 3)

Tabela 05 - Grupo, idade, gênero, classificação clínica e neuropatológica para cada caso do presente estudo

Tabela 06 - Critérios clínicos e neuropatológicos para formação dos grupos no presente estudo

Tabela 07 - Agrupamento dos casos do presente estudo de acordo com a avaliação clínica e neuropatológica

Tabela 08 - Concentrações elementar (mg/kg, base seca) no encefálico do grupo DA

Tabela 09 - Concentração elementar (mg/kg, base seca) no encéfalo do grupo RC . 49

Tabela 10 - Concentração elementar (mg/kg, base seca) no encéfalo do grupo NN. 50

Tabela 11 - Resultados dos parâmetros obtidos na análise de variância com medidas repetidas

Tabela 12 - Concentrações médias ( $\mathrm{mg} / \mathrm{kg}$, base seca) dos elementos nos três grupos de indivíduos e nas duas regiões de estudo.

Tabela 13 - Resultado das comparações das concentrações médias dos elementos entre os grupos de indivíduos, dois a dois, na região frontal e hipocampo

Tabela 14 - Concentração dos elementos nos materiais de referência NIST 1566b Oyster Tissue e NIST 1577b Bovine Liver (mg/kg).

Tabela 15 - Resultados das comparações das médias das concentrações de elementos entre hipocampo e região frontal, para os três grupos em estudo 
Tabela 16 - Valores da concentração média de elementos no encéfalo de indivíduos normais obtidos no presente estudo e na literatura ......................................... 82

Tabela 17 - Valores da concentração média de elementos no encéfalo de indivíduos portadores de DA obtidos no presente estudo e na literatura. .83 


\section{LISTA DE ABREVIATURAS, SIGLAS E SÍMBOLOS}

\begin{tabular}{|c|c|}
\hline$\mu \mathrm{g}$ & Micrograma \\
\hline$<$ & Menor que \\
\hline$=$ & Igual a \\
\hline$>$ & Maior que \\
\hline BEHGEEC & $\begin{array}{l}\text { Banco de Encéfalos Humanos do Grupo de Estudos em } \\
\text { Envelhecimento Cerebral }\end{array}$ \\
\hline $\mathrm{Br}$ & Bromo \\
\hline CAPPesq & Comissão de Ética para Análise de Projetos de Pesquisa \\
\hline CDR & Questionário para Avaliação Clínica da Demência \\
\hline CDTN & Centro de Desenvolvimento de Tecnologia Nuclear \\
\hline CERAD & $\begin{array}{l}\text { Consórcio para estabelecimento de registro de doença de } \\
\text { Alzheimer }\end{array}$ \\
\hline $\mathrm{cm}$ & Centímetros \\
\hline $\mathrm{cm}^{2}$ & Centímetro quadrado \\
\hline $\mathrm{Cu}$ & Cobre \\
\hline DA & Doença de Alzheimer \\
\hline Dr. & Doutor \\
\hline DVa & Demência vascular \\
\hline ed. & Edição \\
\hline ENFs & Emaranhados neurofibrilares \\
\hline et al. & E outros \\
\hline & Ferro \\
\hline
\end{tabular}


FMUSP

GEEC

h

HCFMUSP

HE

$\mathrm{HOBr}$

IEN

IML

IPEN

IQCODE

IUPAC

K

keV

$\mathrm{kg}$

mg

Min

$\mathrm{mm}^{2}$

$\mathrm{Na}$

NIST

NT

OMS

p.

pH
Faculdade de Medicina da Universidade de São Paulo

Grupo de Estudos em Envelhecimento Cerebral

Horas

Hospital das Clínicas da Faculdade de Medicina da Universidade de São Paulo

Hematoxilina-eosina

Ácido hipobromoso

Instituto de Engenharia Nuclear

Instituto Médico Legal

Instituto de Pesquisa Energéticas e Nucleares

Questionário de Declínio Cognitivo do Idoso

International Union of Pure and Applied Chemistry

Potássio

quilo elétrons-volt

Kilograma

Miligrama

Minutos

Milímetros quadrado

Sódio

National Institute of Standards and Technology

Neuropil threads

Organização Mundial da Saúde

Página

potencial hidrogeniônico 


$\begin{array}{ll}\text { PNs } & \text { Placas neuríticas } \\ \text { Prof. } & \text { Professor } \\ \text { Rb } & \text { Rubídio } \\ \text { RC } & \text { Reserva cognitiva } \\ \text { rev. } & \text { Revista } \\ \text { S } & \text { Segundo } \\ \text { Se } & \text { Selênio } \\ \text { SVOC } & \text { Serviço de Verificação de Óbitos da Capital } \\ \text { v. } & \text { Volume } \\ \text { Zn } & \text { Zinco } \\ \beta A & \text { Beta amilóide }\end{array}$




\section{RESUMO}

Leite REP. Determinação de elementos traço no encéfalo de idosos em diferentes estados cognitivos [tese]. São Paulo: Faculdade de Medicina, Universidade de São Paulo; 2009. $123 \mathrm{p}$.

Dentre as várias hipóteses envolvendo a etiologia da doença de Alzheimer (DA), estudos sobre o envolvimento dos elementos traço têm recebido considerável atenção. O objetivo do presente trabalho foi comparar as concentrações de $\mathrm{Br}, \mathrm{Fe}, \mathrm{K}$, $\mathrm{Na}, \mathrm{Rb}$, Se e $\mathrm{Zn}$ no encéfalo de idosos com diferentes estados cognitivos bem como entre regiões do encéfalo de casos post mortem, provenientes do Banco de Encéfalos Humanos do Grupo de Estudos em Envelhecimento Cerebral. O desenvolvimento da presente pesquisa foi aprovado pelo Comitê de Ética local. Os casos foram divididos em três grupos levando-se em conta tanto a análise clínica quanto a neuropatológica: (1) grupo DA: indivíduos com sinais clínicos e neuropatológicos de DA $(\mathrm{n}=13)$, (2) grupo $\mathrm{NN}$ : indivíduos sem sinais clínicos e neuropatológicos de DA ( $\mathrm{n}=11)$ e (3) grupo $\mathrm{RC}$ : indivíduos cognitivamente normais, porém com sinais neuropatológicos característicos de DA $(n=4)$. A análise neuropatológica foi realizada com base em critérios bem aceitos, usando imunoistoquímica. $\mathrm{O}$ diagnóstico de demência foi realizado por meio de entrevista com um informante. As concentrações dos elementos foram determinadas no hipocampo e no giro frontal médio utilizando-se o método de análise por ativação com nêutrons. Materiais de referência certificados foram analisados a fim de verificar a qualidade dos resultados analíticos. A análise estatística dos resultados obtidos nas análises do tecido encefálico foi realizada utilizando-se os aplicativos Minitab v15 e SPSS v11. As variáveis foram comparadas entre os grupos utilizando-se o método de análise de variância com medidas repetidas. A análise dos resultados obtidos nos materiais de referência mostrou que a análise por ativação com nêutrons é um método preciso e exato para análise de encéfalos humanos. Os resultados das análises do encéfalo mostraram que há uma diminuição das concentrações de $\mathrm{Rb}$ no encéfalo de portadores de $\mathrm{DA}$ quando comparadas com as de indivíduos dos grupos NN e RC. Além disso, há uma redução das concentrações de $\mathrm{K}$ e uma elevação das concentrações de Na no encéfalo dos indivíduos portadores de DA quando comparados com as de indivíduos NN. Uma elevação nas concentrações de Fe e de Se também foi verificada no grupo DA quando comparado com as do grupo NN. A comparação entre as concentrações dos elementos na região frontal e no hipocampo mostrou que há diferença nas concentrações entre estas duas regiões para vários elementos. As altas concentrações de Rb nos indivíduos RC quando comparadas com as do grupo DA e sua redução no grupo DA quando comparadas com as do grupo NN sugerem um papel do Rb nos mecanismos contra DA. Entretanto, as variações nas concentrações de $\mathrm{Rb}$, assim como as de $\mathrm{Na}$ e $\mathrm{K}$ podem ser secundárias ao processo patológico. As altas concentrações de Fe nos encéfalos do grupo DA sugerem que este elemento pode ser um fator tóxico na DA e as altas concentrações de Se podem atuar no mecanismo de proteção. No entanto, cabe ainda verificar se a deposição dos elementos é um evento primário ou secundário à doença. As diferenças encontradas entre as concentrações de elementos nas diferentes regiões do encéfalo salientam a importância de realizar-se uma amostragem apropriada para determinação da composição do tecido cerebral.

Descritores: elementos, encéfalo, idoso, envelhecimento, cognição, doença de Alzheimer 


\section{SUMMARY}

Leite REP. Determination of trace elements in brain of elderly people in different cognitive status [thesis]. São Paulo: Faculdade de Medicina, Universidade de São Paulo; 2009. 123p.

Among the many hypotheses concerning the etiology of Alzheimer's disease (AD), studies regarding the involvement of trace elements have gained considerable attention. This study aimed to compare $\mathrm{Br}, \mathrm{Fe}, \mathrm{K}, \mathrm{Na}, \mathrm{Rb}$, Se and $\mathrm{Zn}$ concentrations in brain of elderly people in different cognitive status and between brain regions in postmortem brains belonging to the Brazilian Aging Brain Study Group's Brain Bank. Protocols were approved by the responsible ethics committee. The cases were divided into three groups, according to clinical and neuropathological evaluations: (1) AD group: individuals with clinical symptoms and neuropathological hallmarks of $\mathrm{AD}(\mathrm{n}=13),(2) \mathrm{NN}$ group: individuals without clinical symptoms and neuropathological hallmarks of $\mathrm{AD}(\mathrm{n}=11)$ and (3) RC group: individuals cognitively normal but with neuropathological hallmarks of $\mathrm{AD}(\mathrm{n}=4)$. Neuropathological examinations were carried out based on accepted criteria, using immunohistochemistry. Diagnosis of dementia was established through a postmortem interview with an informant. Element concentration in the hippocampus and medium frontal cortex was determined using instrumental neutron activation analysis. Certified reference materials were analyzed to assure the quality of the analytical results. Statistical analysis of the results obtained in the brain tissue was performed using the Minitab v15 and SPSS v11 package. Variables were compared among groups using repeated measurement analyses of the variances. Reference material analysis results demonstrated that neutron activation analysis is a precise and exact method for element concentration analysis of the human brain. The results of the brain analysis demonstrated a decrease of $\mathrm{Rb}$ concentration in the brains of $\mathrm{AD}$ individuals compared to the $\mathrm{NN}$ and $\mathrm{RC}$ individuals. Furthermore, there is a decrease of $\mathrm{K}$ concentration and an increase of $\mathrm{Na}$ concentration in the brains of AD individuals compared to the $\mathrm{NN}$ individuals. An increase of $\mathrm{Fe}$ and $\mathrm{Se}$ was also verified in the AD group when compared to the NN group. Comparison of the hippocampus and frontal area concentration demonstrated a difference in the concentration of these two areas for many elements. The elevated concentration of $\mathrm{Rb}$ in the $\mathrm{RC}$ group when compared to the DA groups and the reduction in the DA groups when compared to the $\mathrm{NN}$ group suggest that $\mathrm{Rb}$ has a role in the protection mechanism against $\mathrm{AD}$. However, changes in the $\mathrm{Rb}$ concentrations, as well as changes in the $\mathrm{Na}$ e $\mathrm{K}$ concentrations could be secondary to the pathological process. The elevated concentration of Fe could be a toxic factor in $\mathrm{AD}$ and the elevated concentration of Se could be a protection mechanism. Whether element deposition in $\mathrm{AD}$ is a primary or secondary event remains to be determined. As a result of the differences found in the concentrations of elements highlight the importance of having ideal sampling to determine element composition of brain tissue.

Descriptors: elements, brain, elderly, aging, cognition, Alzheimer's disease 
1. INTRODUÇÃO 


\subsection{Envelhecimento populacional}

A Organização Mundial da Saúde (OMS) define a população idosa como aquela a partir dos 60 anos de idade, mas faz uma distinção quanto ao local de residência dos idosos. Este limite é válido para os países em desenvolvimento, subindo para 65 anos de idade quando se trata de países desenvolvidos (IBGE, 2002).

Apesar de o envelhecimento ser um processo comum a todos os animais, ainda hoje persistem pontos obscuros quanto à dinâmica e à natureza deste processo (Papáleo-Netto, 2006). Segundo Comfort (1979), o processo de envelhecimento se caracteriza por uma redução progressiva da capacidade de manutenção da homeostase, em condições de sobrecarga funcional. Este processo é acompanhado de uma tênue divisão entre a fisiologia e a fisiopatologia do envelhecimento. $\mathrm{O}$ envelhecimento natural (senescência) é um conjunto de modificações orgânicas, funcionais e psicológicas próprias do envelhecimento, enquanto que o envelhecimento patológico (senilidade) é um conjunto de alterações decorrentes de doenças. $\mathrm{O}$ exato limite entre estes dois estados não é preciso. Entretanto, para compreender o envelhecimento é importante, antes de tudo, diferenciar envelhecimento de aumento de longevidade.

Longevidade refere-se ao número de anos vividos por um indivíduo ou ao número de anos que, em média, as pessoas de uma mesma geração ou coorte (conjunto de recém-nascidos em um mesmo momento ou mesmo intervalo de tempo) viverão (Carvalho e Garcia, 2003). O envelhecimento populacional não se refere nem 
a indivíduos, nem a cada geração, mas, sim, à mudança na estrutura etária da população, o que produz um aumento do peso relativo das pessoas idosas, considerada como definidora do início da velhice (Carvalho e Garcia, 2003).

Os fatores determinantes do envelhecimento populacional de um país são, fundamentalmente, ditados pelo comportamento de suas taxas de fertilidade e, de modo menos importante, de suas taxas de mortalidade (Kalache, 1987). Ou seja, ao se começar o declínio sustentado de fecundidade é que se dá início ao processo de envelhecimento de uma população (Carvalho e Garcia, 2003).

Em todo o mundo, a proporção de pessoas com 60 anos ou mais está crescendo mais rapidamente que a de qualquer outra faixa etária. Entre 1970 e 2025, espera-se um crescimento de $223 \%$, ou em torno de 694 milhões, no número de indivíduos idosos (OMS, 2005).

\subsection{Envelhecimento da população no Brasil}

O Brasil deste início de milênio já é um país de idosos (Garrido e Menezes, 2002) e o envelhecimento da população brasileira é um fato irreversível, e que deverá se acentuar no futuro próximo imediato (Kalache, 1987). O Brasil já apresenta um dos mais agudos processos de envelhecimento populacional entre os países mais populosos (Giatti e Barreto, 2003) e até 2025 será o sexto país do mundo em número de idosos (OMS, 2005).

De acordo com o censo demográfico, a população de 60 anos de idade ou mais, no Brasil, em 2000 era de 14.536.029 de pessoas, contra 10.722.705 em 1991. Em 1996, eram 16 idosos para cada 100 crianças; em 2000, eram quase 30 idosos 
para 100 crianças. O peso relativo da população idosa no início da década representava 7,3\%, enquanto, em 2000, essa proporção atingia 8,6\%. Neste período, por conseguinte, o número de idosos aumentou em quase 4 milhões de pessoas, fruto do crescimento vegetativo e do aumento gradual da esperança média de vida. Tratase, certamente, de um conjunto bastante elevado de pessoas, com tendência de crescimento nos próximos anos. Na população idosa, o segmento que, no período intercensitário, mais cresceu relativamente foi aquele das pessoas de 75 anos ou mais, 49,3\%, alterando a composição interna do próprio grupo e revelando uma heterogeneidade de características deste segmento populacional (IBGE, 2002).

Em termos regionais, a Região Sudeste tem o maior percentual de pessoas com mais de 60 anos: 11,7\%. E o menor cabe à Região Norte: 6,7\% (Tabela 01). Em termos absolutos, registrou-se no Brasil no ano de 2007 19.955 milhões de idosos (IBGE, PNAD 2007).

Tabela 01 - Proporção da população com mais de 65 anos residentes no Brasil, segundo a região geográfica - Ranking descendente

\begin{tabular}{lr}
\hline Região geográfica & Porcentagem \\
\hline Sudeste & 11,7 \\
Sul & 11,4 \\
Nordeste & 9,8 \\
Centro-Oeste & 8,6 \\
Norte & 6,7 \\
\hline
\end{tabular}

Fonte: IBGE, PNAD (2007)

\section{3 envelhecimento da população nos países em desenvolvimento}

$\mathrm{O}$ rápido envelhecimento populacional não é, naturalmente, uma característica única do Brasil, sendo compartilhado, de modo mais ou menos 
acentuado, por diversos outros países em desenvolvimento (Kalache, 1987) como, por exemplo, o México (Garrido e Menezes, 2002). De modo geral, os países em desenvolvimento vêm sofrendo um crescimento da população de idosos de forma mais acentuada (IBGE, 2002; Lopes e Bottino, 2002), embora este contingente ainda seja proporcionalmente bem inferior ao encontrado nos países desenvolvidos (IBGE, 2002).

Em relação aos países da América Latina, o Brasil assume uma posição intermediária, com uma população de idosos correspondendo a 8,6\% da população total (Figura 01). Entretanto, a região latino-americana apresenta uma grande diversidade, com a proporção de idosos variando de $6,4 \%$ na Venezuela a $17,1 \%$ no Uruguai (IBGE, 2002).

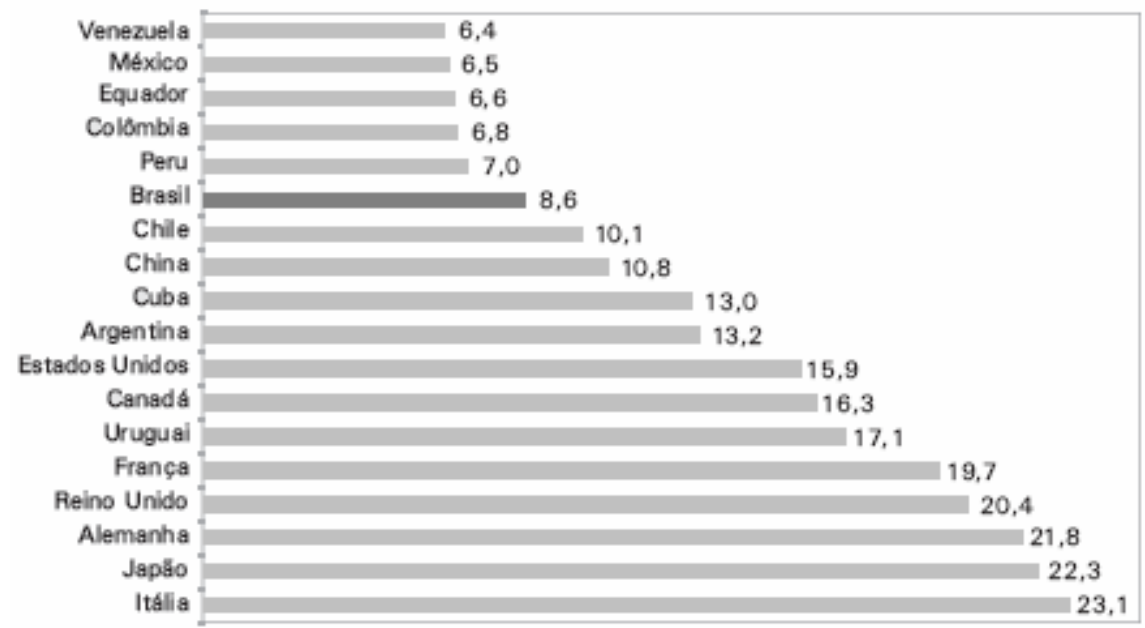

Figura 01 - Representação gráfica da proporção de pessoas com 60 anos de idade ou mais em determinados países - 1990/1999. Modificado de IBGE (2002).

Em 2002, quase 400 milhões de pessoas com 60 anos ou mais viviam no mundo em desenvolvimento. Até 2025, este número terá aumentado para 
aproximadamente 840 milhões, o que representa 70 por cento das pessoas na $3^{\text {a }}$ idade em todo o mundo. Até 2050 haverá dois bilhões, sendo $80 \%$ nos países em desenvolvimento (OMS, 2005).

\subsection{Envelhecimento global}

Em todo o mundo a possibilidade de envelhecer é a maior em toda a história da humanidade (Crews, 2007). China, Japão e países da Europa e da América do Norte já convivem há muito tempo com um grande contingente de idosos (Garrido e Menezes, 2002). As populações européias apresentam, caracteristicamente, proporções mais elevadas, com os idosos representando algo em torno de 1/5 da população de seus países (IBGE, 2002). Ou seja, até agora, o envelhecimento da população esteve muito associado às regiões mais desenvolvidas do mundo. Por exemplo, nove entre dez países com população maior que 10 milhões e com maior proporção de habitantes idosos está localizado na Europa. Espera-se pouca mudança nesta ordem até 2025, quando os indivíduos com 60 anos ou mais irão constituir aproximadamente um terço da população de países como Japão, Alemanha e Itália, seguidos de perto por outros países europeus.

Em todos os países, especialmente nos desenvolvidos, a população mais velha está envelhecendo também. Atualmente, o número de pessoas com mais de 80 anos chega a 69 milhões, e a maioria vive em regiões mais desenvolvidas. Apesar dos indivíduos com mais de 80 anos representarem aproximadamente um por cento da população mundial e três por cento da população em regiões desenvolvidas, esta faixa etária é o segmento da população que cresce mais rapidamente (OMS, 2005). 
À medida que a proporção de crianças e jovens diminui e a proporção de pessoas com 60 anos de idade ou mais aumenta, a pirâmide triangular da população de 2002 será substituída por uma estrutura mais cilíndrica em 2025 (OMS, 2005) (Figura 02).

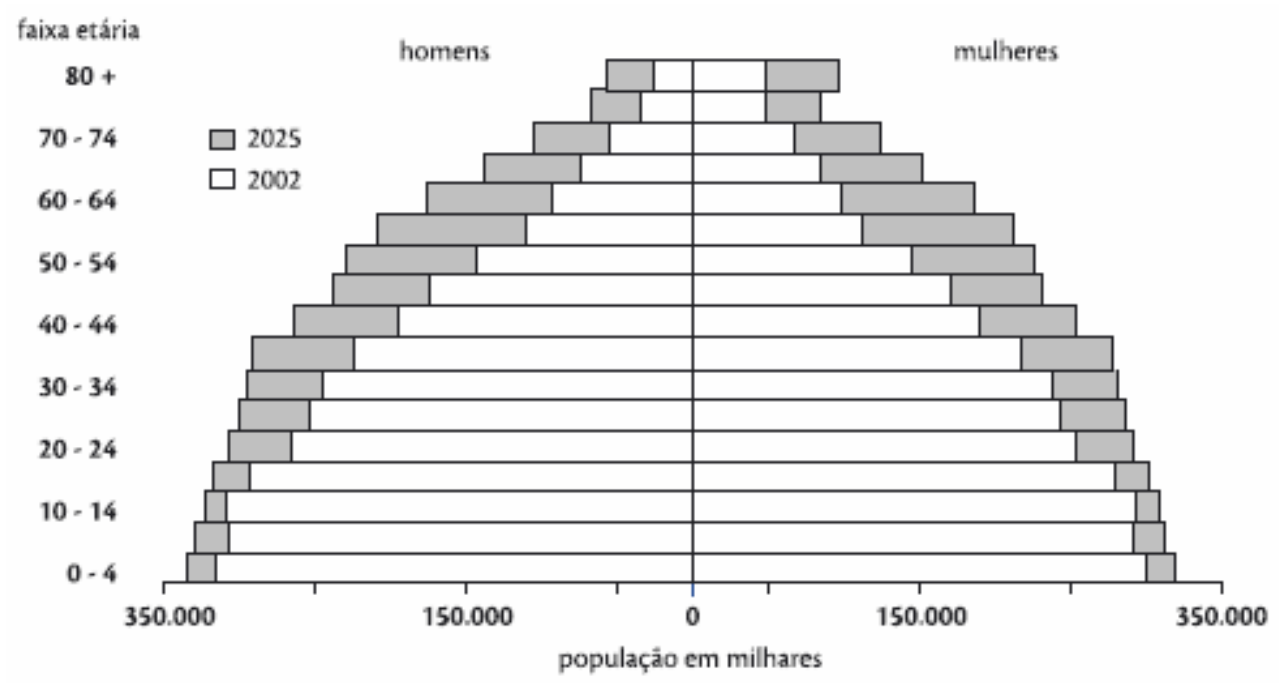

Figura 02 - Pirâmide da população mundial em 2002 e em 2025. Modificado de OMS (2005).

Comparando-se os países desenvolvidos e os em desenvolvimento, esses não têm acompanhado o ritmo rápido de envelhecimento da população em termos de desenvolvimento sócio-econômico (OMS, 2005). Enquanto a França, por exemplo, levou 115 anos para dobrar a proporção de pessoas mais velhas de 7 para 14 por cento, a China levará somente 27 anos para atingir o mesmo aumento. Na maior parte do mundo desenvolvido, o envelhecimento da população foi um processo gradual acompanhado de crescimento socioeconômico constante durante muitas décadas e gerações. Já nos países em desenvolvimento, este processo de envelhecimento está sendo reduzido a duas ou três décadas (OMS, 2005). 


\subsection{Envelhecimento e demência}

Embora o envelhecimento seja um dos maiores triunfos da humanidade, é também um dos nossos grandes desafios (OMS, 2005). As mudanças demográficas, resultantes do aumento da expectativa de vida, e o forte aumento dos indivíduos idosos, particularmente dos muitos idosos, levaram a um drástico aumento no número de indivíduos dementados e portadores de doença de Alzheimer (DA) (Jellinger, 2006), tornando os quadros de demência cada vez mais prevalentes (Lopes e Bottino, 2002) e um dos maiores problemas de saúde pública (Nitrini et al., 2004).

Ferri et al. (2005) estimaram que um novo caso de demência surja no mundo a cada 7 segundos, perfazendo um total de 4,6 milhões de casos ao ano. Estimaram também que o número de pessoas afetadas pela demência irá dobrar a cada ano, a ponto de que em 2040 haverá cerca 81 milhões de indivíduos dementados.

Em um recente estudo brasileiro, realizado com idosos do município de Catanduva, Nitrini et al. (2004) verificaram que a prevalência de demência neste município dobrou a cada cinco anos de idade a partir dos 65 anos até os 79 anos de idade e continuou a aumentar, porém num ritmo menor, com o avançar da idade.

Lopes e Bottino (2002) ao analisarem a prevalência de demência em diversas regiões do mundo encontraram que o efeito da idade sobre o aumento das taxas de prevalência foi pronunciado, principalmente até os 90 anos de idade.

A prevalência de demência pode diferir bastante entre regiões e mesmo dentro do mesmo país e podem refletir reais diferenças regionais nas taxas de prevalência de demência, causadas por diferenças raciais e sócio-culturais, ou mesmo diferenças nas taxas de mortalidade entre estas populações (Lopes e Bottino, 2002). 
Um estudo realizado na comunidade brasileira de Catanduva (Nitrini et al., 2004) revelou que a incidência de demência nesta comunidade é comparável àquelas relatadas em estudos asiáticos e ocidentais e que, entre as demências, a mais comum é a DA.

\subsection{Doença de Alzheimer}

Quando Alois Alzheimer apresentou o primeiro relato de caso da doença neurodegenerativa que agora leva seu nome, pensou-se tratar de uma condição rara, não hereditária e esporádica (Herz, 2007). Agora, pouco mais de cem anos depois, esta patologia alcançou proporções epidêmicas e rapidamente se transformou num grande problema socioeconômico (Herz, 2007).

Quando a doença foi nomeada por Kraepelin, o termo foi frequentemente usado para descrever casos pré-senis da doença (classicamente casos com menos de 65 anos de idade) (Hardy, 2006). Atualmente a DA é descrita como uma doença neurológica progressiva associada com o envelhecimento (Welsh-Bohmer e White, 2009).

A doença se caracteriza por processo degenerativo que acomete inicialmente a formação hipocampal, com posterior comprometimento de áreas corticais associativas e relativa preservação dos córtices primários (Caramelli e Barbosa, 2002). Essa distribuição do processo patológico faz com que o quadro clínico da DA seja caracterizado por um início de dificuldade em aprendizado e memória, que leva ao esquecimento de eventos recentes. A DA piora com o tempo, levando à dificuldade de lembrar novos eventos e dificuldade de raciocínio, prejuízo das 
atividades normais, dependência e por último à morte (Welsh-Bohmer e White, 2009). A DA tem curso lentamente progressivo, com duração média de oito anos entre o início dos sintomas e o óbito (Vilela e Caramelli, 2006). Entretanto, estima-se que a degeneração se inicie por volta de 20 a 30 anos antes do aparecimento dos primeiros sintomas (Goedert e Spillantini, 2006).

O diagnóstico clínico da DA se baseia na observação de quadro clínico compatível e na exclusão de outras causas de demência (Caramelli e Barbosa, 2002). Usando-se critérios de diagnóstico e exames clínicos, neuropsicológicos, de imagem e marcadores biológicos, a acurácia diagnóstica para DA é de aproximadamente $90 \%$ (Jellinger, 2006). O diagnóstico definitivo da DA depende de exame anatomopatológico de tecido cerebral obtido em biópsia ou necrópsia. Entretanto, na prática clínica, não há indicação de biópsia cerebral com esta finalidade (Vilela e Caramelli, 2006).

Quando o cérebro do portador de DA é examinado ao microscópio existem células e estruturas celulares anormais no cérebro, principalmente nas áreas do cérebro relacionadas à memória, incluindo o córtex entorrinal e o hipocampo. Além disso, pode haver atrofia nestas regiões (Welsh-Bohmer e White, 2009).

Os sinais neuropatológicos que atualmente formam os pilares do diagnóstico post mortem são as placas senis, um aglomerado de proteínas denominadas beta amilóide $(\beta \mathrm{A})$, e os emaranhados neurofibrilares, que consistem basicamente da agregação de microtúbulos que estabilizam a proteína tau (Herz, 2007). Placas amilóides localizam-se fora da célula e emaranhados neurofibrilares dentro da célula (Welsh-Bohmer e White, 2009). 
Atualmente sugere-se que o acúmulo de $\beta$ A é a causa da neurodegeneração que ocorre na DA (Small e Cappai, 2006). A presença de depósitos da protéina tau em desordens não relacionadas lança dúvidas sobre a importância da proteína tau e a relevância de sua disfunção para a etiologia e patogênese da DA e desordens relacionadas permanece não esclarecida (Goedert e Spillantini, 2006).

Levando-se em conta os sintomas clínicos e sinais neuropatológicos da DA, cabe ressaltar que a associação entre mudanças cerebrais patológicas e sintomas clínicos na DA não é simples (Burns, 2009). Não raro, pode-se encontrar pacientes com os sinais neuropatológicos da doença e ausência dos sintomas clínicos.

\subsection{Presença de sinais neuropatológicos da DA e ausência de sintomas clínicos}

Desde 1930 ficou demonstrado que os mesmos achados neuropatológicos relacionados à DA poderiam ser encontrados na grande maioria dos idosos com cognição normal. Os pesquisadores passaram a questionar se as placas senis e os emaranhados neurofibrilares seriam realmente relacionados à doença ou relacionados ao próprio processo de envelhecimento (Farfel, 2008).

Knopman et al. (2003) sugeriram que até certo ponto a neuropatologia não exerce efeito sobre a cognição, ou seja, para estes autores, existe limiar neuropatológico separando a senescência e a senilidade. Estes mesmos autores encontraram que a maioria dos indivíduos cognitivamente intactos possuía pouca alteração neuropatológica, mostrando que não há um processo variável de pessoa para pessoa. 
A hipótese de Knopman et al. (2003) foi confrontada por outra que dizia que certos idosos portadores de DA estariam protegidos contra o surgimento de demência e seriam possuidores de uma maior reserva cognitiva que os permitiria tolerar as agressões causadas pelas lesões cerebrais, sem desenvolver sintomas (Bennett et al., 2006), por meio da utilização mais eficiente das redes cerebrais ou um aumento da capacidade de recrutar redes alternativas quando necessário (Stern et al., 2002).

Em estudo envolvendo indivíduos muito idosos (indivíduos com idade igual ou superior a 80 anos), realizado com casuística do Banco de Encéfalos Humanos do Grupo de Estudos em Envelhecimento Cerebral, Farfel (2008) encontrou considerável porcentagem de indivíduos cognitivamente intactos que preencheram critério neuropatológico para DA e concluiu que estes indivíduos provavelmente possuíam maior reserva cognitiva, influenciada pelo grau de escolaridade.

Entretanto, a literatura não é conclusiva a respeito da existência de um possível limiar patológico distinguindo a senescência e a senilidade ou sobre a hipótese de existência de uma reserva cognitiva que permite que certos indivíduos permaneçam com cognição normal mesmo em estágios avançados de comprometimento pela DA. Assim, vários termos têm sido usados para descrever indivíduos com sinais neuropatológicos da DA e cognição normal: DA pré-clínica (Schimitt et al., 2000), envelhecimento patológico (Dickson et al., 1992), DA subclínica (Gerrlings et al., 2000) e reserva cognitiva (Bennett et al., 2006). No presente trabalho optou-se por utilizar o termo reserva cognitiva para referir-se a estes indivíduos. 


\subsection{Elementos traço e neurociências}

Apesar de todo o progresso científico no diagnóstico clínico e neuropatológico da DA desde o primeiro relato da doença há pouco mais de um século, a etiologia da doença é ainda desconhecida (Jellinger, 2006). Das diversas hipóteses envolvendo a etiologia e a patogênese da DA, uma hipótese que têm ganhado considerável atenção é o envolvimento da toxicidade dos elementos traço na patogênese da DA (Lovell et al., 1998).

O termo elemento traço refere-se aos elementos químicos que são necessários em quantidades mínimas para o crescimento, desenvolvimento e fisiologia do organismo (Gao et al., 2008).

De acordo com a International Union of Pure and Applied Chemistry (IUPAC) elemento traço é "qualquer elemento que possua uma concentração média menor do que $100 \mathrm{mg} / \mathrm{kg}$ ", enquanto que elementos maiores possuem concentração média de 1.000 .000 a $10.000 \mathrm{mg} / \mathrm{kg}$ e elementos menores possuem concentração média de 10.000 a $100 \mathrm{mg} / \mathrm{kg}$ (Brown e Milton, 2005).

Uma vez que muitos elementos estão presentes em diversas matrizes em baixas concentrações, quando os métodos analíticos foram desenvolvidos no século dezenove estes elementos não eram detectáveis. Entretanto, quando a tecnologia analítica evoluiu e descobriu-se que estes elementos estavam presentes em baixas concentrações, o termo "traço" foi usado para descrevê-los. Embora os métodos analíticos atualmente permitam uma determinação acurada dos elementos traço em concentrações muito baixas, o termo genérico "traço" e "elemento traço" ainda é usado (Brown e Milton, 2005). 
Segundo Bush (2000), o termo "elemento traço" não seria adequado para referir-se a concentrações de certos elementos que estão presentes em altas concentrações no corpo humano, como por exemplo o ferro e o zinco. Entretanto, muitos autores (Panayi et al., 2001; Hebbrecht et al., 1999; Panayi et al., 2000; Lovell et al., 1998; Belavari et al., 2004, Cutts et al., 2001) adotam o termo “elemento traço" para referir-se a elementos como ferro, sódio e potássio, presentes em altos teores em tecidos humanos. Assim, optou-se, no presente trabalho, por utilizar o termo elemento traço para referir-se aos elementos bromo $(\mathrm{Br})$, ferro $(\mathrm{Fe})$, potássio $(\mathrm{K})$, sódio $(\mathrm{Na})$, rubídio $(\mathrm{Rb})$, selênio $(\mathrm{Se})$ e zinco $(\mathrm{Zn})$.

Sabe-se há mais de cem anos que os elementos traço desempenham um papel vital no metabolismo (Andrasi et al., 1995), sendo fundamentais em uma série de processos necessários para a vida (Andrasi et al., 1999, Bélávari et al., 2004). Cerca de 24 elementos são reconhecidos como sendo essenciais (Andrasi et al., 1995) e uma concentração ótima destes principais elementos traço se faz necessária (Bélavári et al., 2005). Existem muitas fontes de exposição destes elementos traço na vida diária, particularmente nos alimentos, mas somente em quantidades extremamente baixas (Guidotti et al., 2008).

No cérebro, qualquer variação das concentrações ditas normais pode resultar em um declínio do seu funcionamento e então o elemento traço pode ser considerado neurotóxico (Cutts et al., 2001). O controle dos níveis internos de elementos é regulado por sofisticados mecanismos de transporte e a barreira sanguínea, que isola o cérebro do plasma cerebral (Donnelly et al., 2007), é relativamente impermeável às flutuações das concentrações de elementos no plasma. Entretanto, o principal mecanismo pelo qual os elementos entram no cérebro é através da barreira sanguínea 
cerebral (Cutts et al., 2001). Ainda não se sabe se esta barreira se modifica para, de alguma maneira, permitir maior ou menor permeabilidade de um determinado elemento (Cutts et al., 2001), mas um dano na barreira sanguínea cerebral tem sido sugerido em algumas doenças neurodegenerativas, incluindo a DA (Ehmann et al., 1986).

Dentre os elementos determinados no encéfalo humano, a participação dos metais na DA têm recebido grande destaque (Finefrock et al., 2003; Donnelly et al., 2007; Crouch et al., 2007; Bush, 2003; Bush e Curtain, 2008; Bush, 2000; Bush, 2002). Segundo Crouch et al. (2007) a perda da homeostase dos biometais é uma característica consistente no encéfalo de portadores de DA.

A precipitação de $\beta A$ e sua toxicidade na DA podem ser causadas devido às interações anormais com íons metálicos corticais (Bush, 2003) e, embora uma variedade de interações neuroquímicas tenham sido propostas como responsáveis pela precipitação na $\mathrm{DA}$, as interações entre $\beta \mathrm{A}$ e os biometais no cérebro, têm sido selecionadas para as investigações como uma consequência do envelhecimento, afetando a solubilidade da $\beta$ A (Huang et al., 2000). Cabe ressaltar que a mera presença da $\beta$ A não pode iniciar a deposição amilóide porque o peptídeo é um componente normal do líquido cerefalorraqueano. Se a elevação das concentrações de $\beta$ A no córtex fosse por si só responsável por iniciar a deposição amilóide, seria difícil explicar porque os depósitos amilóide são focais e não uniformes na sua distribuição (Huang et al., 2000).

Com relação às interações anormais com íons metálicos corticais há ocorrência de duas reações genéricas de relevância para as doenças neurodegenerativas. Primeira, reação de associação entre proteínas e metais que leva 
à agregação de proteínas. Segunda, oxidação de proteínas catalisada por metais que ocasiona dano de proteínas e desnaturação (Bush, 2000).

As investigações sobre o possível papel dos elementos traço na etiologia da DA tiveram início na década de 80, com pesquisadores nos Estados Unidos e Japão. Nos últimos 20 anos, muitos trabalhos têm sido publicados para verificar se há diferenças entre as concentrações de elementos nos encéfalos de indivíduos portadores de DA e de indivíduos sem doença neurodegenerativa.

Dentre os diversos métodos existentes para determinação de elementos químicos em tecidos biológicos, o método de análise por ativação com nêutrons tem sido aplicado na análise de tecidos cerebrais por diversos pesquisadores (Panayi et al., 2001; Ehmann et al., 1986; Deibel et al., 1996; Andrasi et al., 1995; Cutts et al., 2001), devido às suas muitas vantagens (Bode e Van Meerten, 1999).

Embora alterações das concentrações de elementos traço na DA tenham sido evidenciadas, a relação entre estes elementos e a patologia não tem sido bem estabelecida. Os resultados comparativos entre as concentrações de elementos em encéfalos de indivíduos portadores de DA e do grupo controle não são conclusivos. Consequentemente, a ausência de dados conclusivos sobre a correlação existente entre as concentrações de certos elementos traço e a DA nos despertou interesse para determinação de elementos químicos em amostras de encéfalo pelo método de análise por ativação com nêutrons. No item 1.9 serão apresentadas algumas considerações sobre este método.

As investigações sobre a etiologia da DA e o entendimento dos fatores neuroquímicos no envelhecimento humano e na DA continuam sendo um grande desafio de diversos pesquisadores. Assim, os resultados do presente estudo poderão 
contribuir para o entendimento dos mecanismos da DA e para o desenvolvimento de novas terapêuticas para a doença.

\subsection{Método de análise por ativação com nêutrons}

A primeira utilização da ativação com nêutrons deu-se em 1936 quando C. Hevesy e H. Levi descobriram que amostras contendo elementos do grupo das terras raras se tornavam altamente radioativas após a exposição a uma fonte de nêutrons, constituída pelo elemento rádio incluso $\mathrm{em}$ berílio. Estes pesquisadores reconheceram então o potencial do emprego de reações nucleares seguidas pela medida da radioatividade induzida para analisar qualitativamente e quantitativamente os elementos presentes em uma amostra (Glascock, 2004).

O método de análise por ativação com nêutrons consiste no bombardeamento de nêutrons em um dado material, o qual forma radionuclídeos artificiais a partir de elementos estáveis. Os materiais a serem analisados são submetidos a um fluxo de partículas ativadoras (nêutrons), ocorrendo a formação de isótopos radioativos, por meio de reações nucleares (Aguiar, 2001), conforme o esquema apresentado na Figura 03.

A sequência de eventos que ocorrem numa reação de captura do nêutron pelo núcleo alvo, apresentado na Figura 03, inicia-se quando o nêutron incidente interage com o núcleo alvo numa colisão inelástica, formando um núcleo composto em estado excitado. O núcleo composto formado quase que instantaneamente irá se des-excitar, chegando a uma configuração mais estável, por meio da emissão de um ou mais raios gama "prontos", característicos de cada espécie de núcleo alvo. Em muitos casos esta 
nova configuração produzirá um núcleo radiativo, também chamado de radioisótopo, que irá se des-excitar (ou decair) por meio da emissão de partículas, seguidas de um ou mais raios gama de decaimento, também característicos. Dependendo da espécie radiativa em questão, este decaimento poderá apresentar uma meia-vida de frações de segundo a centenas de anos (Aguiar, 2001).

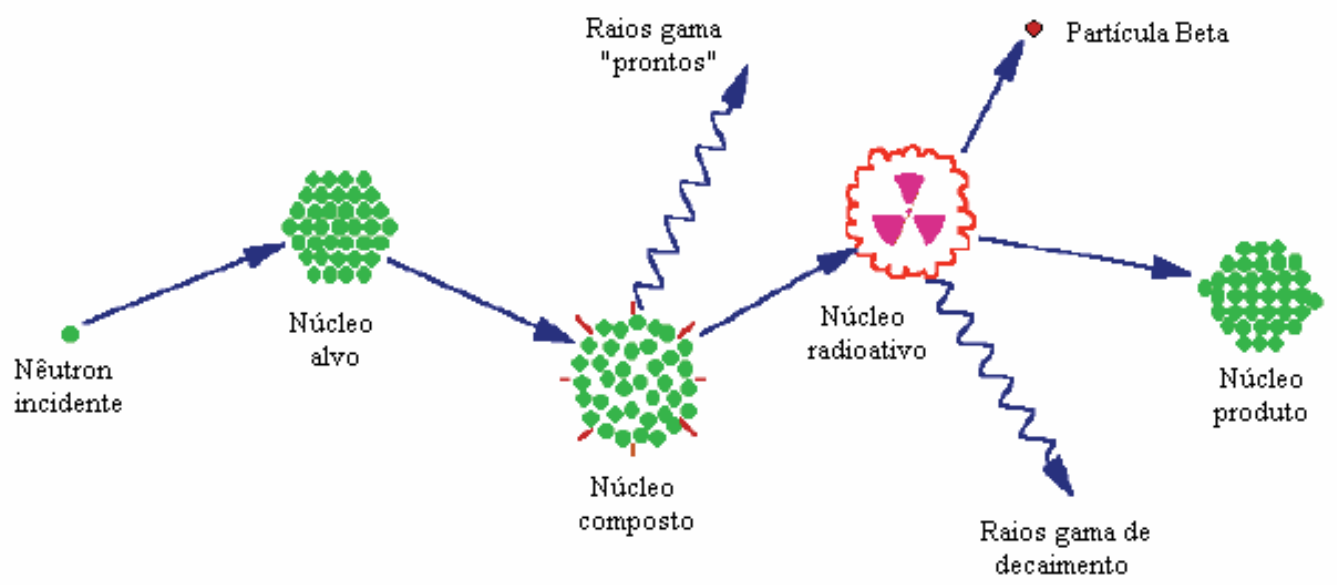

Figura 03 - Ilustração do processo de formação de isótopos radioativos. Modificado de Glascock, 2004.

Esses raios gama de decaimento emitidos podem ser analisados e a medida dessas radiações emitidas pelos radioisótopos formados permite realizar a medida da atividade induzida, para a identificação e determinação quantitativa dos elementos (Aguiar, 2001). A irradiação de uma amostra fornece, portanto, informações que permitem a análise de vários elementos, dependendo das interações entre nêutrons e núcleos atômicos, e das radiações emitidas pelos radioisótopos formados (Aguiar, 2001).

A medida de radiação gama emitida pelos radioisótopos formados é realizada por meio de detectores de radiação. Utilizando-se um detector de alto poder de 
resolução, como os detectores de germânio hiperpuro, obtém-se um espectro no qual se pode discriminar picos de absorção total de diferentes energias de raio gama. No espectro de raios gama a área sob um pico é a medida diretamente proporcional a quantidade do elemento presente na amostra que deu origem a este radioisótopo medido (Aguiar, 2001).

Os recursos básicos necessários para a realização da análise de uma amostra via análise por ativação com nêutrons são uma fonte de nêutrons, instrumentação apropriada para a detecção dos raios gama e um conhecimento detalhado das reações que ocorrem quando os nêutrons interagem com o núcleo alvo. A probabilidade de que ocorra a reação nuclear medida pela secção de choque (probabilidade de uma partícula interagir com o núcleo alvo), a abundância isotópica do nuclídeo alvo e a meia-vida do radioisótopo formado devem ser de uma ordem de grandeza suficiente para que a análise se torne viável (Bode e De Goeij, 1998 apud Aguiar, 2001). Aproximadamente $70 \%$ dos elementos químicos possuem propriedades favoráveis para permitir a sua determinação via análise por ativação com nêutrons (Glascock, 2004).

A análise por ativação com nêutrons é uma técnica bem estabelecida para determinação da concentração de diversos elementos (Spyrou et al., 1999). Esta técnica tem sido aplicada para solução de diversos problemas científicos e tecnológicos e tem provado ser extremamente valiosa na certificação de materiais de referência e de procedimentos para validação da qualidade da qualidade analítica. A técnica de análise por ativação com nêutrons é única porque ela elimina os problemas usuais de perda e contaminação da amostra, visto que não há necessidade de tratamento da amostra como em outras técnicas (Andrási et al., 1995). 
Outra vantagem significativa da técnica de análise por ativação com nêutrons quando comparada às demais é a não necessidade de digestão da amostra, que inevitavelmente resulta em sua diluição e diminuição da sensibilidade (Bélávari et al., 2004). Além disso, o método de análise por ativação com nêutrons requer uma quantidade muito pequena de amostra, não necessita de destruição da amostra (sendo que a mesma pode ser usada para outras investigações), não exige tempo para a separação química e nem o uso de reagentes como em outras análises, tem alta sensibilidade, precisão e exatidão para um grande número de elementos e é multielementar (Aguiar, 2001).

No entanto, o método de análise por ativação com nêutrons apresenta algumas desvantagens: A técnica é cara (Brown e Milton, 2005) e certos elementos não podem ser analisados pelo método de análise por ativação com nêutrons, devido ao fato de não apresentarem características apropriadas para a ativação e medida da emissão gama ou quando as concentrações estiverem abaixo dos seus valores de limite de detecção (Aguiar, 2001).

No método de análise por ativação com nêutrons a irradiação das amostras é realizada em um reator de pesquisa. Atualmente, de acordo com a International Atomic Energy Agency, o Brasil possui quatro reatores de pesquisa, sendo dois em São Paulo (Instituto de Pesquisa Energéticas e Nucleares - IPEN), um no Rio de Janeiro (Instituto de Engenharia Nuclear - IEN) e um em Minas Gerais (Centro de Desenvolvimento de Tecnologia Nuclear - CDTN). Na Figura 04 está a fotografia do prédio do reator IEA-R1 do IPEN. O reator de pesquisa IEA-R1 do IPEN foi utilizado no presente estudo para irradiação das amostras. 


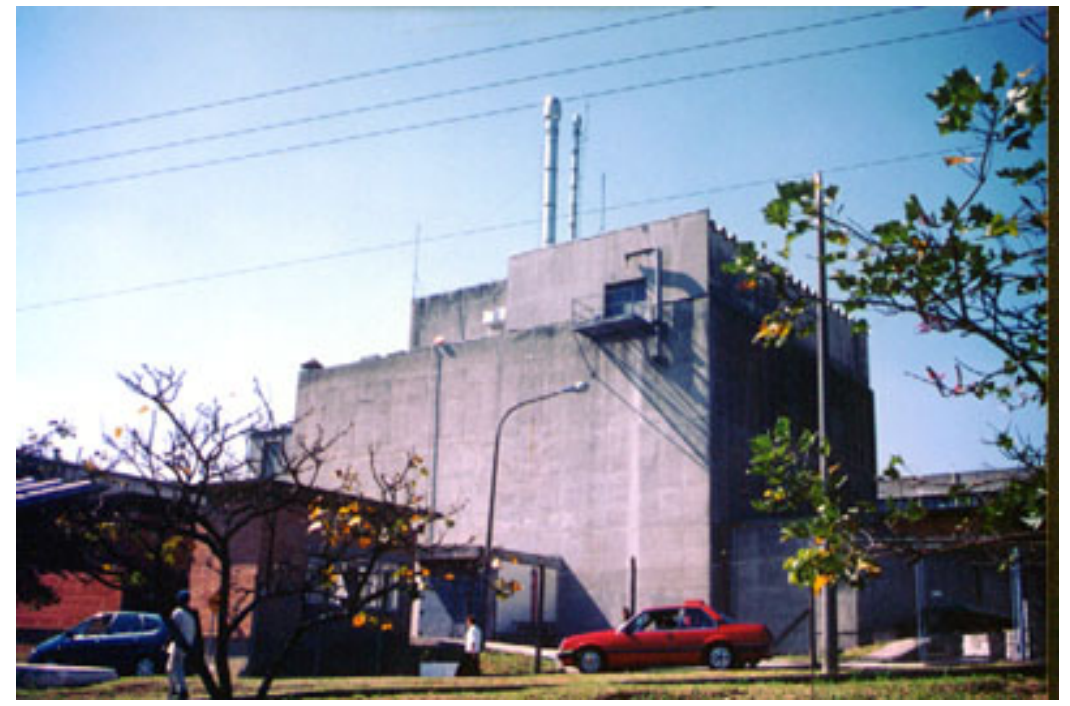

Figura $04-$ Fotografia do prédio do IEA-R1. Retirado de http://www.ipen.br/sitio/?idc=261

\subsection{Banco de encéfalos humanos do Grupo de Estudos em Envelhecimento Cerebral (BEHGEEC)}

As amostras de tecido cerebral utilizadas no presente estudo são provenientes do BEHGEEC. O BEHGEEC foi criado em setembro de 2003 pelo grupo de estudos em envelhecimento cerebral (GEEC). O GEEC é formado por diferentes especialistas da Faculdade de Medicina da Universidade de São Paulo (FMUSP) (Grinberg et al., 2007).

Os casos pertencentes ao BEHGEEC provêm do Serviço de Verificação de Óbitos da Capital - USP (SVOC). O SVOC foi criado em 1931 e em 1939 passou a ser vinculado à FMUSP (SVOC, 2009). Atualmente funciona 24h por dia e está localizado na da FMUSP (Grinberg et al., 2007). Todas as autópsias são realizadas por um médico patologista com o auxílio de um técnico (Grinberg et al., 2007). O SVOC tem por finalidade esclarecer causa da morte em casos de óbito por moléstia 
mal definida ou sem assistência médica ocorridos no município de São Paulo (SVOC, 2009). Os casos cujo óbito tenha ocorrido por causas externas como, por exemplo, acidentes e suicídios são encaminhados para o Instituto Médico Legal (IML).

$\mathrm{Na}$ maioria dos paises a captação de órgãos para pesquisa é feita exclusivamente a partir da doação voluntária prévia do paciente ou de familiares. No Brasil a autópsia é obrigatória sempre que há dúvidas sobre a causa do óbito. $\mathrm{O}$ indivíduo está dispensado do exame apenas quando seus familiares apresentam atestado de óbito preenchido por um médico que acompanhou o indivíduo e pode esclarecer a causa do óbito com exatidão. Além disso, no Brasil é possível solicitar a captação de órgãos para pesquisa científica no momento da necropsia por meio do consentimento da família (Farfel et al., 2008).

Apenas 9\% das famílias se recusam a doar os encéfalos para o BEHGEEC enquanto que em outros países a taxa de sujeitos inscritos para doação é cada vez menor. Além disso, o SVOC realiza um grande número de autópsias quando comparado a outros centros. A cada ano, cerca de 15000 autópsias são realizadas, sendo que destas, aproximadamente 8000 são de indivíduos idosos (Ferretti, 2008).

O custo do processamento de um encéfalo no BEHGEEEC é baixo quando comparado a outros bancos de encéfalos. Nos Estados Unidos, o custo varia de US\$10.000,00 a US\$30.000,00. No BEHGEEC, valendo da estrutura já disponível do SVOC, o dispêndio cai drasticamente para US\$400,00 (Grinberg et al., 2007).

Todas estas diferenças aumentam sobremaneira a disponibilidade de órgãos para pesquisa científica e fazem do BEHGEEC um banco de encéfalos diferenciado. 
A estrutura ímpar do BEHGEEC associada à excelência do método de análise por ativação com nêutrons, possibilitou, no presente trabalho, a investigação da concentração elementar no envelhecimento encefálico humano e sua correlação com o desenvolvimento das doenças neurodegenerativas. 
2. OBJETIVOS 


\subsection{Objetivo principal}

Determinar as concentrações dos elementos $\mathrm{Br}, \mathrm{Fe}, \mathrm{K}, \mathrm{Na}, \mathrm{Rb}$, Se e $\mathrm{Zn}$ no encéfalo (regiões frontal e hipocampo) em três grupos de indivíduos: (1) portadores de doença de Alzheimer clinica e neuropatologicamente comprovadas (grupo DA), (2) indivíduos cognitivamente normais e que não apresentam sinais neuropatológicos da doença de Alzheimer (grupo NN) e (3) um grupo intermediário de indivíduos cognitivamente normais, mas que apresentam sinais neuropatológicos de doença de Alzheimer, ou seja, indivíduos provavelmente portadores de reserva cognitiva (grupo $\mathrm{RC})$.

\subsection{Objetivos específicos}

I. Verificar a aplicabilidade e a qualidade do método de análise por ativação com nêutrons na determinação de elementos traço no encéfalo humano.

II. Comparar as concentrações de elementos obtidas em tecido encefálico nos grupos $\mathrm{NN}$, DA e $\mathrm{RC}$, tanto em região frontal quanto em hipocampo.

III. Comparar as concentrações de elementos obtidas em tecido encefálico na região frontal e hipocampo para cada um dos grupos de indivíduos. 
3. MÉTODOS 


\subsection{Procedência dos casos}

A Comissão de Ética para Análise de Projetos de Pesquisa - CAPPesq, da Diretoria Clínica do Hospital das Clínicas da Faculdade de Medicina da Universidade de São Paulo - HCFMUSP, aprovou o protocolo de $n^{\circ} 59405$ da presente pesquisa apresentado pelo Departamento de Patologia. O termo de aprovação está apresentado no Anexo A.

Os casos, de ambos os gêneros, foram selecionados da série de casos autopsiados entre 2005 e 2007 pertencentes ao BEHGEEC.

\subsection{Características do BEHGEEC}

\subsubsection{Critérios de seleção do BEHGEEC (Grinberg et al., 2007)}

Critério de inclusão:

- Indivíduos com 50 anos de idade ou mais no momento da morte.

Critério de exclusão:

- Sujeitos com infarto cerebral agudo macroscopicamente detectável, hemorragias ou traumas. Nestes casos um exame imediato do encéfalo é necessário para preencher o certificado de óbito, o que impede o armazenamento do caso para estudo. 
- Sujeitos com condições crônicas graves que podem prejudicar a função cognitiva prévia à morte e podem interferir na homeostase cerebral. Estas condições incluem insuficiência cardíaca terminal, insuficiência renal crônica e metástase cerebral.

- Sujeitos sem um cuidador apropriado para prover informações ou responder adequadamente ao questionário funcional e clínico. O cuidador deve ter convivido, no mínimo, uma vez por semana com o indivíduo no período de seis meses que antecederam a morte.

- Indivíduos com indicação de acidose grave devido ao estado agonal (pH líquido cefalorraquidiano $<6,5)$.

\subsubsection{Procedimentos do BEHGEEC (Grinberg et al., 2007)}

O transporte dos corpos até o SVOC só é realizado pelo próprio serviço de verificação de óbitos. O tempo de transporte de casa ou hospital até o SVOC é de 2 a $6 \mathrm{~h}$, o que resulta em um intervalo post mortem médio de 10,4h (4-20h).

\subsubsection{Recepção, seleção e termo de consentimento livre e esclarecido (Grinberg et al., 2007)}

As informações sobre o falecido são recebidas antes da chegada do corpo ao SVOC, o que permite uma pré-seleção dos casos. Um responsável (parente de primeiro grau) deve ir pessoalmente ao SVOC para reclamar o corpo. O tempo 
médio de espera para os procedimentos de autópsia e a liberação dos documentos é de $3 h$.

$\mathrm{Na}$ chegada do cadáver ao SVOC, caso o sujeito atenda aos critérios de seleção do BEHGEEC, a natureza do projeto é explicada ao responsável pelo falecido e lhe é apresentado o Termo de Consentimento Livre e Esclarecido (disponível no Anexo B). No caso de aceite, o cuidador mais indicado para obtenção de confiabilidade das informações transmitidas é identificado, dando preferência ao cuidador primário. No caso de indivíduos que não possuam cuidador primário, a escolha do cuidador é feita a partir da identificação do familiar com maior vínculo com o paciente.

Os indivíduos são entrevistados de segunda a sexta, em uma sala separada, privada e confortável, por uma equipe treinada e coordenada por um enfeirmeiro gerontólogo. Segundo McCulla et al. (1989) enfermeiros gerontólogos podem identificar e estagiar demências de modo confiável por meio do uso do Questionário para Avaliação Clínica da Demência (CDR).

Durante a entrevista o gerontólogo julga se há informação suficiente e se a fonte colateral é confiável. O indivíduo é excluído do estudo se algum destes critérios não é preenchido. Se qualquer procedimento é recusado pelo responsável, o caso não é armazenado. Todo o material do BEHGEEC é anônimo e os espécimes são codificados por números, entretanto, a identificação do espécime é possível em caso de problema de saúde pública ou legal. 


\subsubsection{Avaliação clínica (Grinberg et al., 2007)}

O status clínico é avaliado por meio da fonte colateral. O domínio cognitivo é avaliado utilizando-se o Questionário CDR (Morris, 1993) e o Questionário de Declínio Cognitivo do Idoso (IQCODE) (Jorm, 1994). Além disso, dados como idade no momento do óbito e gênero são coletados. O protocolo de entrevista completo pode ser consultado no Anexo C.

\subsubsection{Procedimentos neuropatológicos (Grinberg et al., 2007)}

No momento da autópsia, o encéfalo é avaliado macroscopicamente, pesado e fotografado. Um dos hemisférios cerebral é representado em 7 áreas (Tabela 02) e congelado a temperatura de $-80^{\circ} \mathrm{C}$. O outro hemisfério é fixado em formalina por, no mínimo, três semanas. Após a fixação em formalina, o cerebelo e o tronco encefálico são separados do cérebro por um corte no nível do colículo superior. O cérebro é coronalmente cortado em fatias de $1 \mathrm{~cm}$. Um conjunto mínimo de 13 áreas é representado, embebido em blocos de parafina e amostrado conforme Tabela 02 . O tecido restante é estocado em potes de plástico com formalina. Todos os procedimentos de pós-fixação são feitos no laboratório do BEHGEEC, localizado um piso acima do SVOC. Qualquer excesso de tecido é descartado e enterrado de acordo com a legislação local. 
Tabela 02 - Tipos de tecidos coletados e seus respectivos procedimentos para amostragem - Banco de encéfalos do Grupo de Estudos em Envelhecimento Cerebral

\begin{tabular}{lcc}
\hline \multicolumn{1}{c}{ Região do encéfalo } & $\begin{array}{c}\text { Emblocado em } \\
\text { parafina }\end{array}$ & $\begin{array}{c}\text { Estocado a } \\
-80^{\circ} \mathrm{C}\end{array}$ \\
\hline Giro frontal médio (área de Brodmann 46) & $\mathrm{X}$ & $\mathrm{X}$ \\
Lóbulo parietal inferior e superior (área de Brodmann 39/40) & $\mathrm{X}$ & $\mathrm{X}$ \\
Giro temporal médio e superior (área de Brodmann 21/22) & $\mathrm{X}$ & $\mathrm{X}$ \\
Giro frontal superior (área de Brodmann 8/9) e giro do cíngulo anterior (área de & $\mathrm{X}$ & $\mathrm{X}$ \\
Brodmann 24) na altura do do gânglio basal anterior & $\mathrm{X}$ & $\mathrm{X}$ \\
Lobo occipital (área de Brodmann 17 e 18) & $\mathrm{X}$ & $\mathrm{X}$ \\
Formação hipocampal anterior, região hipocampal (área de Brodmann 27/28) e giro \\
temporal inferior (área de Brodmann 20)
\end{tabular}

FONTE: Modificado de Grinberg et al. (2007)

NOTA: $\mathrm{X}=$ amostrado

\subsubsection{Técnica histológica e métodos de marcação (Grinberg et}

al., 2007)

Todos os blocos de parafina são seccionados em uma espessura de $8 \mu \mathrm{m}$ e corados com hematoxilina-eosina (HE). A imunoistoquímica de rotina é realizada usando anticorpos contra os seguintes peptídeos ou proteínas: $\beta$-amilóide, tau fosforilada e $\alpha$-sinucleína conforme descrito na Tabela 03 . Se lesões suspeitas são encontradas, colorações adicionais são realizadas. 
Tabela 03 - Áreas imunocoradas e anticorpos usados rotineiramente no Banco de encéfalos do Grupo de Estudos em Envelhecimento Cerebral

\begin{tabular}{lccc}
\hline \multicolumn{1}{c}{ Região do encéfalo } & $\begin{array}{c}\text { Proténa: Amilóide } \\
\text { Anticorpo: } 4 \mathrm{G} 8\end{array}$ & $\begin{array}{c}\text { Protéína: Tau } \\
\text { Anticorpo: PHF-1 }\end{array}$ & $\begin{array}{c}\text { Proté́na: Sinucleína } \\
\text { Anticorpo: } \alpha \text {-synuclein }\end{array}$ \\
\hline Giros frontais médio e inferior & $\mathrm{X}$ & $\mathrm{X}$ & $\mathrm{X}$ \\
Giros temporais anterior e médio & $\mathrm{X}$ & $\mathrm{X}$ & \\
Lobo parietal inferior e superior & $\mathrm{X}$ & $\mathrm{X}$ & $\mathrm{X}$ \\
Córtex de associação visual & $\mathrm{X}$ & $\mathrm{X}$ & $\mathrm{X}$ \\
Giros cingulado anterior & $\mathrm{X}$ & $\mathrm{X}$ & \\
Hipocampo anterior & $\mathrm{X}$ & $\mathrm{X}$ & \\
Amigdala & $\mathrm{X}$ & $\mathrm{X}$ & $\mathrm{X}$ \\
Gânglios da base & & $\mathrm{X}$ & $\mathrm{X}$ \\
Mesencéfalo & & $\mathrm{X}$ & $\mathrm{X}$ \\
Ponte & & $\mathrm{X}$ & \\
Bulbo & $\mathrm{X}$ & $\mathrm{X}$ & \\
Cerebelo & & &
\end{tabular}

NOTA: $\mathrm{X}=$ área imunocorada

\subsubsection{Análise histológica e critério diagnóstico (Grinberg et al.,} 2007)

As avaliações histológicas são baseadas nos critérios mais aceitos para doenças neurodegenerativas relacionadas à idade (Mirra et al., 1991; Braak e Braak 1991; Braak et al., 2004; McKeith et al., 1996; NIA-RR 1997; McKhann et al., 2001; Saito et al., 2004). 


\subsection{Critérios de seleção de casos para o presente estudo}

A seleção dos casos foi realizada a partir da avaliação clínica por meio da classificação do declínio cognitivo de acordo com o Questionário CDR. Sua versão em português é um instrumento válido para o estadiamento da demência no idoso (Montaño e Ramos, 2005). Este questionário, de uso crescente em pesquisas clínicas (Lim et al., 2005), tem sido utilizado ao longo destes anos desde a sua primeira aplicação em 1979 no Projeto de Memória e Envelhecimento da Universidade de Washington (Berg et al., 1982) e tem se tornado padrão-ouro na avaliação global de pacientes portadores de demência tipo Alzheimer. Além disso, está indicado para a avaliação de outros tipos de demência. Avalia seis domínios: memória, orientação, julgamento e resolução de problemas, assuntos comunitários, casa e hobbies, e autocuidado.

Estudos em nosso meio (Montaño e Ramos, 2005; Chaves et al., 2007) para avaliar a validade da versão brasileira do CDR encontraram alta sensibilidade e especificidade do questionário CDR para diagnóstico da demência.

De acordo com a escala CDR o comprometimento cognitivo é classificado da seguinte maneira:

CDR $0=$ Normal

CDR $0.5=$ Demência questionável

CDR 1 = Demência leve

CDR 2 = Demência moderada

CDR 3 = Demência grave 
Seguindo esta classificação, todos os casos com comprometimento cognitivo grave (CDR 3) incluídos no BEHGEEC no período de 2005 a 2007 foram selecionados ( $\mathrm{n}=39)$. Destes, 26 foram excluídos (Tabela 04), restando 13 casos.

Tabela 04 - Motivos de exclusão e número de casos excluídos do grupo de portadores de declínio cognitivo grave (CDR 3)

\begin{tabular}{|l|c|}
\hline \multicolumn{1}{|c|}{ Motivos da exclusão } & $\begin{array}{c}\text { Número de } \\
\text { casos excluídos }\end{array}$ \\
\hline $\begin{array}{l}\text { Não possuir espécime encefálico congelado da região hipocampal em quantidade } \\
\text { suficiente para mensuração da concentração de elementos traço }\end{array}$ & 3 \\
\hline Não possuir encéfalo fixado em formalina & 2 \\
\hline $\begin{array}{l}\text { Problemas técnicos e de rotina no estabelecimento do diagnóstico } \\
\text { anatomopatológico como, por exemplo, descolamento da lâmina durante o processo } \\
\text { de imunoistoquímica e ausência de algumas regiões representadas em tecido fixado }\end{array}$ & 8 \\
\hline $\begin{array}{l}\text { Presença de demência que os impediria a classificação dentro de um grupo } \\
\text { homogêneo ou poderia interferir na determinação dos elementos traço, sendo a } \\
\text { degeneração lobar frontotemporal e a demência com corpúsculos de Lewy }\end{array}$ & 2 \\
\hline Presença de demência vascular & 6 \\
\hline Impossibilidade de estabelecer um diagnóstico neuropatológico & 1 \\
\hline Não realização da determinação de elementos & 26 \\
\hline Total & 26 \\
\hline
\end{tabular}

Indivíduos sem declínio cognitivo (CDR 0$)$ foram aleatoriamente selecionados a fim de comparar as concentrações de elementos entre os dois grupos. Assim, 17 possíveis casos foram selecionados. Destes, 2 casos foram excluídos após a análise neuropatológica por apresentarem demência com corpúsculos de Lewy e atrofia multissistêmica, restando 15 casos. Estas alterações os impediriam de serem classificados dentro de um grupo homogêneo ou poderiam interferir na determinação da concentração elementar.

Uma vez selecionados, os 28 casos foram divididos em 3 grupos (Figura 05) levando-se em conta tanto a análise clínica quanto a neuropatológica. 


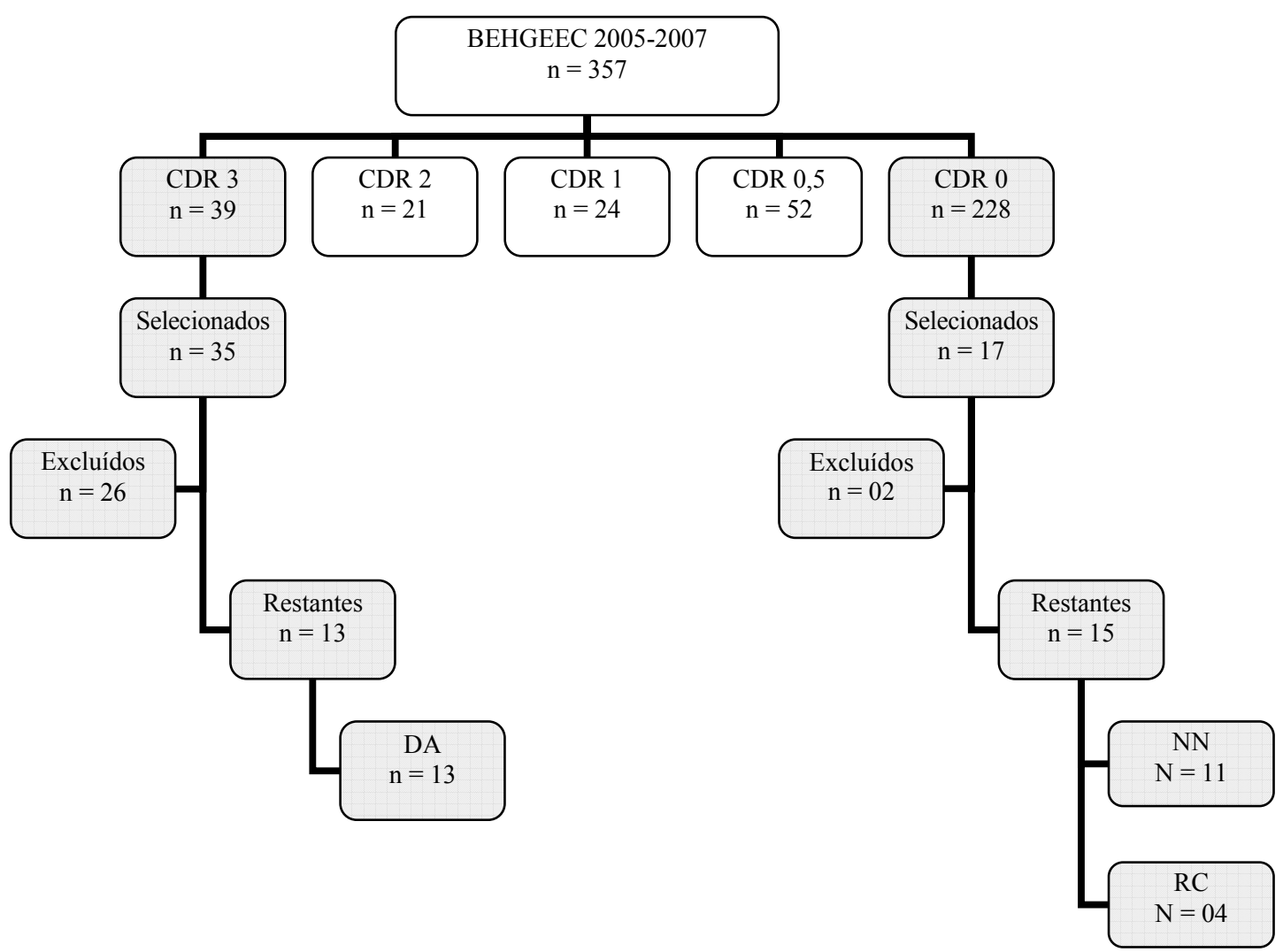

Figura 05 - Organograma representando a seleção de casos para o presente estudo.

Nota: $\mathrm{DA}=$ Doença de Alzheimer, $\mathrm{NN}=$ normal, $\mathrm{RC}=$ reserva cognitiva, $\mathrm{n}=$ número de casos, BEHGEEC $=$ Banco de encéfalos humanos do grupo de estudos em envelhecimento cerebral. Os códigos DA, NN e RC representam os grupos.

\subsubsection{Diagnóstico clínico}

Para análise clínica utilizou-se, além do Questionário CDR, o Questionário IQCODE, uma escala com acurácia elevada no diagnóstico (sindrômico) de demência (Jorm et al., 1989). O Departamento Científico de Neurologia Cognitiva e do Envelhecimento da Academia Brasileira de Neurologia recomenda a utilização combinada de instrumentos de avaliação cognitiva e de escalas de avaliação funcional, como o IQCODE (Nitrini et al., 2005). Sua combinação com testes cognitivos pode melhorar a exatidão do diagnóstico da demência (Jorm, 2004). A 
escala IQCODE é largamente utilizada como um teste de screening de demência principalmente nos casos em que o sujeito é incapaz de passar por um teste cognitivo direto ou para screening em populações com baixa escolaridade (Jorm, 2004). $\mathrm{Na}$ sua versão mais usual, compara-se o estado cognitivo atual do indivíduo com o de 10 anos antes, por meio de um informante. Em estudo caso-controle realizado em uma população brasileira (Bustamante et al., 2003), escores acima de 3,41 apresentaram sensibilidade de $83,3 \%$ e especificidade de 97,4\% no diagnóstico de demência.

Os indivíduos foram classificados como normais quando o escore no IQCODE foi menor do que 3,42 e como cognitivamente comprometidos quando o escore no IQCODE foi maior do que 3,41.

\subsubsection{Diagnóstico neuropatológico}

\subsubsection{Alterações relacionadas à DA}

Para a análise neuropatológica utilizou-se o método de Braak e Braak (Braak e Braak, 1991) e o protocolo publicado pelo Consórcio para estabelecimento de registro de doença de Alzheimer - CERAD (Mirra et al., 1991). As contagens dos achados neuropatológicos foram realizadas em 10 campos consecutivos de $1 \mathrm{~mm}^{2}$ por lâmina, cinco ao longo da superfície pial e 5 ao longo da transição entre o córtex e a substância branca.

O CERAD é um protocolo semiquantitativo para avaliar a freqüência de placas neuríticas (PNs) e emaranhados neurofibrilares (ENFs) no neocórtex. O escore de placas neuríticas com relação à idade é determinado combinando-se a idade do 
paciente e a medida quantitativa de placas neuríticas nas regiões mais afetadas do neocórtex (vide Figura 06 para exemplo da classificação semiquantitativa).

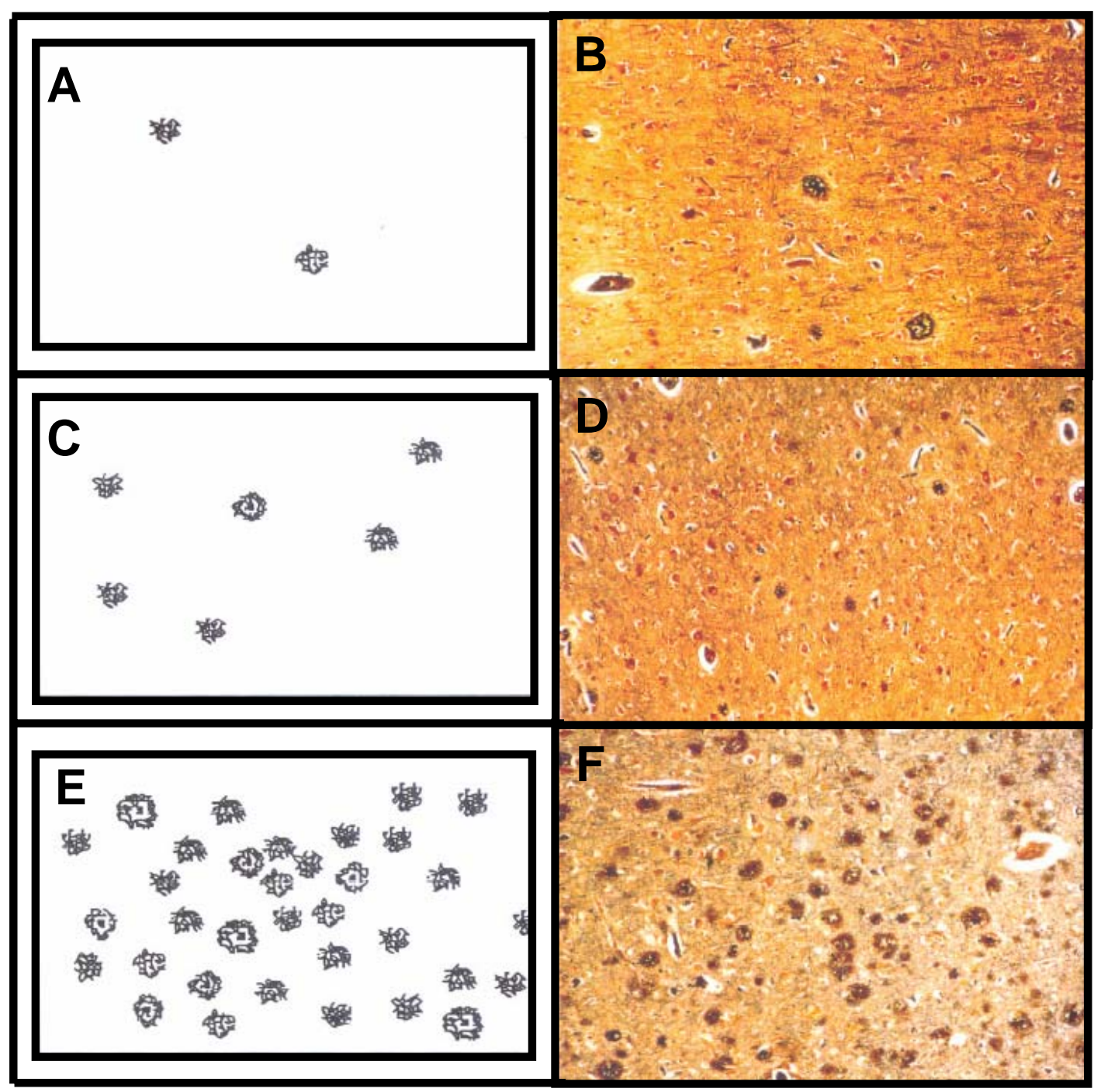

Figura 06 - Classificação semiquantitativa de placas neuríticas. Ilustração da classificação em densidade de placas neuríticas: pequena (A e B), moderada (C e D) e grande (E e F). Marcação por prata (A, C e E) e Bielschowsky (B, D e F). Modificado de Mirra et al. (1991).

Os casos são classificados em relação à densidade de PNs em $0, \mathrm{~A}, \mathrm{~B}$ ou C conforme segue:

CERAD $0=$ ausência de placas neuríticas no córtex cerebral 
CERAD $\mathrm{A}=$ pequena presença de placas neuríticas (1-5 placas por campo 100x)

CERAD $\mathrm{B}=$ moderada presença de placas neuríticas (6-15 placas por campo $100 \mathrm{x})$

$\mathrm{CERAD} \mathrm{C}=$ grande presença de placas neuríticas $(>15$ placas por campo $100 \mathrm{x})$

A idade é levada em consideração de forma que densidade pequena (A) indica o diagnóstico de DA se a idade for inferior a 50 anos, enquanto para casos maiores de 75 anos, a densidade deve ser $\mathrm{C}$ para permitir o diagnóstico. Este escore é então integrado com as informações clínicas com relação à ausência ou presença de demência para determinar o nível de certeza no diagnóstico da DA.

Já o estadiamento instituído por Braak e Braak se baseia no acúmulo gradual de emaranhados neurofibrilares e neuropil threads (NT) (Figura 07).

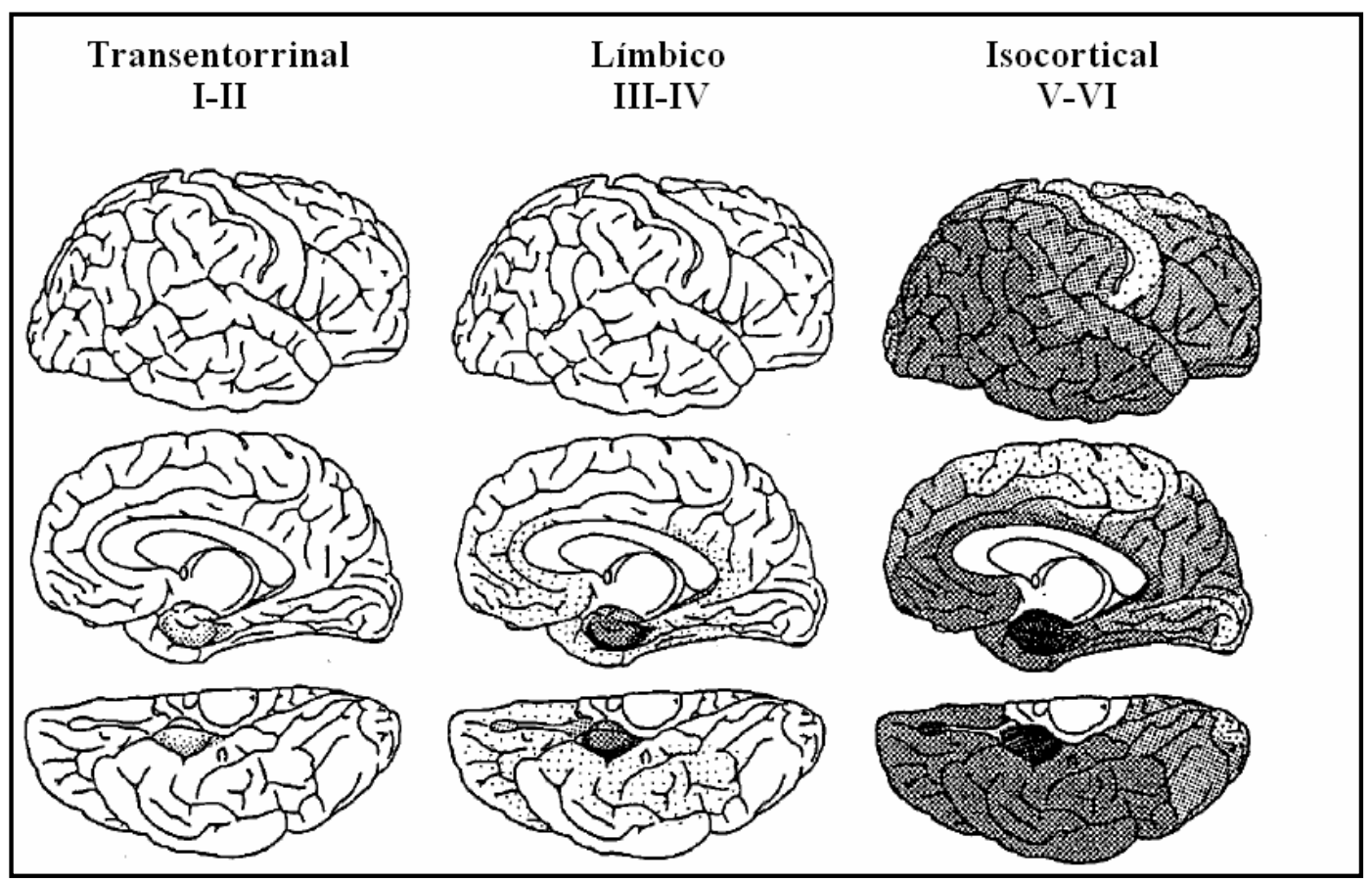

Figura 07 - Padrão de distribuição das alterações neurofibrilares. Seis estágios podem ser distinguidos. Os estágios I-II mostram alterações que estão virtualmente confinadas à uma única porção da região transentorrinal. A característica chave dos estágios III-IV é o grave envolvimento da camada entorrinal e transentorrinal pré- $\alpha$. Os estágios V-VI são marcados pela destruição isocortical. O escurecimento da ilustração indica aumento da severidade das alterações neurofibrilares. Modificado de Braak e Braak, 1991. 
Segundo o estadiamento de Braak e Braak, há uma progressão estereotipada das alterações divididas em seis estágios. Geralmente, a manifestação clínica da DA é concomitante ao estágio IV (Braak et al., 1993).

Diferentemente do protocolo de CERAD, o estadiamento de Braak e Braak não depende nem do diagnóstico clínico de demência nem da idade do paciente.

\subsubsection{Alterações relacionadas às sinucleinopatias}

No córtex cerebral, o número de corpúsculos de Lewy foi avaliado semiquantitativamente em campos consecutivos de $1 \mathrm{~mm}^{2}$ partindo-se da borda medial do córtex em direção ao fundo do sulco colateral utilizando-se lâminas imunocoradas com os anticorpo anti $\alpha$-sinucleina. No tronco cerebral, os corpúsculos de Lewy foram avaliados nos núcleos comumente afetados na Doença de Parkinson (Braak et al., 2004). Para o diagnóstico de demência por corpúsculos de Lewy foram consideradas a presença e a densidade de alterações neuropatológicas da DA (McKeith et al., 2005).

\subsubsection{Alterações relacionadas a outras doenças neurodegenerativas}

A presença de alterações relacionadas a outras doenças neurodegenerativas, tais como grãos argirofílicos, esclerose hipocampal, degeneração granulovacuolar, foi investigada. 
Imunocolorações adicionais com anticorpo anti-ubiquitina foram realizadas quando se notou a presença de características de degeneração lobar frontotemporal (vacuolização, gliose e perda neuronal) na avaliação da lâmina corada por hematoxilina-eosina.

\subsubsection{Alterações vasculares}

A presença de patologia vascular foi registrada de acordo com a área, tamanho e tipo. Para o diagnóstico de demência vascular (DVa) foi necessária a presença de infartos lacunares em áreas estratégicas e/ou a presença de doença vascular evidente e que afetava mais de três áreas corticais, sendo os córtices parietal, frontal e temporal as áreas mais comuns. Siderocalcinose, angiopatia amilóide cerebral na ausência de outras alterações vasculares e na presença de DA bem como alterações microvasculares em cerebelo, gânglios da base e tronco cerebral não foram consideradas suficientes para o diagnostico de DVa.

As avaliações histológicas foram baseadas nos critérios mais aceitos para doenças neurodegenerativas relacionadas à idade (Mirra et al., 1991; Braak e Braak 1991; Braak et al., 2004; McKeith et al., 1996; NIA-RR 1997; McKhann et al., 2001; Saito et al., 2004) e foram realizadas por um neuropatologista (Lea T. Grinberg) com experiência no diagnóstico de demência. 


\subsection{Agrupamento dos casos}

Tabela 05 - Grupo, idade, gênero, classificação clínica e neuropatológica para cada caso do presente estudo

\begin{tabular}{|c|c|c|c|c|c|c|c|}
\hline Caso & Grupo & Idade & Gênero & CDR & IQCODE & $\begin{array}{c}\text { Braak } \\
\text { e Braak }\end{array}$ & CERAD \\
\hline 1 & DA & 94 & $\mathrm{~F}$ & 3 & 4,38 & 4 & B \\
\hline 2 & DA & 77 & $\mathrm{M}$ & 3 & 4,84 & 4 & C \\
\hline 3 & DA & 80 & $\mathrm{~F}$ & 3 & 4,88 & 5 & $\mathrm{C}$ \\
\hline 4 & DA & 77 & $\mathrm{M}$ & 3 & 4,73 & 5 & $\mathrm{~B}$ \\
\hline 5 & DA & 87 & F & 3 & 5,00 & 5 & B \\
\hline 6 & DA & 62 & $\mathrm{~F}$ & 3 & 4,92 & 5 & $\mathrm{C}$ \\
\hline 7 & DA & 84 & $\mathrm{M}$ & 3 & 5,00 & 5 & $\mathrm{C}$ \\
\hline 8 & DA & 77 & $\mathrm{~F}$ & 3 & 4,76 & 6 & $\mathrm{~B}$ \\
\hline 9 & DA & 83 & $\mathrm{~F}$ & 3 & 4,92 & 6 & $\mathrm{~B}$ \\
\hline 10 & DA & 83 & $\mathrm{~F}$ & 3 & 4,92 & 6 & $\mathrm{C}$ \\
\hline 11 & DA & 75 & $\mathrm{~F}$ & 3 & 5,00 & 6 & $\mathrm{C}$ \\
\hline 12 & $\mathrm{DA}$ & 81 & $\mathrm{~F}$ & 3 & 5,00 & 6 & $\mathrm{C}$ \\
\hline 13 & DA & 77 & $\mathrm{~F}$ & 3 & 5,00 & 6 & $\mathrm{C}$ \\
\hline 14 & $\mathrm{NN}$ & 80 & $\mathrm{M}$ & 0 & 3,00 & 0 & 0 \\
\hline 15 & $\mathrm{NN}$ & 79 & $\mathrm{M}$ & 0 & 3,00 & 0 & 0 \\
\hline 16 & $\mathrm{NN}$ & 79 & $\mathrm{M}$ & 0 & 3,15 & 0 & 0 \\
\hline 17 & $\mathrm{NN}$ & 75 & $\mathrm{~F}$ & 0 & 3,00 & 0 & 0 \\
\hline 18 & $\mathrm{NN}$ & 77 & $\mathrm{~F}$ & 0 & 3,00 & 1 & 0 \\
\hline 19 & $\mathrm{NN}$ & 74 & $\mathrm{~F}$ & 0 & 3,00 & 1 & 0 \\
\hline 20 & $\mathrm{NN}$ & 79 & $\mathrm{~F}$ & 0 & 3,00 & 1 & 0 \\
\hline 21 & $\mathrm{NN}$ & 81 & $M$ & 0 & 3,00 & 2 & 0 \\
\hline 22 & $\mathrm{NN}$ & 94 & $\mathrm{~F}$ & 0 & 3,00 & 2 & 0 \\
\hline 23 & $\mathrm{NN}$ & 81 & $\mathrm{~F}$ & 0 & 3,00 & 2 & A \\
\hline 24 & $\mathrm{NN}$ & 81 & $\mathrm{~F}$ & 0 & 3,04 & 3 & $\mathrm{~A}$ \\
\hline 25 & $\mathrm{RC}$ & 75 & $M$ & 0 & 3,00 & 2 & B \\
\hline 25 & $\mathrm{RC}$ & 86 & $\mathrm{M}$ & 0 & 3,04 & 3 & $\mathrm{~B}$ \\
\hline 27 & $\mathrm{RC}$ & 87 & $\mathrm{~F}$ & 0 & 3,04 & 5 & $\mathrm{C}$ \\
\hline 28 & $\mathrm{RC}$ & 72 & $\mathrm{M}$ & 0 & 3,00 & 6 & $\mathrm{C}$ \\
\hline
\end{tabular}

NOTA: $\mathrm{DA}=$ Doença de Alzheimer, $\mathrm{NN}=$ normal, $\mathrm{RC}=$ reserva cognitiva. $\mathrm{A}$ classificação clínica deu-se pelos questionários CDR e IQCODE, enquanto que a classificação neuropatológica deu -se pelos critérios de Braak e Braak e CERAD.

Os 28 casos selecionados para o presente estudo (Tabela 05) foram divididos em três grupos $($ Doença de Alzheimer $=\mathrm{DA}$, normal $=\mathrm{NN}$ e reserva cognitiva $=\mathrm{RC})$ 
levando-se em conta tanto a análise clínica (CDR e IQCODE) como a análise neuropatológica (Braak e Braak e CERAD), conforme demonstrado nas Tabelas 06 e 07. Em um caso (25 da Tabela 05) embora a classificação pelos critérios de Braak e Braak fosse menor que o nosso valor limítrofe adotado, a quantidade de placas amilóide foi valorizada para justificar a sua inclusão dentro o grupo RC.

A presença de grãos argirofílicos e de doença de Parkinson não foi levada em consideração para classificação dos sujeitos nos grupos.

Tabela 06 - Critérios clínicos e neuropatológicos para formação dos grupos no presente estudo

\begin{tabular}{|c|c|c|c|c|}
\hline \multirow[t]{2}{*}{ Grupo } & \multicolumn{2}{|c|}{ Avaliação Clínica } & \multicolumn{2}{|c|}{ Avaliação Neuropatológica } \\
\hline & CDR & IQCODE & $\begin{array}{c}\text { Braake } \\
\text { Braak }\end{array}$ & CERAD \\
\hline Doença de Alzheimer (DA) & 3 & $>3,41$ & $\geq 4$ & $\begin{array}{c}\text { Presença moderada ou freqüente } \\
\text { de placas neuríticas }\end{array}$ \\
\hline Normal (NN) & 0 & $<3,42$ & $\leq 3$ & $\begin{array}{l}\text { Presença pequena ou esparsa de } \\
\text { placas neuríticas }\end{array}$ \\
\hline Reserva Cognitiva (RC) & 0 & $<3,42$ & $\geq 4$ & $\begin{array}{c}\text { Presença moderada ou freqüente } \\
\text { de placas neuríticas }\end{array}$ \\
\hline
\end{tabular}

NOTA: As referências entre parênteses se referem ao código dos grupos.

Tabela 07 - Agrupamento dos casos do presente estudo de acordo com a avaliação clínica e neuropatológica

\begin{tabular}{|c|c|c|}
\hline & $\begin{array}{c}\text { Cognição } \\
\text { preservada }\end{array}$ & $\begin{array}{c}\text { Declínio } \\
\text { cognitivo }\end{array}$ \\
\hline $\begin{array}{c}\text { Neuropatologia } \\
\text { normal }\end{array}$ & $\mathrm{NN} \mathrm{(n=11)}$ & - \\
\hline $\begin{array}{c}\text { Neuropatologia } \\
\text { de DA }\end{array}$ & $\mathrm{RC}(\mathrm{n}=4)$ & $\mathrm{DA}(\mathrm{n}=13)$ \\
\hline
\end{tabular}

NOTA: $\mathrm{DA}=$ Doença de Alzheimer, $\mathrm{NN}=$ normal, $\mathrm{RC}=$ reserva cognitiva, $\mathrm{n}=$ número de casos. A classificação clínica deu-se pelos questionários CDR e IQCODE, enquanto que a classificação neuropatológica deu -se pelos critérios de Braak e Braak e CERAD. 


\subsection{Obtenção e tratamento dos tecidos encefálicos para determinação de elementos pelo método de ativação com nêutrons}

Após a retirada do encéfalo, foram coletadas amostras de tecido encefálico da região hipocampal anterior e formação hipocampal (áreas 27 e 28 conforme classificação de Brodmann) e giro frontal médio (área 46 conforme classificação de Brodmann), conforme a Figura 08. O processo degenerativo na DA tem início em áreas límbicas da região temporal medial, incluindo o hipocampo (Braak e Braak, 1991), uma área do cérebro relacionada à memória (Welsh-Bohmer e White, 2009) e progride para as regiões isocorticais (Braak e Braak, 1991).
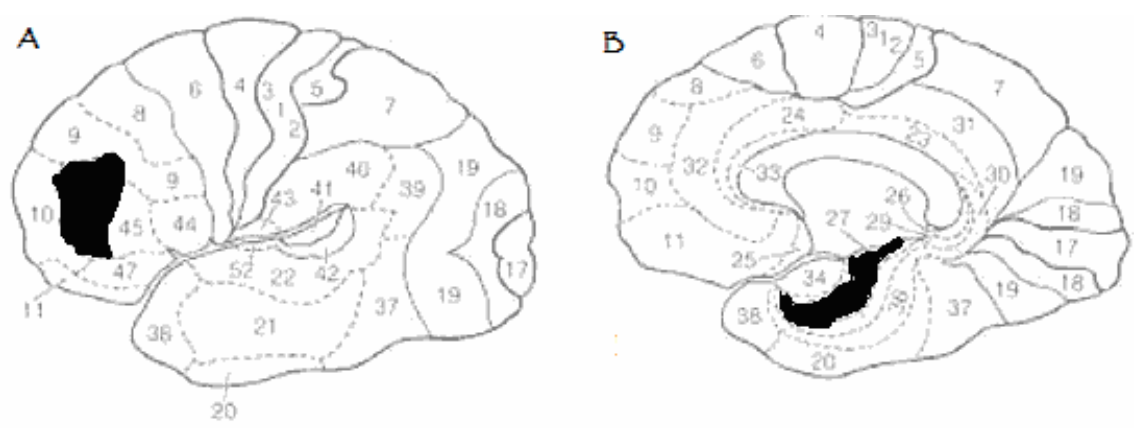

Figura 08 - Esquema representativo das áreas coletadas para determinação de elementos pelo método de ativação com nêutrons. As áreas coletadas estão preenchidas de preto: região frontal (A) e região hipocampal (B).

A coleta dos tecidos foi realizada utilizando-se instrumentos de titânio ou polietileno para evitar a contaminação, conforme os protocolos do BEHGEEC (Grinberg et al., 2007). No tratamento das amostras também foram utilizadas pinças e espátulas de polietileno e luvas livres de talco. 
Cerca de $400 \mathrm{mg}$ do tecido encefálico, colocados em invólucros de polietileno e devidamente identificados, foram estocados em freezer a temperatura de $-80^{\circ} \mathrm{C}$. Posteriormente estas amostras foram enviadas para o Laboratório de Análise por Ativação Neutrônica do Instituto de Pesquisas Energéticas e Nucleares (IPEN) onde foram realizadas as determinações das concentrações dos elementos traço.

Para análise, as amostras de tecidos foram trituradas com o auxílio de uma faca de titânio em superfície de polietileno. A seguir foram colocadas em um frasco Nalgene para a secagem por liofilização. A percentagem média de perda de umidade neste processo de liofilização foi de $81,1 \pm 2,1 \%$.

\subsection{Procedimento para análise por ativação com nêutrons}

Inicialmente, foram preparados os padrões sintéticos dos elementos $\mathrm{Br}, \mathrm{Fe}, \mathrm{K}$, $\mathrm{Na}, \mathrm{Rb}, \mathrm{Se}$ e $\mathrm{Zn}$ a serem utilizados na análise das amostras de encéfalo. Para isso, seguiu-se o protocolo de rotina do Laboratório de Análise por Ativação Neutrônica do Instituto de Pesquisas Energéticas e Nucleares (IPEN). Foram preparadas soluções padrão (Saiki et al., 2007) destes elementos mais diluídas, utilizando as soluções padrão certificadas da Spex Certiprep, USA. Alíquotas destas soluções padrão foram pipetadas sobre tiras de papel de filtro Whatman $\mathrm{n}^{\circ} 40 . \mathrm{O}$ pipetador utilizado foi da marca Eppendorf, previamente verificado quanto à sua calibração. Após a secagem à temperatura ambiente, em um dessecador, estas tiras de papel foram colocadas em invólucros de polietileno. As massas dos elementos utilizados nos padrões, em $\mu \mathrm{g}$ (entre parênteses) foram: $\mathrm{Br}(5,0), \mathrm{Fe}(350), \mathrm{K}(601,5), \mathrm{Na}$ $(100,0), \mathrm{Rb}(10,0)$, Se $(8,0)$ e $\mathrm{Zn}(35,0)$. 
O processo de análise por ativação com nêutrons nas amostras de tecido cerebral foi executado conforme descrito por Leite et al. (2008). Cento e cinqüenta miligramas da amostra seca pesada em invólucros de polietileno, juntamente com os padrões sintéticos de elementos foram irradiados no reator IEA-R1 do Instituto de Pesquisas Energéticas e Nucleares (IPEN) por dois períodos diferentes de 5 min e de 16h sob fluxo de nêutrons térmicos de $4 \times 10^{11}$ e $5 \times 10^{12} \mathrm{n} \mathrm{cm}^{-2} \mathrm{~s}^{-1}$, respectivamente.

As medições das atividades gama foram realizadas depois de adequados tempos de decaimento usando um detector de Ge hiperpuro Modelo GX2020 acoplado a um Processador Integrado de Sinais, Modelo 1510, ambos da Canberra. A resolução do sistema utilizado foi de $0,99 \mathrm{keV}$ para o pico de $121,97 \mathrm{keV}$ do ${ }^{57} \mathrm{Co}$ e de $1,89 \mathrm{keV}$ para o pico de $1332,97 \mathrm{keV}$ do ${ }^{60} \mathrm{Co}$. Para a aquisição dos dados espectrais utilizou-se o programa S100 da Camberra.

Os espectros gama obtidos foram processados utilizando o programa de computação VERSAO2, uma versão do VISPECT2, o qual foi desenvolvido no próprio laboratório. Os radioisótopos formados foram identificados pela meia vida e energias dos raios gama. Os radioisótopos utilizados neste trabalho foram ${ }^{82} \mathrm{Br},{ }^{59} \mathrm{Fe}$, ${ }^{42} \mathrm{~K},{ }^{24} \mathrm{Na},{ }^{86} \mathrm{Rb},{ }^{76} \mathrm{Se} \mathrm{e}{ }^{65} \mathrm{Zn}$.

As concentrações dos elementos foram calculadas pelo método comparativo, usando a seguinte relação (De Soete et al., 1972)

$$
\mathrm{C}_{\mathrm{a}}=\left[\mathrm{m}_{\mathrm{p}} \cdot \mathrm{A}_{\mathrm{a}} \cdot \mathrm{e}^{0,693(\mathrm{tda}-\mathrm{tdp}) / \mathrm{t} 1 / 2}\right] /\left[\mathrm{A}_{\mathrm{p}} \cdot \mathrm{M}_{\mathrm{a}}\right]
$$

Onde os índices a e p se referem, respectivamente, a amostra e padrão; $\mathrm{m}$ é a massa do elemento; A é a taxa de contagens; $\mathrm{M}_{\mathrm{a}}=$ massa total de amostra; $\mathrm{C}_{\mathrm{a}}=$ 
concentração do elemento na amostra $\left(\mathrm{C}_{\mathrm{a}}=\mathrm{m}_{\mathrm{a}} / \mathrm{M}_{\mathrm{a}}\right)$, td é o tempo de decaimento e $\mathrm{t}_{1 / 2}$ é a meia vida do radioisótopo medido. As concentrações dos elementos foram expressas na base seca do material.

O controle de qualidade dos resultados analíticos foi realizado por meio da análise de materiais de referência certificados NIST 1566b Oyster Tissue e NIST 1577b Bovine Liver provenientes do National Institute of Standards and Technology (NIST), Estados Unidos. Estes tipos de matrizes foram utilizadas porque não há materiais de referência certificados de encéfalo. Os materiais de referência foram analisados aplicando as mesmas condições experimentais usadas para análise de encéfalos e foram avaliadas na base seca do material, como recomendado em seus certificados.

\subsection{Tratamento dos dados obtidos nas análises de tecidos cerebrais}

Para análise estatística dos dados obtidos na análise dos tecidos cerebrais foram utilizados os aplicativos Minitab v15 e SPSS v11. Para comparação das médias das concentrações utilizou-se a técnica de análise de variância com medidas repetidas (Neter et al., 2005) e para avaliar as diferenças apontadas pela análise de variância, utilizou-se o método de Tukey.

Nos testes de hipótese foi fixado nível de significância de 0,05 . 
4. RESULTADOS 


\subsection{Caracterização dos grupos}

\subsubsection{Doença de Alzheimer (DA)}

$\mathrm{Na}$ Tabela 08 são apresentadas as concentrações dos elementos $\mathrm{Br}, \mathrm{Fe}, \mathrm{K}, \mathrm{Na}$, $\mathrm{Rb}$, Se e Zn obtidas no hipocampo e na região frontal do grupo DA.

Tabela 08 - Concentrações elementar ( $\mathrm{mg} / \mathrm{kg}$, base seca) no encefálico do grupo DA

\begin{tabular}{cccccccc}
\hline Elemento & $\begin{array}{c}\text { Região do } \\
\text { encéfalo }\end{array}$ & $\mathrm{n}$ & Média & $\begin{array}{c}\text { Desvio } \\
\text { padrão }\end{array}$ & Mediana & Mínimo & Máximo \\
\hline $\mathrm{Rb}$ & Frontal & 13 & 13,9 & 5,7 & 15,4 & 1,7 & 21,1 \\
& Hipocampo & 13 & 14,0 & 6,0 & 16,1 & 1,9 & 21,8 \\
$\mathrm{Se}$ & Frontal & 13 & 0,60 & 0,07 & 0,61 & 0,49 & 0,71 \\
& Hipocampo & 13 & 0,65 & 0,13 & 0,68 & 0,39 & 0,81 \\
$\mathrm{Fe}$ & Frontal & 13 & 257,2 & 41,8 & 254,2 & 179 & 327,9 \\
& Hipocampo & 13 & 239,8 & 58,7 & 228,7 & 151,2 & 365,9 \\
$\mathrm{Zn}$ & Frontal & 13 & 63,0 & 8,9 & 63,4 & 41,9 & 77,2 \\
& Hipocampo & 13 & 79,4 & 17,0 & 75,2 & 51,9 & 120,7 \\
$\mathrm{Br}$ & Frontal & 13 & 3,52 & 1,84 & 2,85 & 1,63 & 8,56 \\
& Hipocampo & 13 & 3,29 & 1,49 & 3,04 & 1,61 & 7,28 \\
$\mathrm{Na}$ & Frontal & 13 & 9800 & 2080 & 10284 & 6365 & 13169 \\
& Hipocampo & 13 & 11511 & 3373 & 9797 & 7548 & 18503 \\
$\mathrm{~K}$ & Frontal & 13 & 10699 & 1623 & 10617 & 8499 & 13386 \\
& Hipocampo & 13 & 9640 & 1578 & 9320 & 6753 & 12408 \\
\hline
\end{tabular}

Nota: $\mathrm{Rb}=$ rubídio, $\mathrm{Se}=$ selênio, $\mathrm{Fe}=$ ferro, $\mathrm{Zn}=$ zinco, $\mathrm{Br}=$ bromo, $\mathrm{Na}=$ sódio, $\mathrm{K}$ = potássio, $\mathrm{n}=$ número de casos.

Os indivíduos do grupo DA representaram $46,4 \%$ da casuística estudada e apresentaram idade média de 79,8 $\pm 7,3$ anos. 
Dos 13 indivíduos pertencentes ao grupo DA, 76,9\% $(\mathrm{n}=10)$ foram do gênero feminino e apresentaram idade média de 79,9 $\pm 8,2$ anos enquanto que 28,1\% $(\mathrm{n}=3)$ foram do gênero masculino com idade média de 79,3 $\pm 3,6$ anos.

\subsubsection{Reserva cognitiva (RC)}

Na Tabela 09 são apresentadas as concentrações dos elementos $\mathrm{Br}, \mathrm{Fe}, \mathrm{K}, \mathrm{Na}$, $\mathrm{Rb}$, Se e Zn no hipocampo e na região frontal do grupo RC.

Tabela 09 - Concentração elementar (mg/kg, base seca) no encéfalo do grupo RC

\begin{tabular}{cccccccc}
\hline Elemento & $\begin{array}{c}\text { Região do } \\
\text { encéfalo }\end{array}$ & $\mathrm{n}$ & Média & $\begin{array}{c}\text { Desvio } \\
\text { padrão }\end{array}$ & Mediana & Mínimo & Máximo \\
\hline $\mathrm{Rb}$ & Frontal & 4 & 19,4 & 8,3 & 16,7 & 12,8 & 31,6 \\
$\mathrm{Se}$ & Hipocampo & 4 & 22,8 & 6,3 & 19,8 & 19,5 & 32,2 \\
& Frontal & 4 & 0,67 & 0,05 & 0,66 & 0,62 & 0,73 \\
$\mathrm{Fe}$ & Hipocampo & 4 & 0,50 & 0,11 & 0,51 & 0,35 & 0,62 \\
& Frontal & 4 & 237,8 & 33,3 & 233,3 & 205,4 & 279,3 \\
$\mathrm{Zn}$ & Hipocampo & 4 & 207,2 & 34,4 & 205,0 & 172,0 & 246,7 \\
& Frontal & 4 & 56,0 & 7,1 & 57,0 & 46,5 & 63,6 \\
$\mathrm{Br}$ & Hipocampo & 4 & 68,5 & 8,3 & 71,4 & 56,7 & 74,5 \\
& Frontal & 4 & 3,00 & 1,23 & 3,12 & 1,68 & 4,08 \\
$\mathrm{Na}$ & Hipocampo & 4 & 2,47 & 1,24 & 2,32 & 1,39 & 3,85 \\
& Frontal & 4 & 10217 & 3615 & 8920 & 7577 & 15452 \\
$\mathrm{~K}$ & Hipocampo & 4 & 8691 & 1745 & 9094 & 6327 & 10247 \\
& Frontal & 4 & 10878 & 1828 & 10559 & 9018 & 13376 \\
& Hipocampo & 4 & 11618 & 1147 & 11577 & 10286 & 13034 \\
\hline
\end{tabular}

Nota: $\mathrm{Rb}=$ rubídio, $\mathrm{Se}=$ selênio, $\mathrm{Fe}=$ ferro, $\mathrm{Zn}=$ zinco, $\mathrm{Br}=$ bromo, $\mathrm{Na}=$ sódio, $\mathrm{K}$ = potássio, $\mathrm{n}=$ número de casos.

O grupo RC representou $14,3 \%$ da casuística estudada e apresentou idade média de $80 \pm 7$ anos. 
Dos 04 indivíduos pertencentes ao grupo RC, 1 foi do gênero feminino com idade de 87 anos enquanto os demais foram do gênero masculino com idade média de $77,7 \pm 6,6$ anos.

\subsubsection{Normal (NN)}

Na Tabela 10 são apresentadas as concentrações dos elementos $\mathrm{Br}, \mathrm{Fe}, \mathrm{K}, \mathrm{Na}$, $\mathrm{Rb}$, Se e Zn no hipocampo e na região frontal do grupo $\mathrm{NN}$.

Tabela 10 - Concentração elementar ( $\mathrm{mg} / \mathrm{kg}$, base seca) no encéfalo do grupo NN

\begin{tabular}{cccccccc}
\hline Elemento & $\begin{array}{c}\text { Região do } \\
\text { encéfalo }\end{array}$ & $\mathrm{n}$ & Média & $\begin{array}{c}\text { Desvio } \\
\text { padrão }\end{array}$ & Mediana & Mínimo & Máximo \\
\hline $\mathrm{Rb}$ & Frontal & 11 & 19,5 & 3,8 & 19,1 & 12,3 & 25,2 \\
$\mathrm{Se}$ & Hipocampo & 11 & 23,4 & 4,8 & 21,9 & 17,6 & 33,2 \\
& Frontal & 11 & 0,68 & 0,12 & 0,62 & 0,53 & 0,96 \\
$\mathrm{Fe}$ & Hipocampo & 11 & 0,52 & 0,07 & 0,53 & 0,40 & 0,65 \\
& Frontal & 11 & 225,3 & 33,8 & 233 & 176,1 & 283,9 \\
$\mathrm{Zn}$ & Hipocampo & 11 & 185,7 & 28,9 & 182,0 & 129,1 & 222,2 \\
$\mathrm{Br}$ & Frontal & 11 & 60,8 & 11,7 & 59,6 & 48,5 & 92,1 \\
$\mathrm{Br}$ & Hipocampo & 11 & 66,5 & 8,4 & 66,5 & 55,8 & 82,3 \\
& Frontal & 11 & 2,83 & 0,80 & 2,98 & 1,50 & 3,89 \\
$\mathrm{Na}$ & Hipocampo & 11 & 2,30 & 0,52 & 2,19 & 1,63 & 3,25 \\
& Frontal & 11 & 8546 & 1061 & 8752 & 6739 & 10215 \\
$\mathrm{~K}$ & Hipocampo & 11 & 7635 & 821 & 7578 & 6296 & 9204 \\
& Frontal & 11 & 12268 & 975 & 12196 & 10914 & 14034 \\
& Hipocampo & 11 & 11904 & 1732 & 12420 & 8621 & 14062 \\
\hline
\end{tabular}

Nota: $\mathrm{Rb}=$ rubídio, $\mathrm{Se}=$ selênio, $\mathrm{Fe}=$ ferro, $\mathrm{Zn}=$ zinco, $\mathrm{Br}=$ bromo, $\mathrm{Na}=$ sódio, $\mathrm{K}$ = potássio, $\mathrm{n}=$ número de casos.

O grupo NN representou $39,3 \%$ da casuística estudada e idade média de $80 \pm$ 5 anos. 
Dos 11 indivíduos pertencentes ao grupo NN, 63,6\% $(\mathrm{n}=7)$ foram do gênero feminino e apresentaram idade média de $80,1 \pm 6,4$ anos enquanto que $36,4 \%(n=3)$ foram do gênero masculino com idade média de 79,8 $\pm 0,9$ anos.

\subsection{Comparação das médias das idades entre os grupos e entre os gêneros} dos indivíduos

A comparação entre as médias de idade nos três grupos (DA, RC e NN) e nos gêneros feminino e masculino, utilizando a técnica de análise de variância com medidas repetidas, não detectou interação entre gênero e grupo $(p=0,592)$, ou seja, as médias das idades são iguais nos três grupos, tanto para homens, quanto para mulheres. Também não houve efeito de gênero $(p=0,320)$ e de grupo $(p=0,834)$ nas médias das idades, ou seja, não há diferença significativa entre as médias da idade nos dois gêneros e nos três grupos.

\subsection{Comparação das concentrações médias dos elementos obtidos entre os grupos de indivíduos e entre regiões do encéfalo}

A comparação das concentrações médias dos elementos entre os grupos (DA, $\mathrm{RC}$ e $\mathrm{NN}$ ) e entre as regiões do encéfalo (hipocampo e frontal), realizada por meio da análise de variância com medidas repetidas, demonstrou efeito de interação entre grupo e região do encéfalo para os elementos $\mathrm{Rb}$, Se e $\mathrm{Na}$ (Tabela 11), ou seja, para estes elementos, as diferenças das concentrações entre os grupos dependem da região 
do encéfalo e as diferenças entre as regiões do encéfalo dependem do grupo para um nível de significância $\mathrm{p}$ de 0,05 . Assim, as comparações entre as médias das concentrações dos elementos foram realizadas par a par para os grupos em cada região e entre regiões para cada grupo.

Para os demais elementos $(\mathrm{Br}, \mathrm{Fe}, \mathrm{K}$ e $\mathrm{Zn})$ os resultados não indicaram efeito de interação entre grupo de indivíduos e região do encéfalo (Tabela 11), ou seja, para estes elementos, as diferenças entre os grupos não dependem da região do encéfalo e as diferenças entre as regiões do encéfalo não dependem do grupo. Dessa forma, as comparações entre as médias das concentrações foram realizadas par a par, entre os grupos e entre as regiões.

Tabela 11 - Resultados dos parâmetros obtidos na análise de variância com medidas repetidas

\begin{tabular}{cccc}
\hline Elemento & Grupo x Região (interação) & Grupo & Região \\
\hline $\mathrm{Rb}$ & $\mathbf{p}=\mathbf{0 , 0 1 4}$ & - & - \\
$\mathrm{Se}$ & $\mathbf{p}=\mathbf{0 , 0 0 5}$ & - & - \\
$\mathrm{Fe}$ & $\mathrm{p}=0,305$ & $\mathbf{p}=\mathbf{0 , 0 3 7}$ & $\mathbf{p}=\mathbf{0 , 0 0 1}$ \\
$\mathrm{Zn}$ & $\mathrm{p}=0,235$ & $\mathrm{p}=0,085$ & $\mathbf{p}=\mathbf{0 , 0 0 1}$ \\
$\mathrm{Br}$ & $\mathrm{p}=0,463$ & $\mathrm{p}=0,267$ & $\mathbf{p}=\mathbf{0 , 0 0 4}$ \\
$\mathrm{Na}$ & $\mathbf{p}=\mathbf{0 , 0 1 1}$ & - & - \\
$\mathrm{K}$ & $\mathrm{p}=0,144$ & $\mathbf{p}=\mathbf{0 , 0 0 5}$ & $\mathrm{p}=0,508$ \\
\hline
\end{tabular}

Nota: $\mathrm{Rb}=$ rubídio, $\mathrm{Se}=$ selênio, $\mathrm{Fe}=$ ferro, $\mathrm{Zn}=$ zinco, $\mathrm{Br}=$ bromo, $\mathrm{Na}=$ sódio, $\mathrm{K}$ = potássio.

\subsection{Comparação das concentrações de cada um dos elementos obtidos entre} grupos de indivíduos 


\subsubsection{Rubídio (Rb)}

Os portadores de doença de Alzheimer (grupo DA) apresentaram concentrações mais baixas de $\mathrm{Rb}$, tanto na região frontal $(\mathrm{p}=0,046)$ como no hipocampo $(\mathrm{p}=0,001)$, quando comparadas com as obtidas no encéfalo de indivíduos cognitivamente normais (grupo NN). À semelhança, concentrações mais baixas de $\mathrm{Rb}$ foram obtidas no hipocampo $(\mathrm{p}=0,028)$ do grupo DA quando comparadas com as obtidas para indivíduos cognitivamente normais, porém com sinais neuropatológicos de DA (grupo RC). Estes dados estão apresentados na Figura 09.

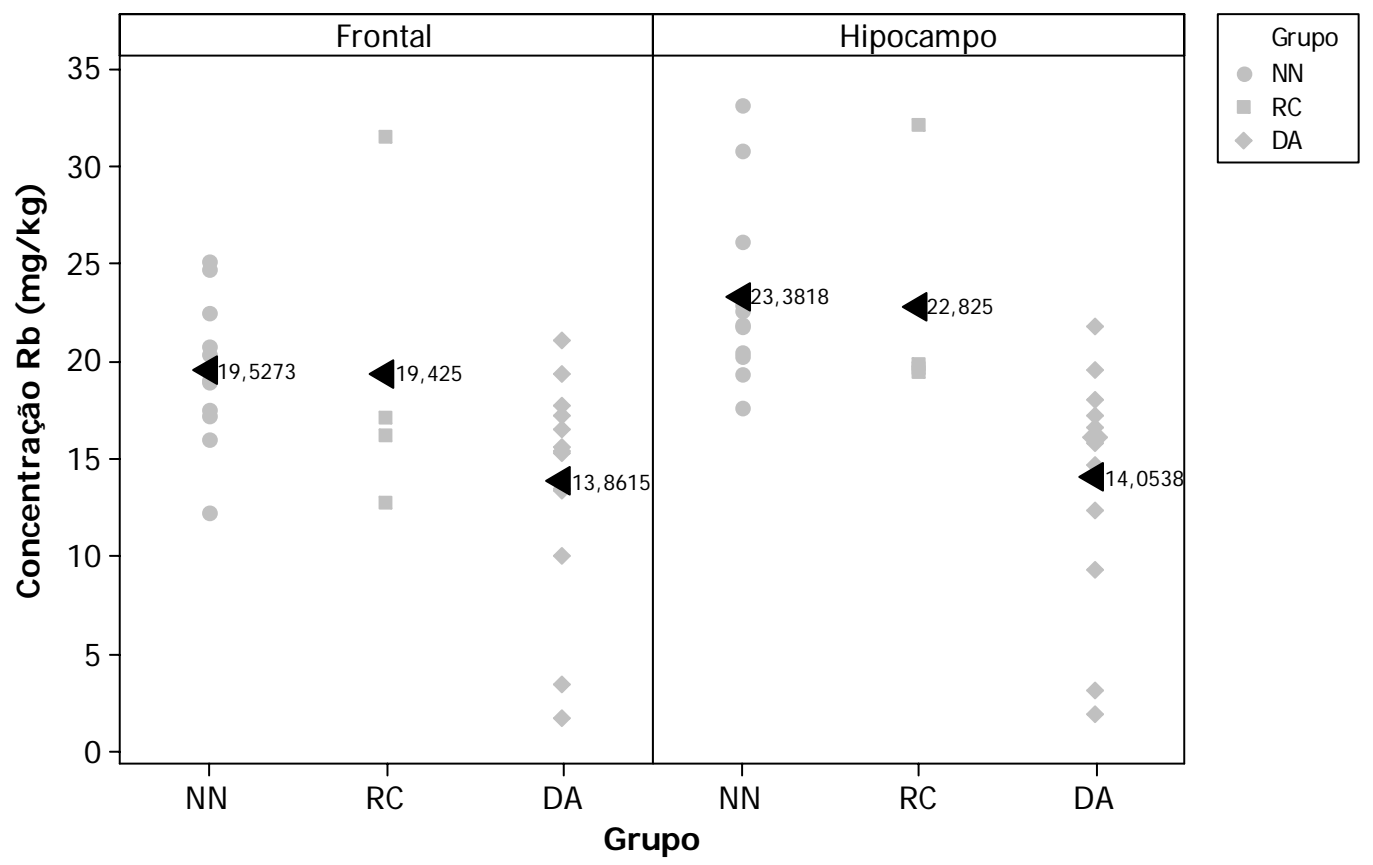

Figura 09 - Valores individuais e médios das concentrações de rubídio $(\mathrm{Rb})$ para grupos de indivíduos e regiões do encéfalo. Nota: $\mathrm{NN}=$ grupo normal, $\mathrm{RC}=$ grupo reserva cognitiva, $\mathrm{DA}=$ grupo doença de Alzheimer, $\boldsymbol{\Psi}$ = média das concentrações. 


\subsubsection{Selênio (Se)}

Os indivíduos com doença de Alzheimer (grupo DA) apresentaram concentrações mais elevadas de Se no hipocampo quando comparadas com as obtidas para indivíduos cognitivamente normais (grupo NN) $(\mathrm{p}=0,023)$ (Figura 10).

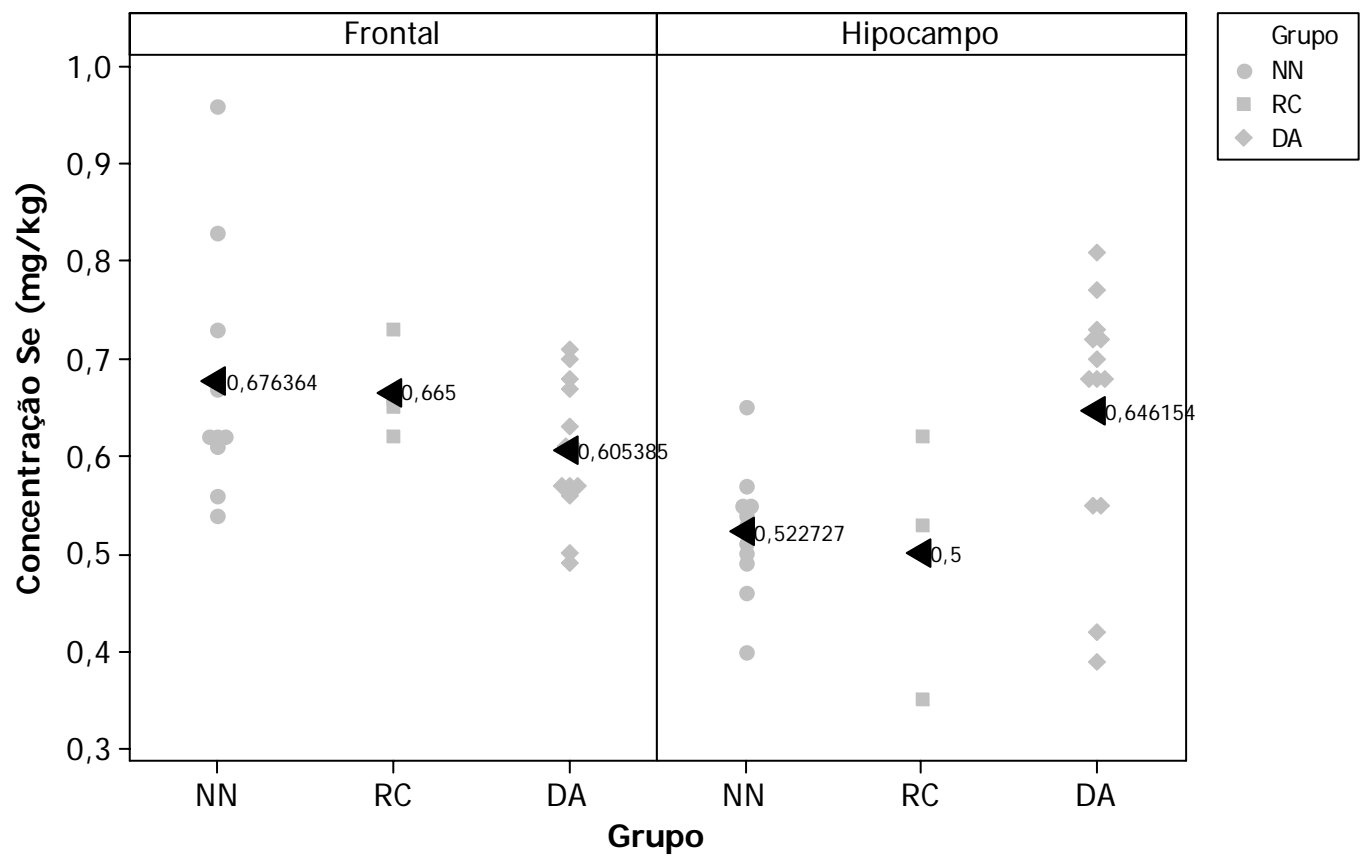

Figura 10 - Valores individuais e médios das concentrações de selênio (Se) para grupos de indivíduos e regiões do encéfalo. Nota: $\mathrm{NN}=$ grupo normal, $\mathrm{RC}=$ grupo reserva cognitiva, $\mathrm{DA}=$ grupo doença de Alzheimer, $\boldsymbol{\Psi}$ = média das concentrações. 


\subsubsection{Ferro (Fe)}

Os indivíduos com doença de Alzheimer (grupo DA) apresentaram concentrações mais elevadas de Fe quando comparadas com as obtidas no encéfalo de indivíduos cognitivamente normais (grupo $\mathrm{NN})(\mathrm{p}=0,030)$, tanto na região frontal quanto no hipocampo (Figura 11).

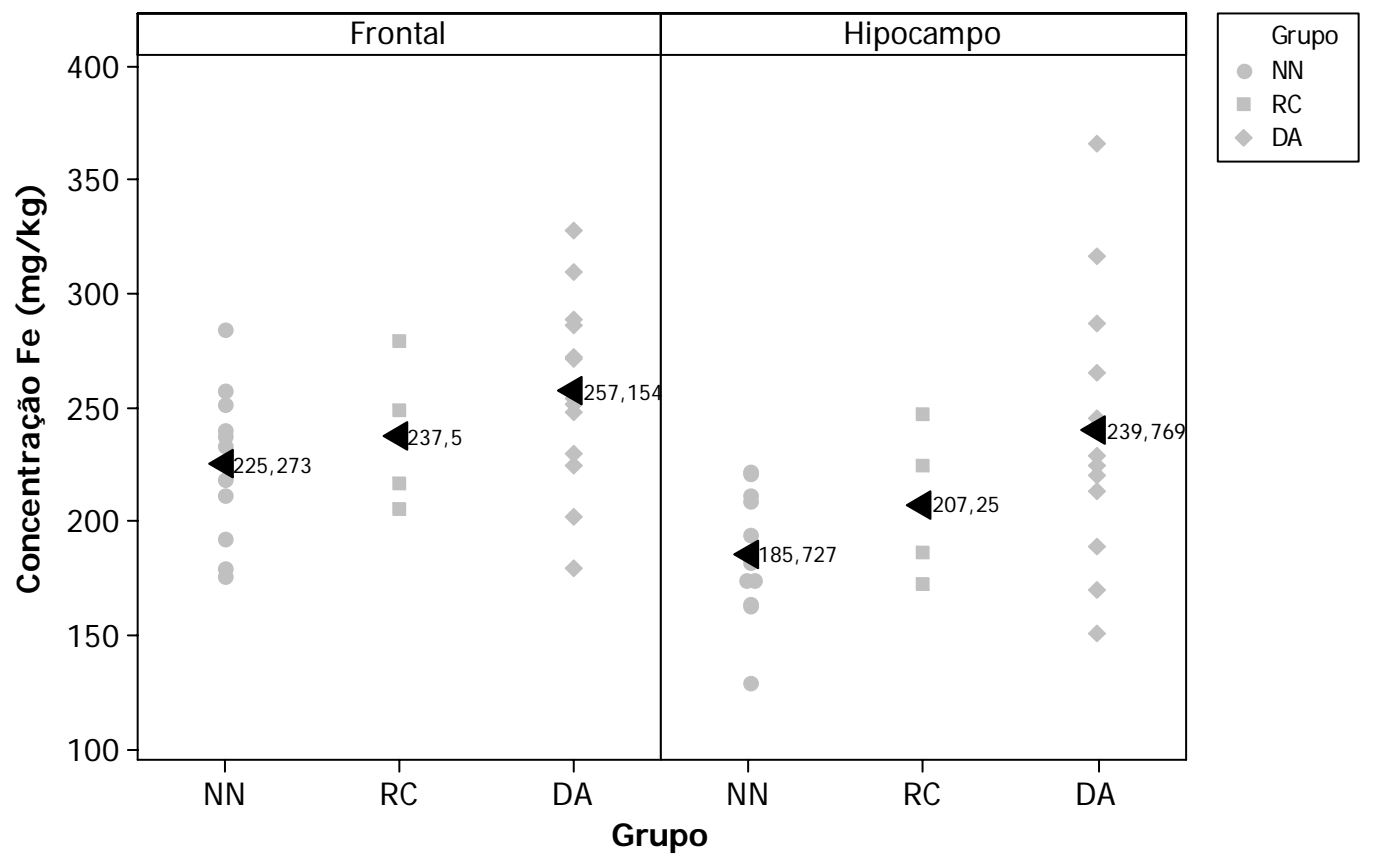

Figura 11 - Valores individuais e médios das concentrações de ferro $(\mathrm{Fe})$ para grupos de indivíduos e regiões do encéfalo. Nota: $\mathrm{NN}=$ grupo normal, $\mathrm{RC}=$ grupo reserva cognitiva, DA = grupo doença de Alzheimer, 4 = média das concentrações. 


\subsubsection{Zinco (Zn)}

Não houve diferença significativa entre os grupos quanto às concentrações de $\mathrm{Zn}(\mathrm{p}=0,085)$. As concentrações de $\mathrm{Zn}$ obtidas para cada indivíduo bem como as médias de cada grupo, obtidas para as duas regiões do encéfalo são apresentadas na Figura 12.

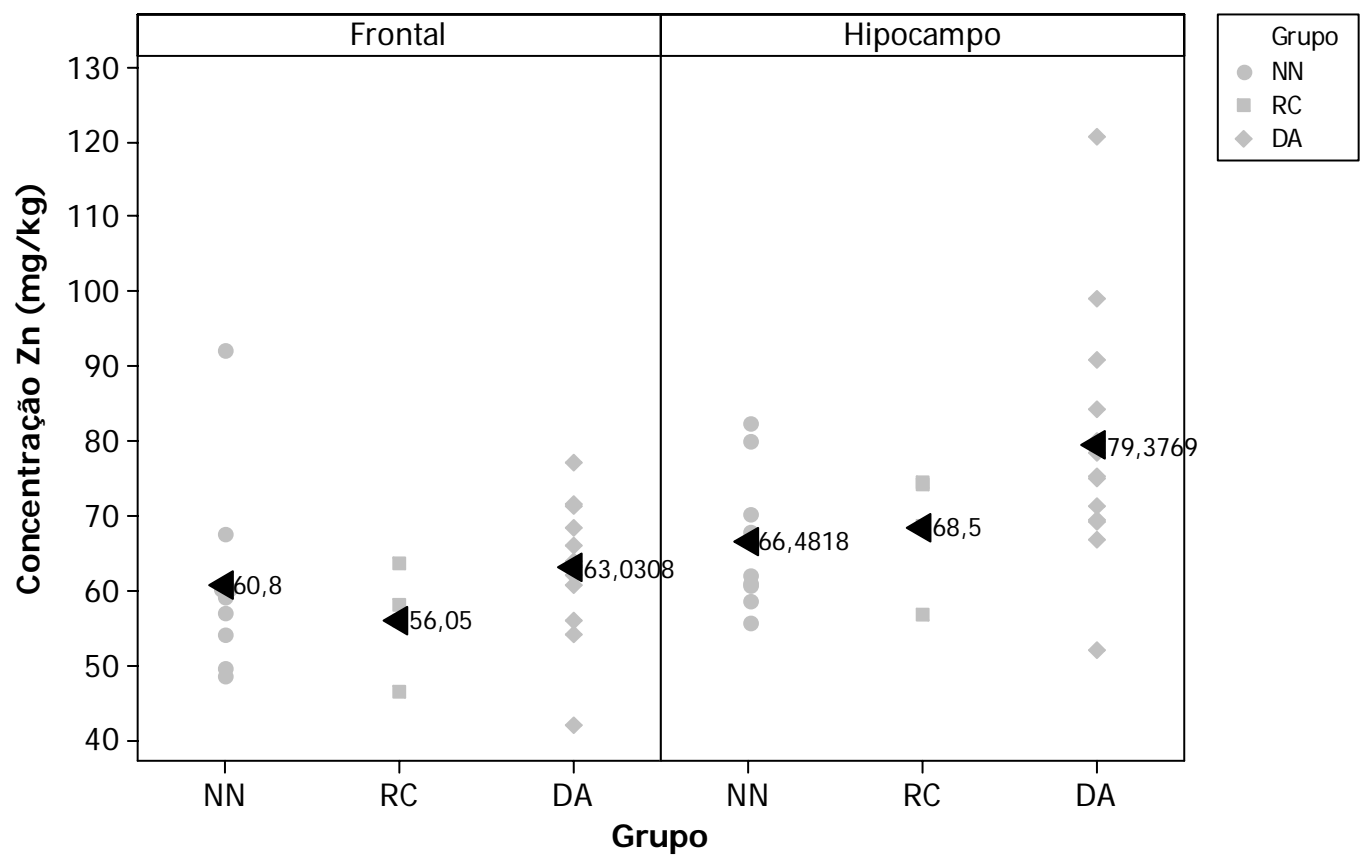

Figura 12 - Valores individuais e médios das concentrações de zinco ( $\mathrm{Zn}$ ) para grupos de indivíduos e regiões do encéfalo. Nota: $\mathrm{NN}=$ grupo normal, $\mathrm{RC}=$ grupo reserva cognitiva, $\mathrm{DA}=$ grupo doença de Alzheimer, $\boldsymbol{\Psi}$ = média das concentrações. 


\subsubsection{Bromo (Br)}

Não foi verificada diferença significativa das concentrações de $\mathrm{Br}$ entre os grupos de indivíduos. As concentrações de $\mathrm{Br}$ para cada um dos indivíduos bem como a média obtida para cada grupo, nas duas regiões de estudo, são apresentadas na Figura 13.

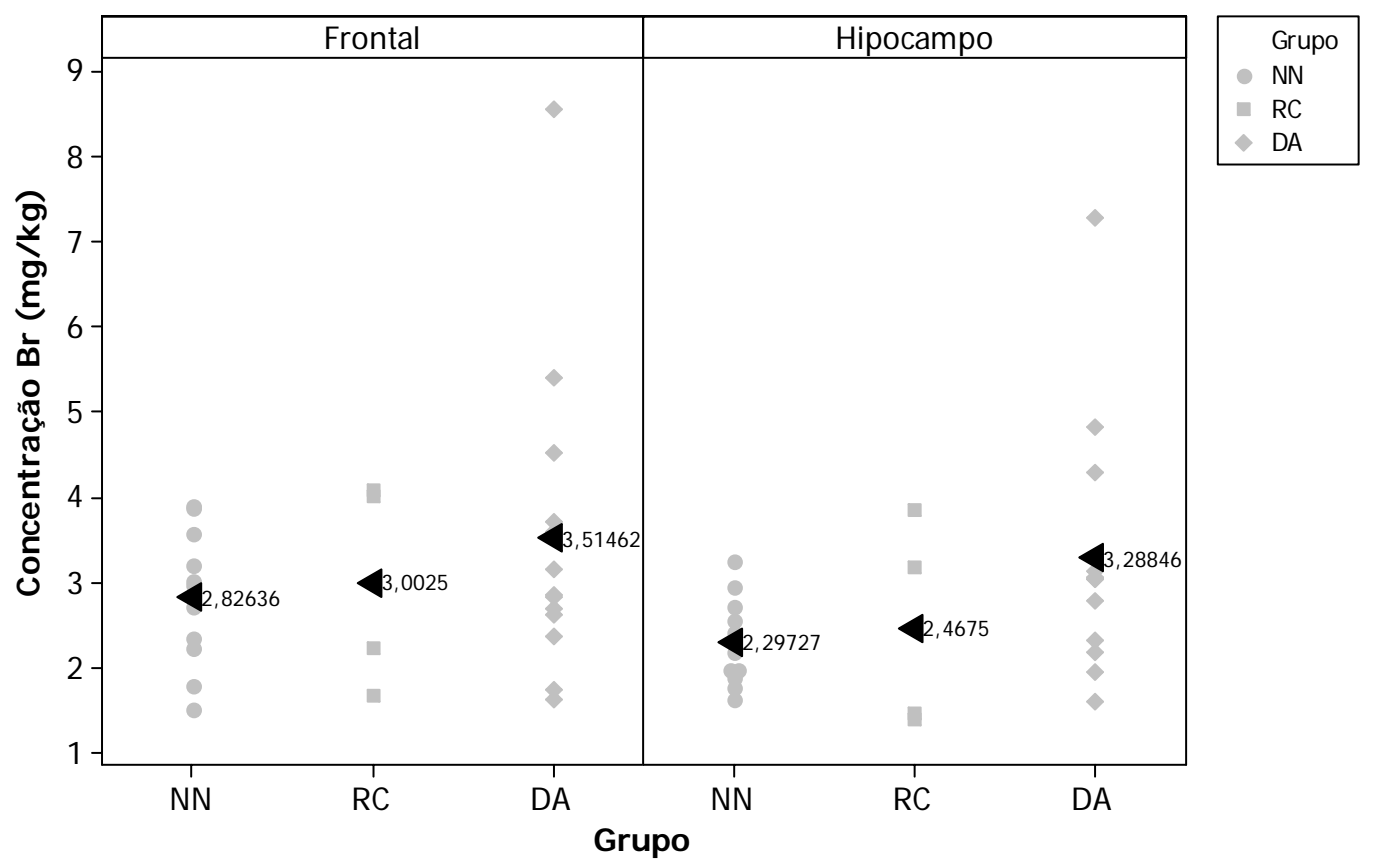

Figura 13 - Valores individuais e médios das concentrações de bromo $(\mathrm{Br})$ para grupos de indivíduos e regiões do encéfalo. Nota: $\mathrm{NN}=$ grupo normal, $\mathrm{RC}=$ grupo reserva cognitiva, $\mathrm{DA}=$ grupo doença de Alzheimer, $\boldsymbol{\Psi}$ = média das concentrações. 


\subsubsection{Sódio (Na)}

Os indivíduos com doença de Alzheimer (grupo DA) apresentaram concentrações mais elevadas de $\mathrm{Na}$ no hipocampo quando comparadas com as dos indivíduos cognitivamente normais (grupo NN) $(\mathrm{p}=0,002)$ (Figura 14).

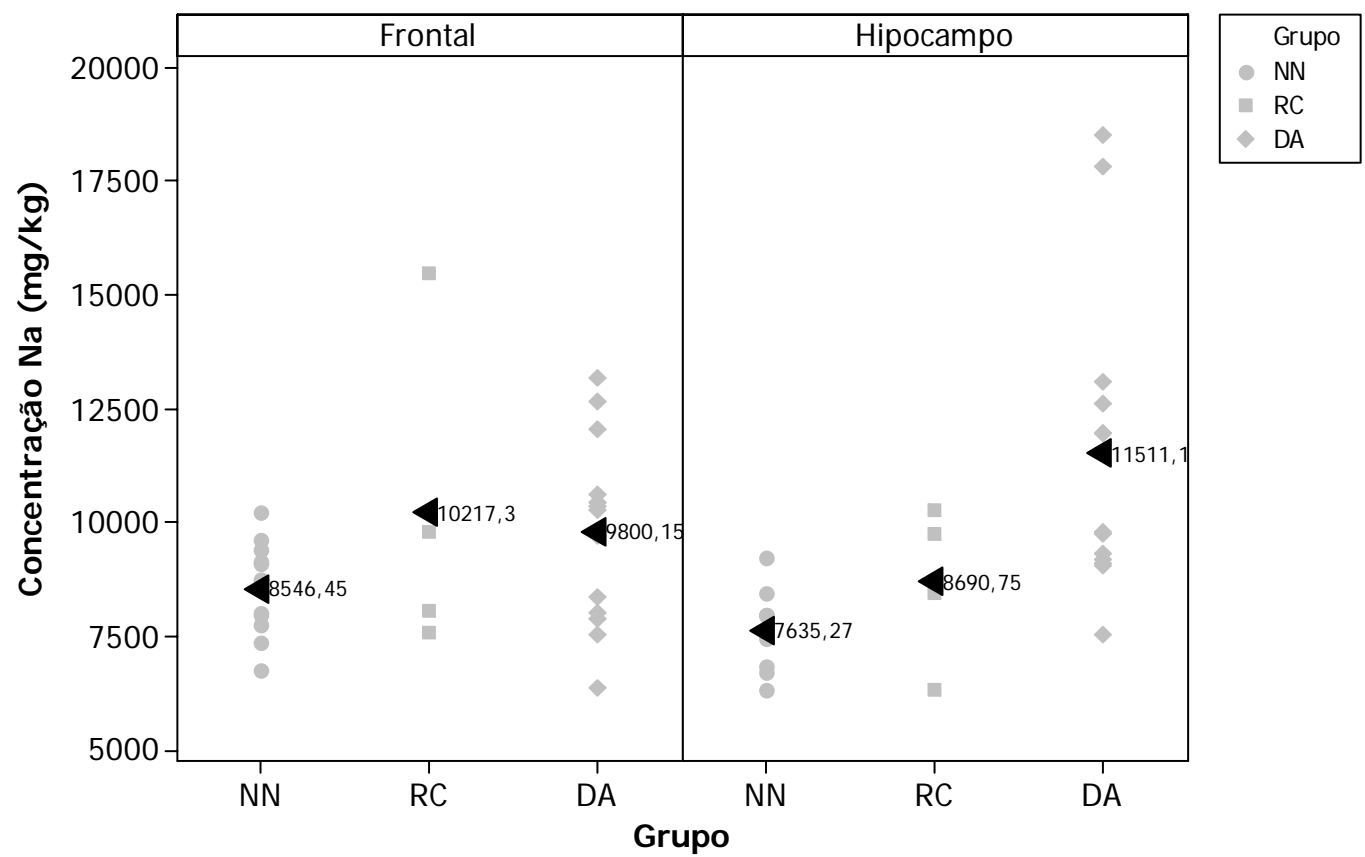

Figura 14 - Valores individuais e médios das concentrações de sódio (Na) para grupos de indivíduos e regiões do encéfalo. Nota: $\mathrm{NN}=$ grupo normal, $\mathrm{RC}=$ grupo reserva cognitiva, $\mathrm{DA}=$ grupo doença de Alzheimer, $\boldsymbol{\Psi}$ = média das concentrações. 


\subsubsection{Potássio (K)}

Os indivíduos com doença de Alzheimer (grupo DA) apresentaram concentrações mais baixas de $\mathrm{K}$ quando comparados aos indivíduos cognitivamente normais (grupo $\mathrm{NN})(\mathrm{p}=0,004)$, tanto na região frontal quanto no hipocampo (Figura $15)$.

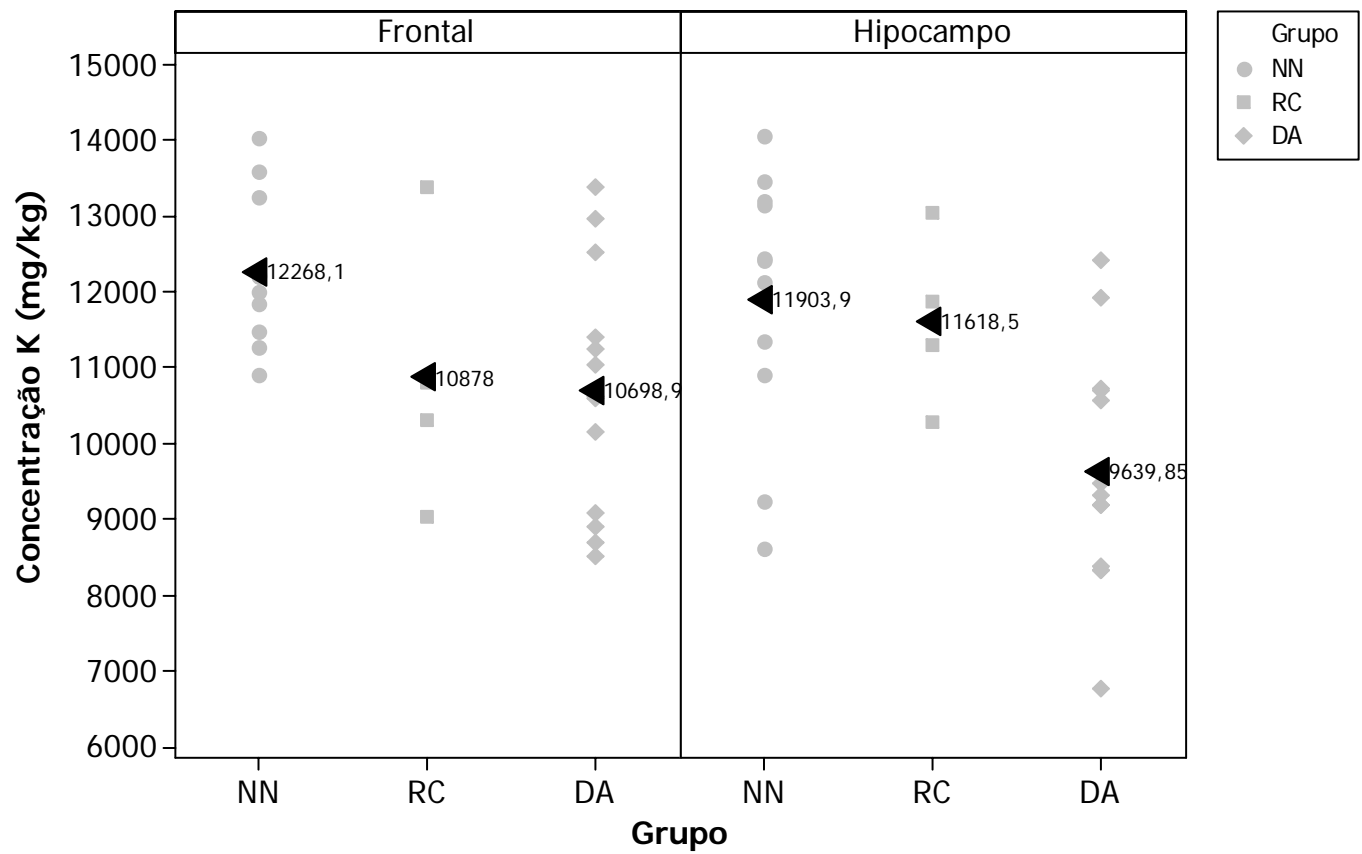

Figura 15 - Valores individuais e médios das concentrações de potássio $(\mathrm{K})$ para grupos de indivíduos e regiões do encéfalo. Nota: $\mathrm{NN}=$ grupo normal, $\mathrm{RC}=$ grupo reserva cognitiva, $\mathrm{DA}=$ grupo doença de Alzheimer, $\boldsymbol{\Psi}$ = média das concentrações. 


\subsection{Comparação das médias das concentrações entre grupos de indivíduos}

As concentrações médias de cada um dos elementos, nos três grupos de indivíduos e nas duas regiões de estudo, estão reunidas na Tabela 12. O resultado da comparação das médias dos grupos, dois a dois, está apresentado na Tabela 13.

Tabela 12 - Concentrações médias ( $\mathrm{mg} / \mathrm{kg}$, base seca) dos elementos nos três grupos de indivíduos e nas duas regiões de estudo

\begin{tabular}{|c|c|c|c|c|c|c|}
\hline \multirow[t]{2}{*}{ Elemento } & \multicolumn{3}{|c|}{ Hipocampo } & \multicolumn{3}{|c|}{ Frontal } \\
\hline & NN & $\mathrm{RC}$ & DA & NN & $\mathrm{RC}$ & DA \\
\hline $\mathrm{Rb}$ & 23,4 & 22,8 & 14,0 & 19,5 & 19,4 & 13,9 \\
\hline $\mathrm{Se}$ & 0,52 & 0,50 & 0,65 & 0,68 & 0,67 & 0,60 \\
\hline $\mathrm{Fe}$ & 185,7 & 207,2 & 239,8 & 225,3 & 237,8 & 257,2 \\
\hline $\mathrm{Zn}$ & 66,5 & 68,5 & 79,4 & 60,8 & 56,0 & 63,0 \\
\hline $\mathrm{Br}$ & 2,30 & 2,47 & 3,29 & 2,83 & 3,00 & 3,52 \\
\hline $\mathrm{Na}$ & 7635 & 8691 & 11511 & 8546 & 10217 & 9800 \\
\hline $\mathrm{K}$ & 11904 & 11618 & 9640 & 12268 & 10878 & 10699 \\
\hline
\end{tabular}


Tabela 13 - Resultado das comparações das concentrações médias dos elementos entre os grupos de indivíduos, dois a dois, na região frontal e hipocampo

\begin{tabular}{|c|c|c|c|c|c|c|}
\hline \multirow[t]{2}{*}{ Elemento } & \multicolumn{3}{|c|}{ Hipocampo } & \multicolumn{3}{|c|}{ Frontal } \\
\hline & DA x NN & DA x RC & RC x NN & DA x NN & DA $\times$ RC & RC x NN \\
\hline $\mathrm{Rb}$ & $\begin{array}{l}\text { DA }<\text { NN } \\
(p=0,001)\end{array}$ & $\begin{array}{l}\mathrm{DA}<\mathrm{RC} \\
(\mathrm{p}=\mathbf{0 , 0 2 8})\end{array}$ & $\begin{array}{c}\text { Não houve } \neq \\
(\mathrm{p}=0,983)\end{array}$ & $\begin{array}{l}\text { DA }<\text { NN } \\
(p=0,046)\end{array}$ & $\begin{array}{c}\text { Não houve } \neq \\
(\mathrm{p}=0,198)\end{array}$ & $\begin{array}{c}\text { Não houve } \neq \\
(\mathrm{p}=0,999)\end{array}$ \\
\hline $\mathrm{Se}$ & $\begin{array}{l}\text { DA }>\text { NN } \\
(p=0,023)\end{array}$ & $\begin{array}{c}\text { Não houve } \neq \\
(\mathrm{p}=0,053)\end{array}$ & $\begin{array}{l}\text { Não houve } \neq \\
(p=0,907)\end{array}$ & $\begin{array}{c}\text { Não houve } \neq \\
(\mathrm{p}=0,176)\end{array}$ & $\begin{array}{c}\text { Não houve } \neq \\
(\mathrm{p}=0,493)\end{array}$ & $\begin{array}{c}\text { Não houve } \neq \\
(\mathrm{p}=0,985)\end{array}$ \\
\hline $\mathrm{Fe}$ & $\begin{array}{l}\text { DA }>\text { NN } \\
(p=0,030)\end{array}$ & $\begin{array}{c}\text { Não houve } \neq \\
(\mathrm{p}=0,476)\end{array}$ & $\begin{array}{c}\text { Não houve } \neq \\
(\mathrm{p}=0,732)\end{array}$ & $\begin{array}{l}\text { DA > NN } \\
(p=0,030)\end{array}$ & $\begin{array}{c}\text { Não houve } \neq \\
(p=0,476)\end{array}$ & $\begin{array}{c}\text { Não houve } \neq \\
(p=0,732)\end{array}$ \\
\hline $\mathrm{Na}$ & $\begin{array}{l}\text { DA > NN } \\
(p=0,002)\end{array}$ & $\begin{array}{c}\text { Não houve } \neq \\
(\mathrm{p}=0,134)\end{array}$ & $\begin{array}{c}\text { Não houve } \neq \\
(\mathrm{p}=0,747)\end{array}$ & $\begin{array}{c}\text { Não houve } \neq \\
(\mathrm{p}=0,302)\end{array}$ & $\begin{array}{c}\text { Não houve } \neq \\
(\mathrm{p}=0,931)\end{array}$ & $\begin{array}{c}\text { Não houve } \neq \\
(p=0,349)\end{array}$ \\
\hline $\mathrm{K}$ & $\begin{array}{l}\mathrm{DA}<\mathrm{NN} \\
(\mathrm{p}=0,004)\end{array}$ & $\begin{array}{c}\text { Não houve } \neq \\
(\mathrm{p}=0,329)\end{array}$ & $\begin{array}{c}\text { Não houve } \neq \\
(\mathrm{p}=0,519)\end{array}$ & $\begin{array}{l}\mathrm{DA}<\mathrm{NN} \\
(\mathrm{p}=0,004)\end{array}$ & $\begin{array}{c}\text { Não houve } \neq \\
(\mathrm{p}=0,329)\end{array}$ & $\begin{array}{c}\text { Não houve } \neq \\
(\mathrm{p}=0,519)\end{array}$ \\
\hline $\mathrm{Zn}$ & $\begin{array}{c}\text { Não houve } \neq \\
(\mathrm{p}=0,085)\end{array}$ & $\begin{array}{c}\text { Não houve } \neq \\
(\mathrm{p}=0,085)\end{array}$ & $\begin{array}{c}\text { Não houve } \neq \\
(\mathrm{p}=0,085)\end{array}$ & $\begin{array}{c}\text { Não houve } \neq \\
(\mathrm{p}=0,085)\end{array}$ & $\begin{array}{c}\text { Não houve } \neq \\
(\mathrm{p}=0,085)\end{array}$ & $\begin{array}{c}\text { Não houve } \neq \\
(\mathrm{p}=0,085)\end{array}$ \\
\hline $\mathrm{Br}$ & $\begin{array}{c}\text { Não houve } \neq \\
(p=0,267)\end{array}$ & $\begin{array}{c}\text { Não houve } \neq \\
(\mathrm{p}=0,267)\end{array}$ & $\begin{array}{c}\text { Não houve } \neq \\
(\mathrm{p}=0,267)\end{array}$ & $\begin{array}{c}\text { Não houve } \neq \\
(p=0,267)\end{array}$ & $\begin{array}{c}\text { Não houve } \neq \\
(p=0,267)\end{array}$ & $\begin{array}{c}\text { Não houve } \neq \\
(p=0,267)\end{array}$ \\
\hline
\end{tabular}

4.6 Comparação das concentrações de cada um dos elementos entre região frontal e hipocampo 


\subsubsection{Rubídio (Rb)}

Em indivíduos cognitivamente normais (grupo $\mathrm{NN}$ ), as concentrações de $\mathrm{Rb}$ no hipocampo foram maiores do que as da região frontal $(\mathrm{p}=0,005)$ (Figura 16). Já para os grupos de indivíduos $\mathrm{DA}$ e $\mathrm{RC}$ as comparações entre a região frontal e o hipocampo não indicaram diferenças significativas $(p=0,786$ e 0,092 , respectivamente).

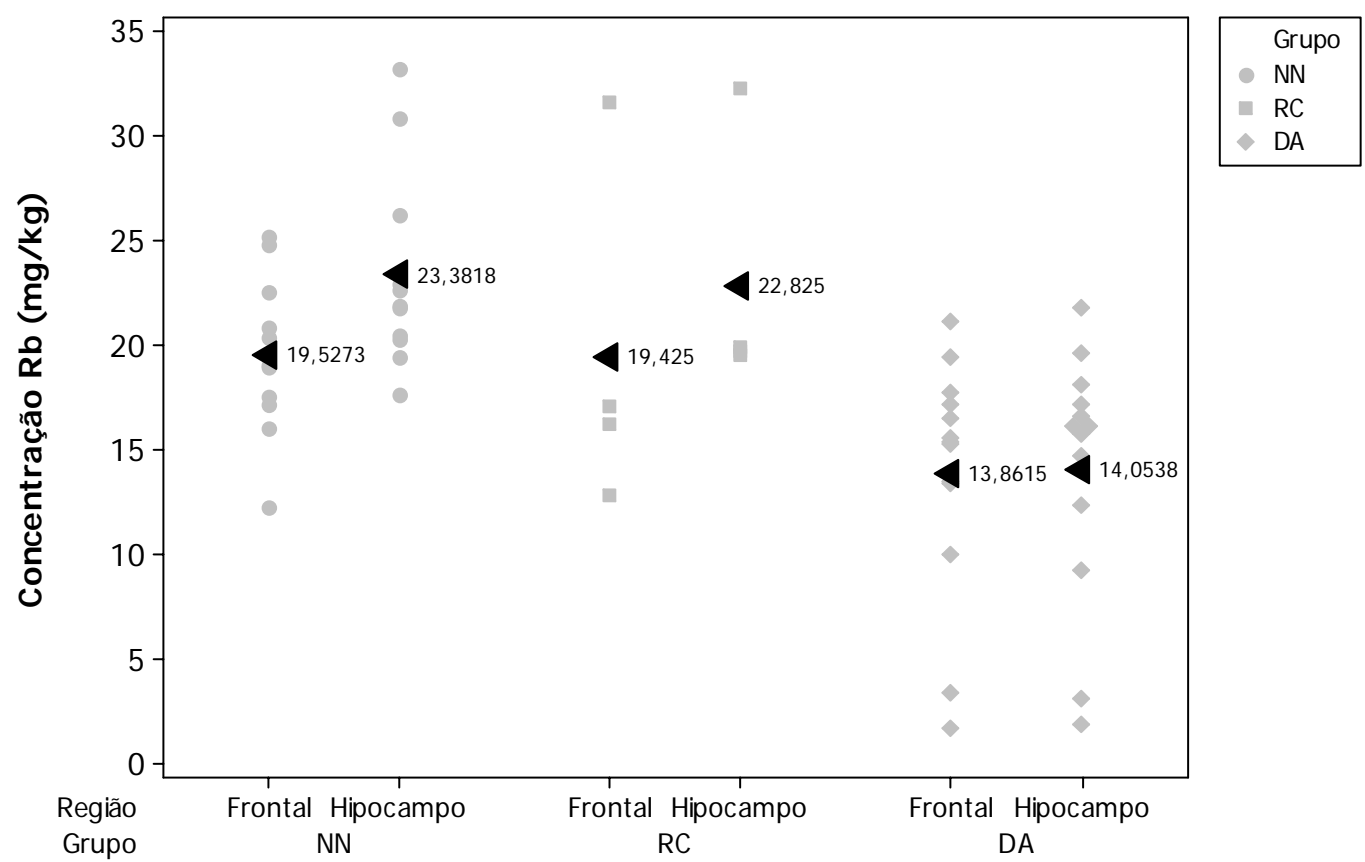

Figura 16 - Valores individuais e médios das concentrações de rubídio $(\mathrm{Rb})$ em região frontal e hipocampo para cada um dos grupos de indivíduos. Nota: $\mathrm{NN}=$ grupo normal, $\mathrm{RC}=$ grupo reserva cognitiva, $\mathrm{DA}=$ grupo doença de Alzheimer, $\oplus$ indica média das concentrações. 


\subsubsection{Selênio (Se)}

Em indivíduos cognitivamente normais (grupo $\mathrm{NN}$ ), as concentrações de $\mathrm{Se}$ obtidas no hipocampo foram mais baixas do que as da região frontal $(p=0,006)$ (Figura 17). Já para os grupos de indivíduos DA e RC as comparações entre a região frontal e o hipocampo não indicaram diferenças significativas $(p=0,294$ e 0,105, respectivamente).

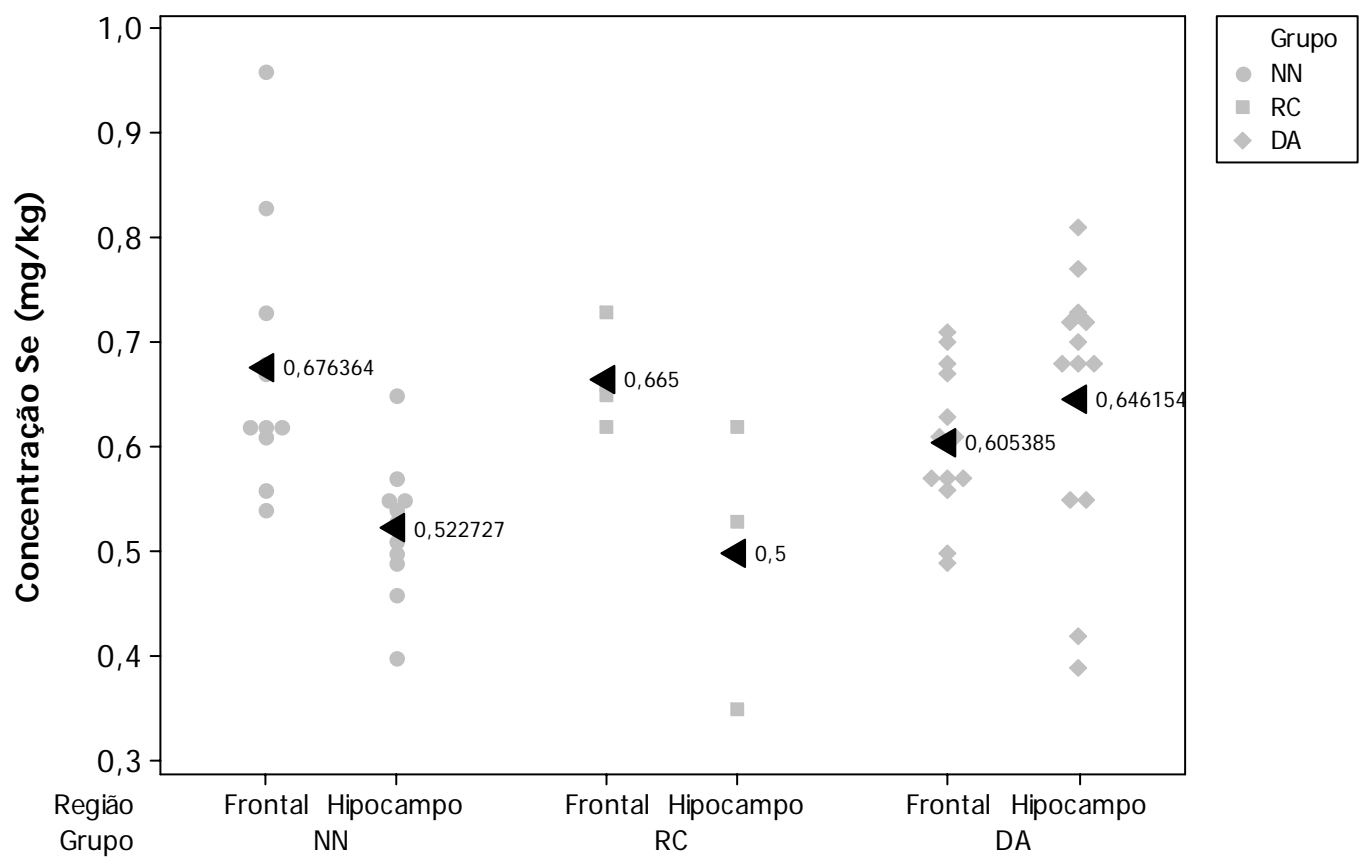

Figura 17 - Valores individuais e médios das concentrações de selênio (Se) em região frontal e hipocampo para cada um dos grupos de indivíduos. Nota: $\mathrm{NN}$ = grupo normal, $\mathrm{RC}=$ grupo reserva cognitiva, $\mathrm{DA}=$ grupo doença de Alzheimer, $\oplus$ indica média das concentrações. 


\subsubsection{Ferro (Fe)}

As concentrações de Fe obtidas no hipocampo foram mais baixas do que as da região frontal em todos os grupos analisados (DA, RC e NN) $(p=0,001)$, conforme mostra a Figura 18.

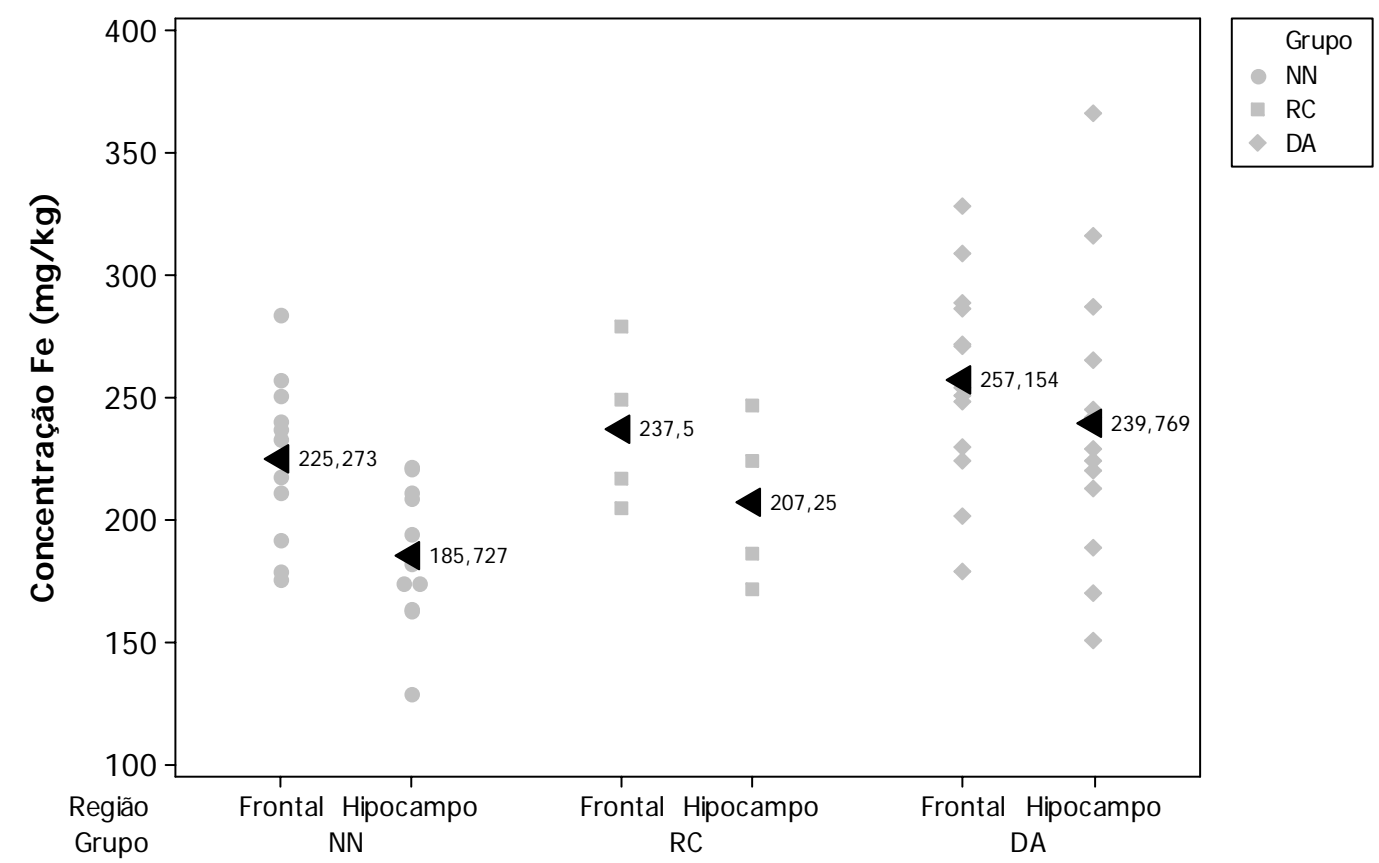

Figura 18 - Valores individuais e médios das concentrações de ferro (Fe) em região frontal e hipocampo para cada um dos grupos de indivíduos. Nota: $\mathrm{NN}=$ grupo normal, $\mathrm{RC}=$ grupo reserva cognitiva, $\mathrm{DA}=$ grupo doença de Alzheimer, $\oplus$ indica média das concentrações. 


\subsubsection{Zinco (Zn)}

As concentrações médias de $\mathrm{Zn}$ obtidas no hipocampo foram maiores do que as da região frontal em todos os grupos estudados (DA, RC e $\mathrm{NN}(\mathrm{p}=0,001)$, conforme mostra a Figura 19.

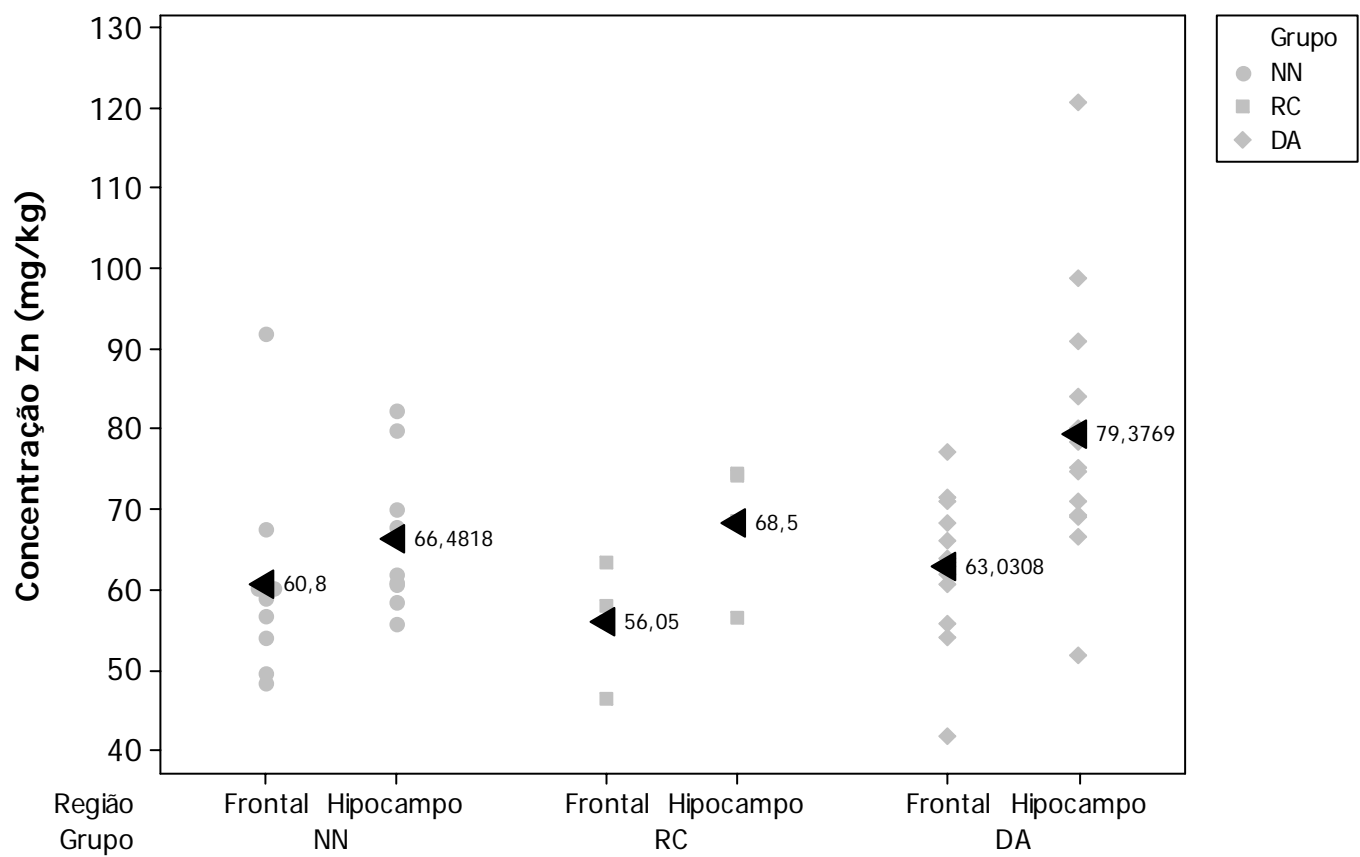

Figura 19 - Valores individuais e médios das concentrações de zinco (Zn) em região frontal e hipocampo para cada um dos grupos de indivíduos. Nota: $\mathrm{NN}=$ grupo normal, $\mathrm{RC}=$ grupo reserva cognitiva, $\mathrm{DA}=$ grupo doença de Alzheimer, $\oplus$ indica média das concentrações. 


\subsubsection{Bromo (Br)}

As concentrações de $\mathrm{Br}$ no hipocampo foram mais baixas do que as da região frontal em todos nos três grupos de indivíduos (DA, RC e NN) $(p=0,004)$, conforme apresentado na Figura 20.

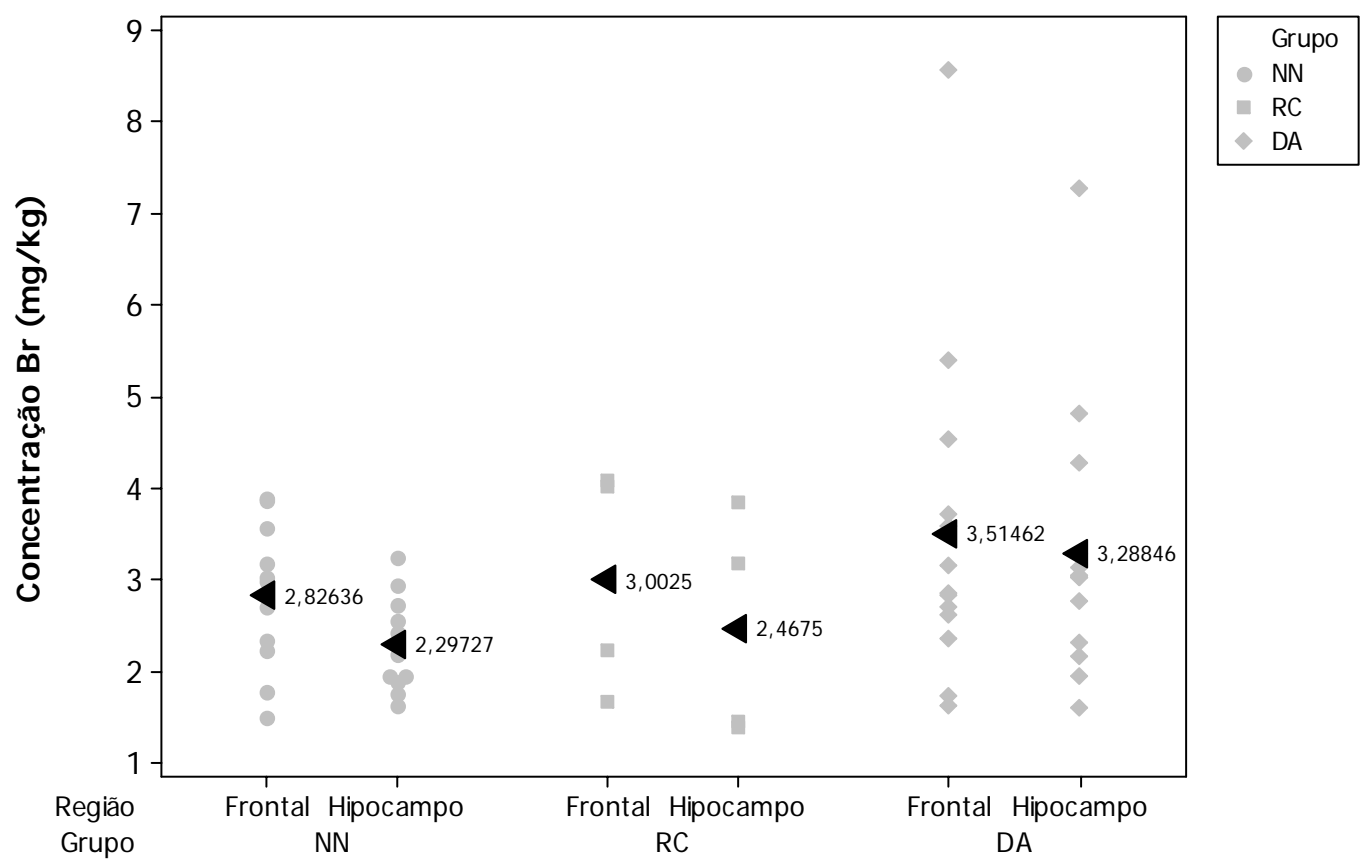

Figura 20 - Valores individuais e médios das concentrações de bromo $(\mathrm{Br})$ em região frontal e hipocampo para cada um dos grupos de indivíduos. Nota: $\mathrm{NN}=$ grupo normal, $\mathrm{RC}=$ grupo reserva cognitiva, $\mathrm{DA}=$ grupo doença de Alzheimer, $\oplus$ indica média das concentrações. 


\subsubsection{Sódio (Na)}

Os portadores de DA (grupo DA) apresentaram maiores concentrações de $\mathrm{Na}$ no hipocampo do que as da na região frontal $(\mathrm{p}=0,045)$. De maneira inversa, os indivíduos cognitivamente normais (grupo $\mathrm{NN}$ ) apresentaram menores concentrações $(\mathrm{p}=0,032)$ (Figura 21). Para os indivíduos do grupo $\mathrm{RC}$ não houve diferença estatística na comparação entre região frontal e hipocampo $(p=0,317)$.

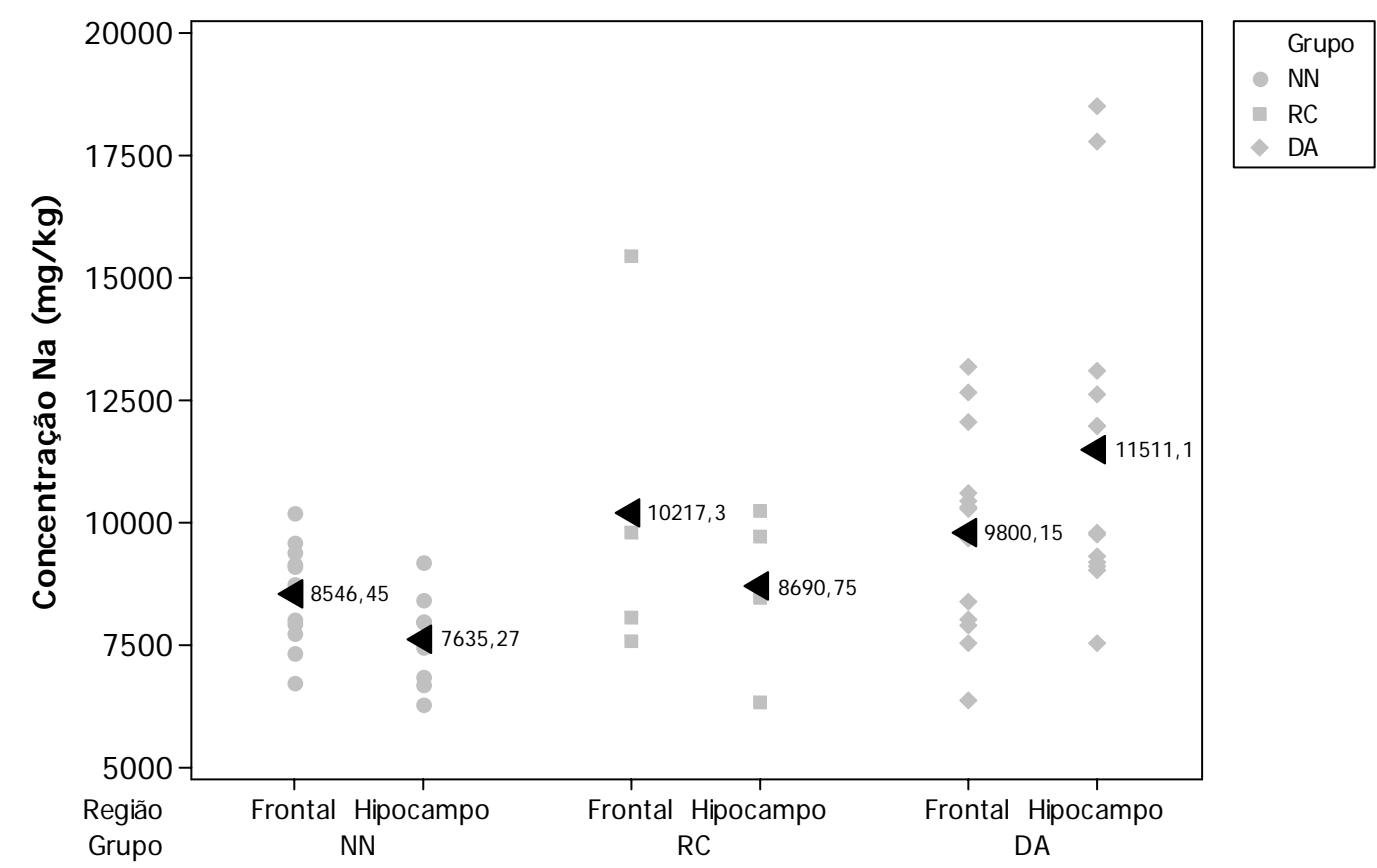

Figura 21 - Valores individuais e médios das concentrações de sódio $(\mathrm{Na})$ em região frontal e hipocampo para cada um dos grupos de indivíduos. Nota: $\mathrm{NN}=$ grupo normal, $\mathrm{RC}=$ grupo reserva cognitiva, $\mathrm{DA}=$ grupo doença de Alzheimer, $\oplus$ indica média das concentrações. 


\subsubsection{Potássio (K)}

Os resultados obtidos para $\mathrm{K}$ indicaram que não houve diferença significativa na comparação das concentrações deste elemento entre hipocampo e região frontal nos três grupos estudados (DA, RC e $\mathrm{NN})(\mathrm{p}=0,508)$. Os valores individuais e as médias das concentrações de K estão apresentados na Figura 22.

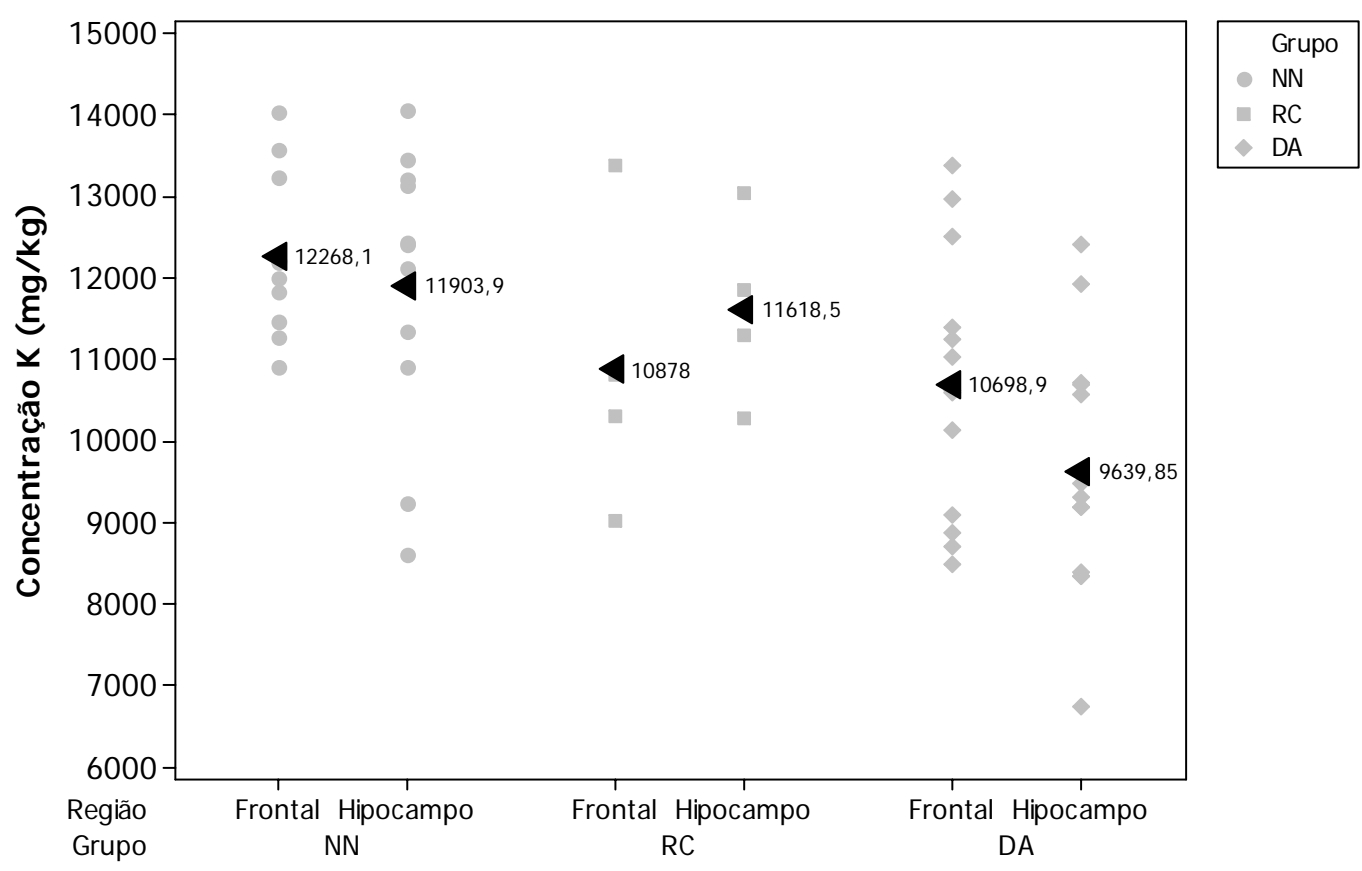

Figura 22 - Valores individuais e médios das concentrações de potássio $(\mathrm{K})$ em região frontal e hipocampo para cada um dos grupos de indivíduos. Nota: $\mathrm{NN}=$ grupo normal, $\mathrm{RC}=$ grupo reserva cognitiva, $\mathrm{DA}=$ grupo doença de Alzheimer, $\oplus$ indica média das concentrações. 
4.7 Determinação da concentração dos elementos nos materiais de referência

Os resultados obtidos nos materiais de referência NIST 1566b Oyster Tissue e NIST 1577b Bovine Liver são apresentados na Tabela 14.

Tabela 14 - Concentração dos elementos nos materiais de referência NIST 1566b Oyster Tissue e NIST 1577b Bovine Liver (mg/kg)

\begin{tabular}{|c|c|c|c|c|c|}
\hline \multicolumn{6}{|c|}{$\begin{array}{c}\text { NIST 1566b Oyster Tissue } \\
\text { NIST, } 2001 \\
\end{array}$} \\
\hline \multirow[t]{2}{*}{ Elemento } & \multicolumn{4}{|c|}{ Presente trabalho } & Valor certificado \\
\hline & Média \pm DP & $\begin{array}{l}\text { Desvio padrão } \\
\text { relativo }\end{array}$ & $\begin{array}{l}\% \text { Erro } \\
\text { relativo }\end{array}$ & Escore-z & \\
\hline $\mathrm{Rb}$ & $3,151 \pm 0.132$ & 4.2 & 3.4 & -0.56 & $3.262 \pm 0.145$ \\
\hline $\mathrm{Se}$ & $2,08 \pm 0.02$ & 0.1 & 0.1 & 0.13 & $2.06 \pm 0.15$ \\
\hline $\mathrm{Fe}$ & $196,4 \pm 7.1$ & 3.6 & 4.6 & -0.97 & $205.8 \pm 6.8$ \\
\hline $\mathrm{Zn}$ & $1373 \pm 41$ & 3.0 & 3.6 & -0.83 & $1424 \pm 46$ \\
\hline $\mathrm{Br}$ & $50,9 \pm 3.8$ & 7.5 & $*$ & $*$ & $*$ \\
\hline $\mathrm{Na}$ & $3164 \pm 146$ & 4.6 & 4.0 & -0.86 & $3297 \pm 53$ \\
\hline \multirow[t]{2}{*}{$\mathrm{K}$} & $6428 \pm 346$ & 5.4 & 1.4 & -0.26 & $6520 \pm 90$ \\
\hline & \multicolumn{4}{|c|}{$\begin{array}{l}\text { NIST 1577b Bovine Liver } \\
\text { NIST, } 1991\end{array}$} & \\
\hline \multirow[t]{2}{*}{ Elemento } & \multicolumn{4}{|c|}{ Presente trabalho } & Valor certificado \\
\hline & Média \pm DP & $\begin{array}{l}\text { Desvio padrão } \\
\text { relativo }\end{array}$ & $\begin{array}{l}\% \text { Erro } \\
\text { Relativo }\end{array}$ & Escore-z & \\
\hline $\mathrm{Rb}$ & $12,30 \pm 0,91$ & 7,4 & 10,0 & $-0,97$ & $13,7 \pm 1,1$ \\
\hline $\mathrm{Se}$ & $0,749 \pm 0,0315$ & 4,1 & 2,6 & 0,28 & $0,73 \pm 0,06$ \\
\hline $\mathrm{Fe}$ & $181,7 \pm 8,1$ & 4,5 & 1,3 & $-0,13$ & $184 \pm 15$ \\
\hline $\mathrm{Zn}$ & $12, .7 \pm 6,6$ & 5,5 & 5,0 & $-0,36$ & $127 \pm 16$ \\
\hline $\mathrm{Br}$ & $10,9 \pm 0,7$ & 6,4 & $*$ & $*$ & $*$ \\
\hline $\mathrm{Na}$ & $2257 \pm 185$ & 8,2 & 6,7 & $-0,84$ & $2420 \pm 60$ \\
\hline $\mathrm{K}$ & $10151 \pm 1084$ & 10,7 & 2,1 & 0,19 & $9940 \pm 20$ \\
\hline
\end{tabular}


5. DISCUSSÃO 
Embora notórios avanços no diagnóstico e tratamento de doenças relacionadas ao envelhecimento tenham sido alcançados, ainda se sabe muito pouco sobre os mecanismos do envelhecimento e sua contribuição para o desenvolvimento e progressão das doenças (Troulinaki e Tavernarakis, 2005).

No que se refere à DA, doença cuja etiologia ainda é desconhecida, a hipótese de envolvimento da toxicidade dos elementos traço na patogênese desta doença tem recebido cada vez mais atenção. Acredita-se que para um funcionamento adequado do cérebro é necessária a presença de uma quantidade ideal de elementos traço (Cutts et al., 2001), sendo que seu excesso ou a sua uma deficiência poderia acarretar desordens metabólicas (Bélavári et al., 2005).

Assim, a comparação das concentrações de elementos traço entre encéfalos de indivíduos portadores de DA e indivíduos cognitivamente normais pode ser um importante passo no entendimento da fisiopatologia da doença.

\subsection{Rubídio, sódio e potássio na doença de Alzheimer}

Nakagawa et al. (1998), sugeriram que o metabolismo anormal dos elementos traço no cérebro poderia causar a aceleração da senescência. Assim, uma diminuição das concentrações de $\mathrm{Rb}$ poderia estar relacionada ao processo de envelhecimento. $\mathrm{O}$ modelo animal utilizado por Nakagawa e colaboradores (senescence-accelerated mouse prone10) desenvolve atrofia cerebral e déficit no aprendizado e memória, o que sugere que um desequilíbrio na concentração de elementos traço, incluindo a 
diminuição do $\mathrm{Rb}$, estaria relacionado ao processo de envelhecimento patológico (senilidade). Estes resultados foram confirmados pelo presente trabalho, assim como outros trabalhos da literatura (Wenstrup et al., 1990, Ehmann et al., 1986), que encontraram concentrações mais baixas de $\mathrm{Rb}$ no encéfalo dos portadores de DA quando comparadas com as de indivíduos sem alteração cognitiva, de idade equivalente.

À semelhança da diminuição do $\mathrm{Rb}$, detectou-se, no presente trabalho, uma diminuição das concentrações de $\mathrm{K}$ nas duas regiões estudadas no encéfalo de indivíduos portadores de DA.

Os estudos realizados por Bradbury (1970) indicaram que os elementos Rb e K são transportados para o cérebro por meio dos mesmos mecanismos e em taxas específicas de comportamento. Estes mesmos íons podem ser removidos do cérebro por meio de bombas Na-K que estariam localizadas no plexo coróide ou na barreira hemato-encefálica.

Segundo Belavari et al. (2004) existe pouca possibilidade do corpo humano distinguir elementos que são similares do ponto de vista químico. Assim, a presença de um elemento em concentração mais elevada (elementos maiores) permite a ocorrência concomitante de outro elemento em menor concentração (elementos traço menores), tal como no caso do $\mathrm{K}$ e $\mathrm{Rb}$. Esta associação entre $\mathrm{Rb}$ e $\mathrm{K}$ foi confirmada no presente trabalho por meio do comportamento similar de diminuição na concentração média destes elementos nas duas regiões de estudo de pacientes com DA.

De acordo com Belavari et al. (2005) os portadores de DA apresentam igual ou menor concentração de $\mathrm{Rb}$ no cérebro quando comparados aos indivíduos sem 
alteração cognitiva enquanto que as concentrações de $\mathrm{Na}$ são significantemente maiores em cada parte do cérebro dos portadores de DA. Os achados do presente trabalho estão de acordo com os de Belavari et al. (2005): além da diminuição da concentração de $\mathrm{Rb}$, também encontramos uma maior concentração de $\mathrm{Na}$ no hipocampo dos indivíduos portadores de DA

$\mathrm{O} \mathrm{Rb}, \mathrm{Na}$ e $\mathrm{K}$ são elementos alcalinos pertencentes à mesma família periódica. O desequilíbrio destes elementos na DA (Thompson et al., 1988) e no envelhecimento (Cohadron e Desbordes, 1986) foi sugerido como resultante de uma anormalidade do transporte de membranas. Anormalidades nos canais de $\mathrm{K}$ foram demonstradas em culturas de células de pacientes com DA (Fraser et al., 1997; de Silva et al., 1998), o que sugere que o efluxo de $\mathrm{Rb}$ possa ocorrer através de tais canais causando uma diminuição na concentração deste elemento no encéfalo de pacientes com DA, além de alterar as concentrações de $\mathrm{Na}$ e K.

No cérebro, o Na e o K são fundamentais para a neurotransmissão (Donnelly et al., 2007). Por causa de sua essencialidade à quase todos os organismos e devido sua significância eletrolítica, o Na e K têm recebido considerável atenção, mas dados sobre a distribuição topográfica destes elementos no cérebro humano ainda são escassos (Bélavári et al., 2005).

Uma vez que o $\mathrm{Rb}$ possui uma íntima correlação com o $\mathrm{K}$ (Versieck et al., 1977), podendo imitar seu papel bioquímico (Gambarana et al., 1999), este elemento tem sido utilizado para monitorar a dinâmica do K no cérebro (Yushmanov et al., 2007). O Rb também tem sido utilizado como um elemento de rastreamento na medicina nuclear não invasiva para o diagnóstico de tumores cerebrais (Tamano et 
al., 2002) e, nas últimas décadas, um efeito antidepressivo do $\mathrm{Rb}$ tem sido proposto (Williams et al., 1987; Gambarana et al., 1999).

Pouco se sabe sobre o $\mathrm{Rb}$ e seu papel na patologia humana (Hendrix et al., 1997) e, assim como o $\mathrm{Na}$ e $\mathrm{K}$, os dados sobre a distribuição de Rb no cérebro são escassos. Este elemento não tem uma função fisiológica bem estabelecida e sua importância foi enfatizada apenas recentemente (Belavari et al., 2005). Alguns dados sugerem que o mesmo participe no processo de diferenciação celular (Petrini et al., 1990).

\subsection{Rubídio e a reserva cognitiva}

A combinação do envelhecimento populacional e o aumento no número de indivíduos dementados fazem da caracterização da fase pré-clínica e dos estágios precoces da DA um tópico de grande importância e interesse na pesquisa (Nestor et al., 2004). Além disso, é importante entender os fatores que podem colaborar para proteger os indivíduos do desenvolvimento de sintomas. Assim, optamos por incluir indivíduos portadores de reserva cognitiva no presente estudo. Ao comparar as concentrações de $\mathrm{Rb}$ no hipocampo dos indivíduos do grupo RC e DA, notou-se uma diminuição das concentrações deste elemento no hipocampo dos indivíduos do grupo DA.

Conforme discutido no item 5.1, o efluxo do $\mathrm{Rb}$ na DA poderia ser causado por uma alteração nas membranas e no funcionamento da bomba Na-K. Assim, embora o hipocampo dos indivíduos do grupo RC esteja tomado pelos achados 
neuropatológicos da DA, estes indivíduos ainda não apresentariam uma redução de $\mathrm{Rb}$ secundária ao processo patológico.

Outro fator importante a considerar-se na determinação da concentração de $\mathrm{Rb}$ nos indivíduos DA e RC é a teoria da reserva cognitiva. Esta teoria defende que certos indivíduos estariam protegidos contra o surgimento da demência por possuírem maior reserva cognitiva que os permitiria tolerar as agressões causadas pelas lesões cerebrais, sem desenvolver os sintomas clássicos da síndrome demencial (Bennett et al., 2006). Assim, faz-se importante questionar se a maior concentração de $\mathrm{Rb}$ neste grupo poderia protegê-lo do desenvolvimento dos sintomas clínicos da doença.

Embora a caracterização de estágios precoces da DA e o entendimento dos mecanismos da doença sejam tópicos de grande interesse na pesquisa, o número de estudos, principalmente de pesquisa básica, envolvendo indivíduos portadores de reserva cognitiva ainda é pequeno. Isto ocorre, em parte, devido ao fato de que a maioria dos tecidos doados para aos bancos de encéfalos, principalmente em países desenvolvidos, são de indivíduos portadores de doenças em estágios avançados. Não

é de nosso conhecimento a existência de outros trabalhos determinando a concentração de elementos traço em indivíduos com função cognitiva preservada na presença dos sinais neuropatológicos da DA (reserva cognitiva).

\subsection{Selênio na doença de Alzheimer}

Os dados sobre a distribuição das concentrações de Se na DA não são bem estabelecidos e os achados são discrepantes, com relatos de aumento (Basun et al., 
1991), diminuição (Wenstrup et al., 1990) e inalteração (Meseguer et el., 1999) das concentrações de Se na presença da doença.

O Se desempenha um papel importante na manutenção do funcionamento adequado do sistema nervoso, sendo um agente protetor dos neurônios (Schweizer et al., 2004). É um elemento traço associado com a atividade antioxidante e é considerado agente protetor das lesões provocadas por radicais livres (Gao et al., 2007, Hebbrecht et al., 1999; Cornett et al., 1998), exercendo importante papel no processo de envelhecimento.

No presente trabalho, ao analisar-se o hipocampo, área tipicamente acometida pela DA, notou-se uma elevação das concentrações de Se nesta região, nos encéfalos de indivíduos portadores de DA quando comparadas às de indivíduos sem alteração cognitiva de idade equivalente. Para Hebbrecht et al. (1999) este aumento das concentrações de Se seria um estímulo dos mecanismos de defesa celular contra o estresse oxidativo. Uma associação da proteína transportadora de Se com placa amilóide foi recentemente demonstrada (Bellinger et al.2008), sugerindo uma associação do Se com a DA.

Também se tem demonstrado na literatura uma correlação entre baixos escores cognitivos e baixas concentrações de Se (Gao et al., 2007). Assim, cabe ainda esclarecer se uma diminuição das concentrações de Se torna o indivíduo mais vulnerável às lesões provocadas pelos radicais livres e se $\mathrm{o}$ aumento das concentrações deste elemento nos portadores de DA é uma resposta de defesa ineficiente contra o estresse oxidativo. 


\subsection{Ferro na Doença de Alzheimer}

O Fe é um elemento vital para a vida e a saúde, principalmente durante o período reprodutivo. Assim, a evolução humana resultou em estoques extras deste elemento no organismo. Entretanto estes estoques podem contribuir para o desenvolvimento das doenças durante o envelhecimento, tornando necessário verificar se este elemento está em concentrações adequadas nas fases avançadas da vida (Brewer, 2007)

$\mathrm{O} \mathrm{Fe}$ é um co-fator universal para geração de energia na mitocôndria e suporta o crescimento e diferenciação de todos os tipos celulares (Roskams e Connor, 1994; Crouch et al., 2007). No sistema nervoso central, o Fe é um componente chave dos sistemas responsáveis pela mielinização e a síntese de vários neurotransmissores (Roskams e Connor, 1994; Donnelly et al., 2007), havendo suporte na literatura para estabelecer conceitos de que um suprimento de $\mathrm{Fe}$ é essencial para o desenvolvimento neurológico normal (Roskams e Connor, 1994).

As altas concentrações de Fe necessárias para o funcionamento do cérebro associadas à alta susceptibilidade do Fe em produzir dano oxidativo (Brewer, 2007) requerem uma regulação da disponibilidade de Fe no organismo humano. Alterações nas concentrações deste elemento tem sido associado à patogênese da DA (Finefrock et al., 2003). De acordo com Hebbrecht et al. (1999) o Fe estaria envolvido no processo degenerativo iniciado pelos radicais livre de oxigênio. $\mathrm{O}$ aumento de $\mathrm{Fe}$ pode hipermetilar o peptídeo $\beta A$ causando dano oxidativo (Bush, 2003), o que precede a deposição amilóide (Nunomura et al., 2001). 
Uma elevação estatisticamente significante de Fe tem sido observada em diversas regiões do cérebro de portadores de DA (Cornett et al., 1998; Panayi et al., 2002), inclusive em estudos utilizando o método de análise por ativação com nêutrons. No presente trabalho houve aumento nas concentrações de Fe nas duas regiões de estudo do encéfalo de portadores de DA (grupo DA) quando comparado aos indivíduos do grupo NN.

\subsection{Zinco na doença de Alzheimer}

$\mathrm{O} \mathrm{Zn}$ é um elemento essencial, requerido para o crescimento e desenvolvimento normal. Existem mais de 200 enzimas identificadas contendo este elemento (Panayi et al., 2002). Talvez o mais crítico papel para o Zn no cérebro é na neurotransmissão por meio das sinapses glutamatérgicas (Crouch et al., 2007; Donnelly et al., 2007). As sinapses glutamérgicas, onde a patologia amilóide se inicia na DA, contém altas concentrações de Zn, que é liberado durante a neurotransmissão (Crouch et al., 2007).

Acredita-se que o $\mathrm{Zn}$ atue na precipitação da $\beta \mathrm{A}$ e consequentemente na formação das placas amilóides no cérebro com DA (Finefrock et al., 2003; Tõugu et al., 2008; Cuajungco e Fáget, 2003; Bush, 2003). Religa e colaboradores (2006) demonstraram uma correlação entre o acúmulo de $\mathrm{Zn}$ no neocórtex de indivíduos com DA e a severidade da presença de placas, emaranhados neurofibrilares e demência.

Para Huang et al. (2000) a interação entre $\mathrm{Zn}$ e $\beta \mathrm{A}$ é conseqüência do envelhecimento. Para Hebbrecht et al. (1999) o Zn está envolvido em reações 
imunológicas de contenção do processo de envelhecimento. Entretanto, o significado funcional das alterações nas concentrações de $\mathrm{Zn}$ e das interações entre $\mathrm{Zn}$ e amilóide não é claro e precisam ser melhor investigado (Cuajungco and Fáget, 2003).

Para avaliar o papel do $\mathrm{Zn}$ na DA, uma boa abordagem seria observar as quantidades anormais deste elemento no cérebro de pacientes com DA. Entretanto, esta análise não tem produzido respostas claras, com relatos de aumento (Cornett et al., 1998; Danscher et al., 1997; Religa et al., 2006; Deibel et al., 1996) e diminuição (Wenstrup et al., 1990; Andrasi et al., 1995; Panayi et al., 2002) da concentração deste elemento na DA.

O uso de amostras fixadas em fomalina pode alterar a análise da concentração do Zn por meio dos sítios de ligação de Zn desnaturado (Religa et al., 2006). Assim, no presente estudo, foram utilizadas amostras congeladas a fim de evitar-se a alteração das concentrações deste elemento.

O presente estudo não encontrou nenhuma diferença significativa entre as concentrações nos grupos de indivíduos, colocando em questionamento o papel deste elemento na fisiopatologia da DA.

\subsection{Bromo na doença de Alzheimer}

Pouco se tem pesquisado sobre a participação do $\mathrm{Br}$ na patogênese da DA. As análises da unha (Vance et al., 1990) e sangue (Basun et al., 1991) destes indivíduos não mostraram diferença das concentrações de $\mathrm{Br}$ nos portadores de $\mathrm{DA}$ quando comparados a indivíduos normais, assim como no presente trabalho ao analisar-se este elemento no encéfalo humano. Entretanto, existem relatos de aumento nas 
concentrações de $\mathrm{Br}$ no cérebro de portadores de DA (Ehmann et al., 1986), determinados inclusive pelo método de análise por ativação com nêutrons (Panayi et al., 2001). Para Panayi et al. (2001), o HOBr, um oxidante altamente tóxico, pode produzir radicais livres levando a destruição proteica na DA.

\subsection{Comparação entre concentrações de elementos presentes nas regiões frontal e hipocampo}

Em indivíduos sem qualquer sinal clínico e neuropatológico de DA (grupo $\mathrm{NN}$ ) foram obtidas concentrações mais baixas de $\mathrm{Fe}, \mathrm{Br}$, Se e $\mathrm{Na}$ e concentrações mais elevadas de $\mathrm{Zn}$ e $\mathrm{Rb}$ no hipocampo quando comparadas as da à região frontal. Para os elementos $\mathrm{Fe}, \mathrm{Zn}$ e Br esta situação se manteve mesmo na presença de sinais clínico-patológicos ou somente neuropatológicos da DA. Nos grupos de indivíduos que apresentam os sinais neuropatológicos da DA (grupos DA e RC) não houve diferença significativa entre frontal e hipocampo ao analisar-se as concentrações de $\mathrm{Rb}$ e Se. Para o elemento $\mathrm{Na}$, as suas concentrações foram maiores no hipocampo quando comparadas as da região frontal para o grupo DA e para o grupo RC não houve diferença significativa entre frontal e hipocampo para as concentrações de NA. Já para as concentrações de $\mathrm{K}$, não houve diferença significativa entre as regiões frontal e hipocampo nos três grupos de estudo. Na Tabela 15 são apresentados os resultados do estudo comparativo entre as concentrações dos elementos obtidos na região frontal e hipocampo. 
Tabela 15 - Resultados das comparações das médias das concentrações de elementos entre hipocampo e região frontal, para os três grupos em estudo

\begin{tabular}{|c|c|c|c|}
\hline Elemento & $\mathrm{DA}$ & $\mathrm{NN}$ & $\mathrm{RC}$ \\
\hline $\mathrm{Rb}$ & $\begin{array}{l}\text { Não houve diferença } \\
(p=0,786)\end{array}$ & $\begin{array}{c}\text { Hipocampo }>\text { Frontal } \\
(p=0,005)\end{array}$ & $\begin{array}{l}\text { Não houve diferença } \\
\qquad(p=0,092)\end{array}$ \\
\hline $\mathrm{Se}$ & $\begin{array}{c}\text { Não houve diferença } \\
(p=0,294)\end{array}$ & $\begin{array}{c}\text { Hipocampo }<\text { Frontal } \\
(p=0,006)\end{array}$ & $\begin{array}{c}\text { Não houve diferença } \\
\quad(p=0,105)\end{array}$ \\
\hline $\mathrm{Fe}$ & $\begin{array}{c}\text { Hipocampo }<\text { Frontal } \\
\mathbf{p}=\mathbf{0 , 0 0 1}\end{array}$ & $\begin{array}{c}\text { Hipocampo }<\text { Frontal } \\
\mathbf{p}=\mathbf{0 , 0 0 1}\end{array}$ & $\begin{array}{c}\text { Hipocampo }<\text { Frontal } \\
\mathbf{p}=\mathbf{0 , 0 0 1}\end{array}$ \\
\hline $\mathrm{Na}$ & $\begin{array}{c}\text { Hipocampo }>\text { Frontal } \\
(p=0,045)\end{array}$ & $\begin{array}{c}\text { Hipocampo }<\text { Frontal } \\
(p=0,032)\end{array}$ & $\begin{array}{c}\text { Não houve diferença } \\
(p=0,317)\end{array}$ \\
\hline $\mathrm{K}$ & $\begin{array}{c}\text { Não houve diferença } \\
(p=0,508)\end{array}$ & $\begin{array}{l}\text { Não houve diferença } \\
(p=0,508)\end{array}$ & $\begin{array}{c}\text { Não houve diferença } \\
(p=0,508)\end{array}$ \\
\hline $\mathrm{Zn}$ & $\begin{array}{c}\text { Hipocampo }>\text { Frontal } \\
\mathbf{p}=\mathbf{0 , 0 0 1}\end{array}$ & $\begin{array}{c}\text { Hipocampo }>\text { Frontal } \\
\mathbf{p}=\mathbf{0 , 0 0 1}\end{array}$ & $\begin{array}{c}\text { Hipocampo }>\text { Frontal } \\
\mathbf{p}=\mathbf{0 , 0 0 1}\end{array}$ \\
\hline $\mathrm{BR}$ & $\begin{array}{c}\text { Hipocampo }<\text { Frontal } \\
\mathbf{p}=\mathbf{0 , 0 0 4}\end{array}$ & $\begin{array}{c}\text { Hipocampo }<\text { Frontal } \\
\mathbf{p}=\mathbf{0 , 0 0 4}\end{array}$ & $\begin{array}{c}\text { Hipocampo }<\text { Frontal } \\
\mathbf{p}=\mathbf{0 , 0 0 4}\end{array}$ \\
\hline
\end{tabular}

De acordo com os resultados obtidos neste trabalho, bem como o de Panayi et al. (2000), podemos afirmar que tanto na fisiologia normal quanto na presença da DA, podem ocorrer diferenças nas concentrações de elementos traço presentes em diferentes regiões do cérebro. Estes achados salientam a importância da escolha das áreas alvo além do uso das mesmas regiões anatômicas ao compararem-se indivíduos cognitivamente normais e portadores de DA.

\subsection{Considerações sobre a qualidade dos resultados analíticos}

Para avaliar a qualidade dos resultados analíticos em relação à exatidão e precisão, foram analisados neste trabalho os materiais de referência certificados. A análise dos materiais de referência certificados mostrou que nossos resultados estão 
de acordo com os valores certificados apresentando erros relativos menores do que $10 \%$. Os dados obtidos apresentam boa precisão com desvio padrão relativo variando de 0,1 a $10,7 \%$. Os valores de escore-z ou diferença padronizada foram menores do que 1, indicando que os resultados são satisfatórios e concordam com os valores certificados.

Com relação à concentração média dos elementos no encéfalo humano de indivíduos cognitivamente normais e indivíduos portadores de DA, os valores encontrados no presente estudo, na região frontal e hipocampo, são da mesma ordem de grandeza ou estão dentro da faixa dos dados apresentados na literatura. Nas Tabelas 16 e 17 são apresentados dados da literatura e dados obtidos no presente estudo para indivíduos normais e portadores de DA, respectivamente.

Tabela 16 - Valores da concentração média de elementos no encéfalo de indivíduos normais obtidos no presente estudo e na literatura

\begin{tabular}{|c|c|c|c|c|c|c|}
\hline FRONTAL & $\begin{array}{c}\text { Panayi } \\
\text { et al. }(2001)\end{array}$ & $\begin{array}{c}\text { Andrasi } \\
\text { et al. (1995) }\end{array}$ & $\begin{array}{c}\text { Bélavári } \\
\text { et al. (2004) }\end{array}$ & $\begin{array}{c}\text { Andrasi } \\
\text { et al. (1999) }\end{array}$ & $\begin{array}{c}\text { Bélavári } \\
\text { et al. (2005) }\end{array}$ & $\begin{array}{c}\text { Presente } \\
\text { estudo }\end{array}$ \\
\hline $\mathrm{Rb}$ & 12,32 & $*$ & $10 \pm 4$ & $*$ & $10,5 \pm 4$ & $19,5 \pm 3,8$ \\
\hline $\mathrm{Se}$ & 0,674 & $*$ & $*$ & $*$ & * & $0,68 \pm 0,13$ \\
\hline $\mathrm{Fe}$ & 284 & $150 \pm 30$ & $*$ & 183 & $*$ & $225,3 \pm 33,8$ \\
\hline $\mathrm{Zn}$ & 65,8 & $47 \pm 14$ & $*$ & 68 & $*$ & $60,8 \pm 11,68$ \\
\hline $\mathrm{Br}$ & 1,742 & $*$ & $*$ & $*$ & $*$ & $2,83 \pm 0,80$ \\
\hline $\mathrm{Na}$ & 9115 & $*$ & $9300 \pm 2400$ & $*$ & $9230 \pm 2440$ & $8546 \pm 1061$ \\
\hline K & 13021 & $*$ & $11800 \pm 700$ & $*$ & $12030 \pm 650$ & $12268 \pm 975$ \\
\hline $\begin{array}{c}\text { HIPO- } \\
\text { CAMPO }\end{array}$ & $\begin{array}{c}\text { Andrasi } \\
\text { et al. (1995) }\end{array}$ & $\begin{array}{c}\text { Deibel } \\
\text { et al. (1996) }\end{array}$ & $\begin{array}{c}\text { Bélavári } \\
\text { et al. (2004) }\end{array}$ & $\begin{array}{c}\text { Andrasi } \\
\text { et al. (1999) }\end{array}$ & $\begin{array}{c}\text { Presente } \\
\text { estudo }\end{array}$ & \\
\hline $\mathrm{Rb}$ & $*$ & $*$ & $*$ & $*$ & $23,4 \pm 4,8$ & \\
\hline $\mathrm{Se}$ & $*$ & $*$ & $*$ & $*$ & $0,52 \pm 0,07$ & \\
\hline $\mathrm{Fe}$ & $223 \pm 30$ & $216 \pm 16$ & $*$ & 214 & $185,7 \pm 28,9$ & \\
\hline $\mathrm{Zn}$ & $55 \pm 8$ & $72 \pm 4,8$ & $*$ & 75 & $66,5 \pm 8,4$ & \\
\hline $\mathrm{Br}$ & $*$ & $*$ & $*$ & $*$ & $2,30 \pm 0,52$ & \\
\hline $\mathrm{Na}$ & $7300 \pm 800$ & $*$ & $10200 \pm 1000$ & $*$ & $7635 \pm 821$ & \\
\hline $\mathrm{K}$ & $11900 \pm 1500$ & $*$ & $14800 \pm 1600$ & $*$ & $11904 \pm 1732$ & \\
\hline
\end{tabular}

Nota: $\mathrm{Rb}=$ rubídio, $\mathrm{Se}=$ selênio, $\mathrm{Fe}=$ ferro, $\mathrm{Zn}=$ zinco, $\mathrm{Br}=$ bromo, $\mathrm{Na}=$ sódio, $\mathrm{K}$ = potássio, $*$ indica que o elemento não foi determinado. 
Tabela 17 - Valores da concentração média de elementos no encéfalo de indivíduos portadores de DA obtidos no presente estudo e na literatura

\begin{tabular}{ccccc}
\hline FRONTAL & $\begin{array}{c}\text { Panayi } \\
\text { et al. }(2001)\end{array}$ & $\begin{array}{c}\text { Andrasi } \\
\text { et al. }(1995)\end{array}$ & $\begin{array}{c}\text { Bélavári et al. } \\
(2005)\end{array}$ & Presente estudo \\
\hline $\mathrm{Rb}$ & 9,3 & $*$ & $7,6 \pm 1$ & $13,9 \pm 5,7$ \\
$\mathrm{Se}$ & 0,665 & $*$ & $*$ & $0,60 \pm 0,07$ \\
$\mathrm{Fe}$ & 275 & $400 \pm 30$ & $*$ & $257,2 \pm 41,8$ \\
$\mathrm{Zn}$ & 63,5 & $46 \pm 12$ & $*$ & $63,0 \pm 8,9$ \\
$\mathrm{Br}$ & 4,59 & $*$ & $*$ & $3,52 \pm 1,84$ \\
$\mathrm{Na}$ & 9500 & $*$ & $12070 \pm 3200$ & $9800 \pm 2080$ \\
$\mathrm{~K}$ & 12730 & $*$ & $10960 \pm 1230$ & $10699 \pm 1623$ \\
\hline HIPOCAMPO & Deibel et al. (1996) & Presente estudo & & \\
$\mathrm{Rb}$ & $*$ & $14,0 \pm 6,0$ & & \\
$\mathrm{Se}$ & $*$ & $0,65 \pm 0,13$ & & \\
$\mathrm{Fe}$ & $288 \pm 20$ & $239,8 \pm 58,7$ & & \\
$\mathrm{Zn}$ & $85,1 \pm 4,7$ & $79,4 \pm 17,0$ & & \\
$\mathrm{Br}$ & $*$ & $3,29 \pm 1,49$ & & \\
$\mathrm{Na}$ & $*$ & $11511 \pm 3373$ & & \\
$\mathrm{~K}$ & $*$ & $9640 \pm 1578$ & & \\
\hline
\end{tabular}

Nota: $\mathrm{Rb}=$ rubídio, $\mathrm{Se}=$ selênio, $\mathrm{Fe}=$ ferro, $\mathrm{Zn}=$ zinco, $\mathrm{Br}=$ bromo, $\mathrm{Na}=$ sódio, $\mathrm{K}$ $=$ potássio, $*$ indica que o elemento não foi determinado.

O presente trabalho confirmou os achados de Bélavári et al. (2005) de que o método de método de análise por ativação com nêutrons pode ser usado como um método acurado e preciso para análise de encéfalos humanos.

O método de análise por ativação com nêutrons tem desempenhado um importante papel nas áreas biomédicas e bioquímicas onde a determinação de elementos traço e ultratraço são necessárias tanto para a pesquisa quanto para aplicação em análises de rotina, colaborando para entender a estrutura e função dos sistemas biológicos, para caracterizar tecidos normais e patológicos e para estudar doenças específicas (Spyrou et al., 1999). 


\subsection{Terapias para DA envolvendo os elementos traço}

Nos últimos anos, muitas estratégias terapêuticas surgiram, visando atuar sobre a proteína $\beta$ A. Entre estas abordagens estão a inibição da geração de $\beta$ A a partir da proteína percursora amilóide (Dovey et al., 2001) e a vacina anti $\beta A$, que tem como objetivo diluir esta proteína no cérebro a partir de anticorpos específicos (Schenk et al., 1999). Um outro método, complementar aos demais, envolve os biometais.

Crouch et al. (2007), em sua revisão, mostraram evidências de que a diminuição da biodisponibilidade de metais dentro da célula está associada com aumento do estresse oxidativo, perda de regulação da produção de $\beta$ A e aumento na hiperfosforilação da proteína tau. Além disso, estes pesquisadores mostraram que um aumento extracelular do patamar de metal pode catalizar a oligomerização e agregação da $\beta$ A. Em resposta a evidências de que um desequilíbrio de certos elementos e sua interação com a $\beta$ A tenha associação com a fisiopatologia da doença, terapias que impeçam esta interação e dissolvam os depósitos de $\beta$ A têm recebido progressiva atenção. O clioquinol, por exemplo, tem recebido considerável atenção por sua capacidade de cruzar a barreira sanguínea (Donnelly et al., 2007). O clioquinol é uma droga capaz de agir como um quelante (moléculas capazes de realizar múltiplas ligações com um único íon metálico) com afinidade seletiva para Fe e Zn. O tratamento com clioquinol pode funcionar de duas maneiras: ligando-se a metais no meio extracelular, o que previne agregação mediada pelos metais e toxicidade e, forçando os metais a entrarem na célula, o que ativa proteíno-quinases específicas e aumenta a produção de matrizes metaloproteinases degradantes de $\beta \mathrm{A}$ 
(Bush and Curtain, 2008). Entretanto alguns autores defendem que os quelantes podem alterar a química dos metais e também podem não ultrapassarem a barreira sanguínea cerebral de modo satisfatório (Lannfelt et al., 2008). Assim, está em desenvolvimento um novo composto denominado PBT2, da companhia de biotecnologia australiana Prana, ainda em fase II de estudo clínico. Este composto interrompe a reação química mediada por metais que faz com que a $\beta$ A se deposite. Esta droga tem como alvo o $\mathrm{Zn}$ e o cobre $(\mathrm{Cu})$, que são liberados nas sinapses glutamatérgicas (Lannfelt et al., 2008).

A metalobiologia da proteína $\beta$ A pode representar um significante avanço para entender a fisiopatologia da DA e buscar intervenções farmacológicas para as interações anormais entre $\beta \mathrm{A}$ e certos elementos podendo se transformar em uma grande promessa para o desenvolvimento de novas drogas para DA.

\subsection{Considerações finais}

O número de pesquisas sobre a DA vem crescendo consideravelmente, o que pode ser verificado facilmente pelo número de publicações. No entanto, no nosso entendimento quanto a patogênese da DA, não estamos muito mais próximos do conhecimento da sua etiologia quando comparado a algumas décadas atrás, quando muitas das idéias que se dirigiam a esta pesquisa ainda estavam se iniciando (Smith and Perry, 1998). As terapias medicamentosas em uso atualmente para o tratamento da DA objetivam aliviar os sintomas e não agem na fisiopatologia da doença (Bush, 2002; Citron, 2004), o que sugere a necessidade de mais pesquisas enfocando os fatores que estão causando a doença. 
Recentemente tem sido de considerável interesse a relação entre os elementos traço e o estado das doenças, no entanto, concentrações permitidas e riscos específicos de elementos traço na saúde humana são pobremente definidos. Para avaliar estes riscos, estudos detalhados das concentrações de elementos traço em humanos devem ser implementados (Civit et al., 2000). Estudos que tentaram quantificar a concentração de elementos traço no cérebro de portadores de DA produziram resultados dissonantes. Estas inconsistências podem ser devido às diferenças de método, dificuldades técnicas encontradas durante o processamento do tecido e pequeno número de amostras (Cuajungco and Fragét, 2003). Além disso, é importante ressaltar que a variação nas concentrações elementares para determinadas regiões cerebrais, tanto em sujeitos "normais" quanto em portadores de DA pode depender do gênero, idade e duração da doença. Assim, estudos em grande parcela da população são necessários (Panayi et al., 2000).

Cabe ressaltar que, no presente estudo, a maioria das diferenças nas concentrações de elementos entre os grupos foram detectadas no hipocampo, uma das principais áreas relacionadas à memória e é um dos primeiros locais onde os sinais neuropatológicos da doença são detectados.

Alguns estudos têm correlacionado alterações nas concentrações de elemento traço com o envelhecimento (Nakagawa et al., 1998; Hebbrecht et al., 1999). Em nosso estudo não houve diferença significativa de idade entre os grupos e gêneros. Assim, as diferenças nas concentrações entre os grupos, detectadas no presente estudo, não estão correlacionadas ao processo normal de envelhecimento, mas sim ao envelhecimento patológico. 
Baseado neste estudo, a possibilidade de um papel etiológico para os elementos traço na DA claramente merece futuras investigações. Assim, ainda há muito a ser feito. Planeja-se aumentar a casuística estudada e incluir outros tipos de demências. $\mathrm{O}$ aumento da casuística possibilitará analisar os grupos de acordo com a faixa etária e gênero. Além disso, estudos correlacionando as concentrações dos elementos traço no encéfalo com outros tecidos/fluídos corporais já se encontram em desenvolvimento.

Pouco mais de cinco anos se passaram desde a união de uma equipe interdisciplinar obstinada a entender o processo de envelhecimento cerebral e a tênue linha divisória entre o envelhecimento normal e o envelhecimento patológico. Após alguns meses de estruturação do projeto e aplicação de estudos pilotos, este grupo deu início ao Banco de Encéfalos Humanos do Grupo de Estudos em Envelhecimento Cerebral, contando com o auxílio do SVOC, os departamentos de Patologia e Neurologia e a disciplina de Geriatria. Neste período montamos o Laboratório de Fisiopatologia no Envelhecimento, da disciplina de Geriatria, e enfrentamos os desafios que a instalação de um banco de encéfalos impõe. No entanto, a generosidade das famílias ao doarem os encéfalos de seus entes queridos, os auxílios e incentivos recebidos e a dedicação do grupo permitiram a concretização de nossos planos.

Nossa proposta despertou o interesse de outros grupos de pesquisadores em âmbito nacional e internacional e permitiu o estabelecimento de parcerias com grupos renomados, como no presente estudo. Este estudo representa a finalização de um ciclo de quatro estudos inicialmente propostos por nosso grupo, mas o caminho a percorrer ainda é longo. A partir deste e de outros trabalhos, muitos estudos surgiram 
e outros membros juntaram-se a nossa equipe, visando entender o processo de envelhecimento e colaborar para um avanço no diagnóstico e tratamento das doenças neurodenerativas relacionadas ao envelhecimento. 
6. CONCLUSÕES 
I. Os resultados obtidos nas análises de materiais certificados de referência apresentaram boa precisão e exatidão, o que nos permite concluir que o procedimento de análise por ativação com nêutrons é um método acurado e preciso para análise dos elementos $\mathrm{Br}, \mathrm{Fe}, \mathrm{K}, \mathrm{Na}, \mathrm{Rb}$, Se, Zn em encéfalos humanos.

II. Houve diferenças significativas nas concentrações dos elementos traço no encéfalo de portadores de DA. Os portadores de DA apresentaram menores concentrações de $\mathrm{Rb}$ quando comparadas com as de indivíduos normais (no hipocampo e na região frontal) e indivíduos portadores de reserva cognitiva (no hipocampo). Estudos complementares são necessários para verificar $\mathrm{o}$ papel protetor do $\mathrm{Rb}$ contra $\mathrm{o}$ desenvolvimento dos sintomas clínicos da DA.

Os portadores de DA apresentaram concentrações mais baixas de K (em frontal e hipocampo) e mais altas de $\mathrm{Na}$ (em hipocampo) quando comparados aos indivíduos normais. Este desequilíbrio bioquímico pode ser secundário ao processo patológico. Visto que $\mathrm{Na}, \mathrm{K}$ e Rb são elementos quimicamente similares, torna-se necessário verificar se as alterações das concentrações de $\mathrm{Rb}$ na $\mathrm{DA}$ são resultantes do mimetismo com o $\mathrm{K}$.

Os indivíduos que possuem DA apresentaram concentrações mais altas de $\mathrm{Fe}$ (em frontal e hipocampo) e Se (em hipocampo) no encéfalo quando comparadas com as de indivíduos normais. Este aumento da 
concentração pode estar relacionado à toxicidade e reações de proteção, respectivamente. Entretanto ainda é necessário verificar se o aumento das concentrações destes elementos é um evento primário ou secundário.

III. Houve diferença significativa nas concentrações dos elementos $\mathrm{Br}, \mathrm{Fe}$, $\mathrm{Zn}, \mathrm{Rb}, \mathrm{Na}$ e Se entre hipocampo e região frontal. As concentrações de $\mathrm{Br}$ e $\mathrm{Fe}$ são menores e as concentrações de $\mathrm{Zn}$ são maiores no hipocampo quando comparadas com as da região frontal, tanto no envelhecimento cerebral normal quanto no patológico. As concentrações de $\mathrm{Rb}$ são maiores e as concentrações de $\mathrm{Na}$ e $\mathrm{Se}$ são menores no hipocampo dos indivíduos cognitivamente normais sem sinais neuropatológicos de DA quando comparadas com as da região frontal, sendo que isto se altera na manifestação da doença. 
7. ANEXOS 


\section{Anexo A}

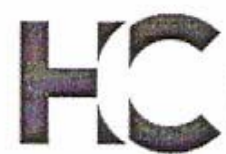

\section{WOSPTAL DAS CLIHICAS}

\section{APROVACÃO}

A Comissão de Ética para Análise de Projetos de Pesquisa - CAPPesq da Diretoria Clínica do Hospital das Clínicas e da Faculdade de Medicina da Universidade de São Paulo, em sessão de 29.09.05, APROVOU o Protocolo de Pesquisa $n^{\circ}$ 594/05, intitulado: "Detecção de elementos traço por ativação com nêutrons no envelhecimento encefálico humano" apresentado pelo Departamento de PATOLOGIA, inclusive o Termo de Consentimento Livre e Esclarecido.

Cabe ao pesquisador elaborar e apresentar à CAPPesq, os relatórios parciais e final sobre a pesquisa (Resolução do Conselho Nacional de Saúde $n^{\circ} 196$, de 10.10.1996, inciso IX. 2, letra "c")

Pesquisador(a) Responsável: Prof. Dr. Wilson Jacob Filho Pesquisador (a) Executante: Sra. Renata Elaine Paraizo Leite

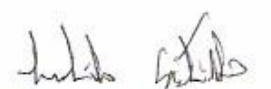

PROF. DR. EUCLIDES AYRES DE CASTILHO Presidente da Comissão de Ética para Análise de Projetos de Pesquisa

\footnotetext{
Comissăo de Ettica para Análise de Projetos de Pesquisa do HCFMUSP e da FMUSP

Diretoria Clinica do Hospital das Clinicas da Faculdade de Medicina da Universidade de São Paulo Rua Ovídio Pires de Campos. 225, $5^{\circ}$ andar - CEP 05430010 - São Paulo - SP 


\begin{abstract}
Anexo B

\title{
I - DADOS DE IDENTIFICAÇÃO DO SUJEITO DA PESQUISA OU RESPONSÁVEL LEGAL
}

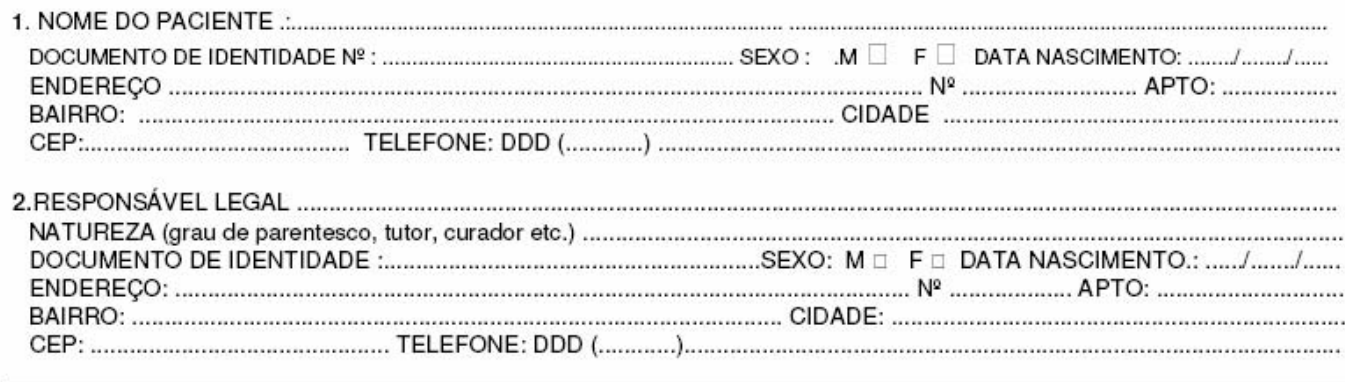

\section{II - DADOS SOBRE A PESQUISA CIENTIFICA}

1. TITULO DO PROTOCOLO DE PESQUISA: CORRELAÇÃO ANÁTOMO - FUNCIONAL DAS ALTERAÇÕES

CEREBRAIS NO ENVELHECIMENTO:Um estudo quantitativo em material de necropsia

2. PESQUISADOR: Lea Tenenholz Grinberg

CARGO/FUNÇĀO: Médica- pesquisadora INSCRIÇĀO CONSELHO REGIONAL N² 105290 UNIDADE DO HCFMUSP: Departamento de Patologia

3. AVALIAÇÄO DO RISCO DA PESQUISA:

$\begin{array}{llll}\text { SEM RISCO } & X \square & \text { RISCO MINIMO } \\ \text { RISCO BAIXO } & \square & \text { RISCO MAIOR } & \square\end{array}$

4.DURAÇÃO DA PESQUISA :3 anos 


\section{III - REGISTRO DAS EXPLICAÇÕES DO PESQUISADOR AO PACIENTE OU SEU REPRESENTANTE LEGAL SOBRE A PESQUISA CONSIGNANDO:}

Muito obrigada por sua atenção.

Estamos realizando um estudo para identificar como o envelhecimento ocorre no cérebro. Este estudo é muito importante porque ainda não sabemos direito porque as pessoas têm demência ou ficam mais esquecidas ou tremendo. Este trabalho também irá ajudar a descobrir a causa de morte de seu parente. Tratamentos novos para as doenças só são descorbertos fazendo estudos como este.

Este estudo irá funcionar da seguinte maneira:

$\mathrm{O}$ (a) Senhor(a) será entrevistado por um enfermeiro (a) à respeito de seu parente que faleceu. As perguntas são simples, porém é importante que o(a) senhor(a) pense por dois minutos antes de responder e que seja o mais exato possível. Caso não saiba a resposta, diga "não sei".

Durante a autópsia serão amostrados fragmentos de sistema nervoso central e de órgãos cujo comprometimento podem afetar a função cerebral, incluindo: coração, rim e carótidas. Esses fragmentos serão analisados com bastante cuidado e armazenados para estudos futuros nas áreas de anatomia, bioquímica, genética e imagem. Os resultados serão comparados com as respostas que o(a) senhor(a) respondeu. Não será feito nada a mais que o procedimento normal da autópsia e o corpo não será mutilado.

Com sua colaboração, poderemos saber se existiam alterações no cérebro de seu familiar que pudessem ser responsáveis por provocar doenças. Desta forma, outras pessoas poderão ser beneficiadas por conhecermos melhor doenças com Alzheimer e mal de Parkinson. Algumas das doenças passam de pai para filho e. além disso, podem afetar grande parte da população. Então, os resultados que conseguiremos poderão ajudar muitas pessoas a não ficarem doentes.

Não há nenhum risco neste estudo, porque o(a) senhor(a) não precisará voltar aqui novamente e este estudo não atrasará a realização da autópsia.

\section{IV - ESCLARECIMENTOS DADOS PELO PESQUISADOR SOBRE GARANTIAS DO SUJEITO DA} PESQUISA CONSIGNANDO:

Qualquer dúvida que o(a) senhor(a) tenha será esclarecida pela própria médica responsável pelo trabalho, os resultados estarão disponíveis somente $\mathrm{a}(\mathrm{o})$ senhor(a). A qualquer momento, se for sua vontade, o seu familiar pode ser retirado da pesquisa e todas as informações obtidas serão sigilosas. Uma cópia deste documento será entregue $\mathrm{a}(\mathrm{o})$ senhor(a)

\section{INFORMAÇÕES DE NOMES, ENDERECOS E TELEFONES DOS RESPONSÁVEIS PELO ACOMPANHAMENTO DA PESQUISA, PARA CONTATO}

A responsável pela pesquisa em caso de dúvidas é,

Dra. Lea Tenemholz Grinberg

CRM-SP: 105290

Telefone: (011) 30667322

\section{VI - CONSENTIMENTO PÓS-ESCLARECIDO}

Declaro que, após convenientemente esclarecido pelo pesquisador e ter entendido o que me foi explicado, consinto em participar do presente Protocolo de Pesquisa
São Paulo,
de
de 200
Horário do término: 


\section{Anexo C}

ENTREVISTA CLÍNICA
Data Óbito:

$\overline{ } \overline{ }$

HPMA:

AP: Nega ou desconhece qualquer antecedente patológico
HAS DM DAC ICC (TF Arritmia MP IVP/OAC IRC DLP TCE

AVCi // h prévio? Há a - sem seqüela com seqüela: cognitiva motora

AIDS Sífilis $\overline{\mathrm{AO} / \mathrm{OP}}$ Dist Tireóide Bronquite/Asma DPOC

Down Depressão Esquizofrenia Mania TOC D Parkinson Neoplasia

Internação Psiquiátrica

TTOs anteriores: Clínicos: Cirúrgicos:

Não fazia tto ou acompanhamento médico atualmente Nunca foi ao médico: recusa/ sem acesso

Sd demencial diagnosticada em vida: não sim Há___a Etiologia:

História compatível com Síndrome demencial: não sim

Curso: lento e progressivo rápido evolução em degraus curso flutuante

\section{Função anterior à morte}

Acuidades visual e auditiva preservadas \acuidade visual óculos hipoacusia prótese

Dentição preservada falhas dent/ anodontia uso de prótese dentária disfagia SNG/SNE/GTS

Sedentário Atividade física: doméstica caminhada trabalho outra__ Freq_/sem

Andava: s/auxílio c/ auxílio: pessoas parede/ móveis equipamentos auxiliares

Acamado___ Amputações___ Lesões cutâneas (úlceras)

Independente Dependente Tomava decisões sozinho Não tomava decisões

Em que situações convivia com muitas pessoas 


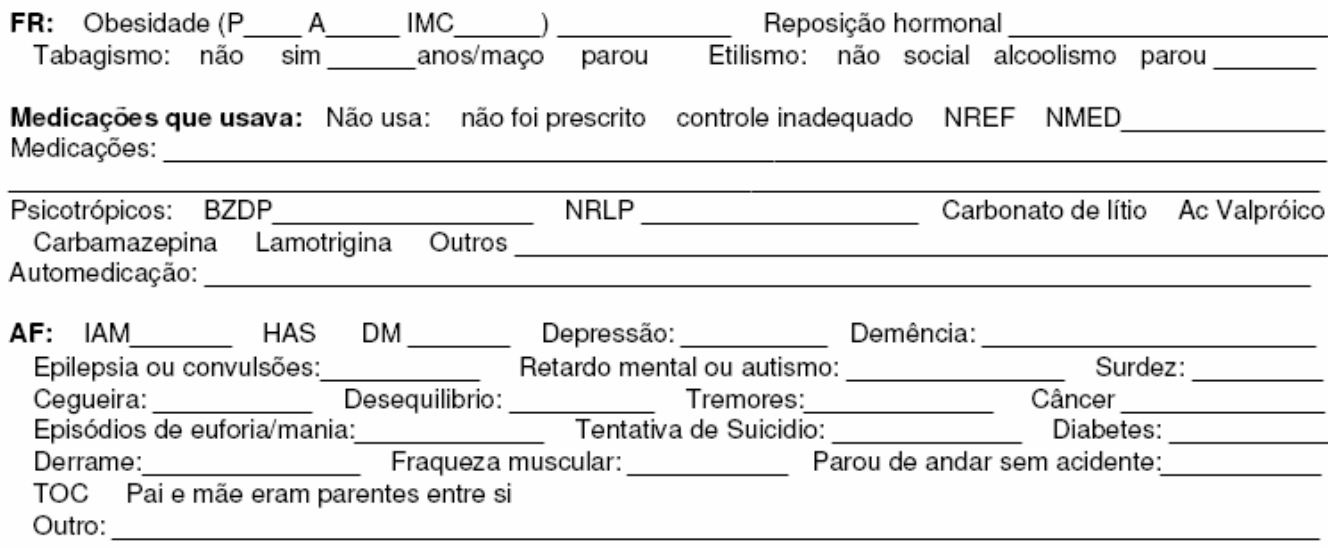

\section{Outras Informaçōes relevantes:}

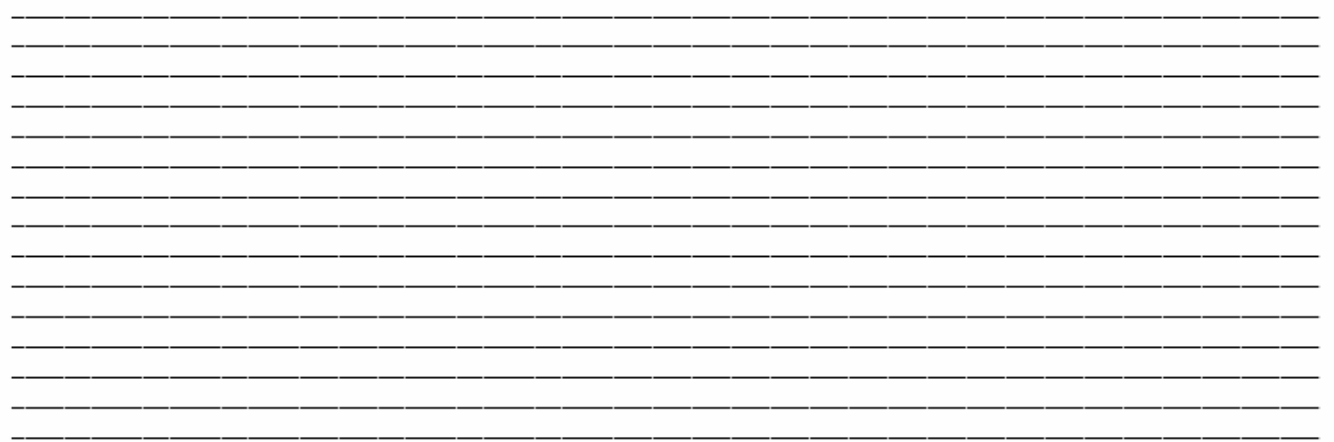

\section{ESCORES DAS ESCALAS:}

IQCODE:

SCID M:

CDR

SB__ NPI:_ KATZ:

IADL:

PARK: SCID D:

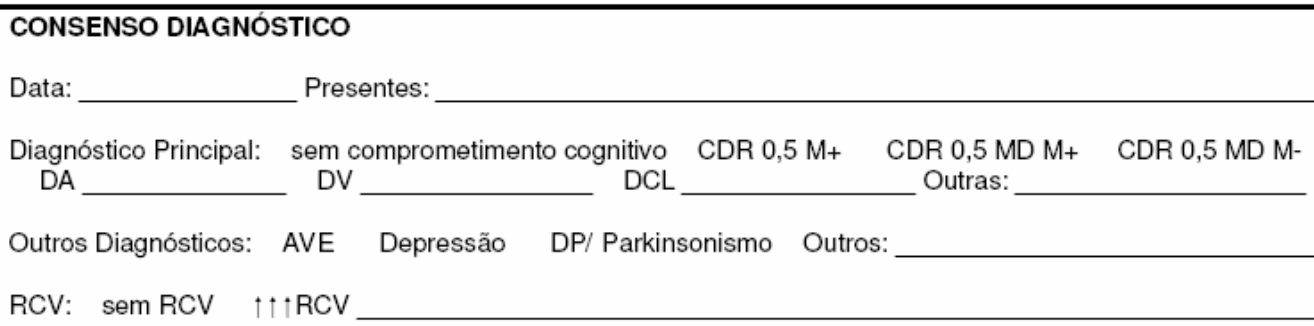




\section{Informant questionnaire on cognitive decline in the elderly}

\section{(IQCODE - Versão retrospectiva)}

Gostaríamos que você se lembrasse de como era seu amigo ou familiar há 10 anos atrás e compare com o estado em que ele estava há $\underline{3 \text { meses antes de sua morte. }}$

Comparada com há 10 anos atrás, como estava a pessoa antes de sua morte:

\begin{tabular}{|c|c|c|c|c|c|}
\hline & $\begin{array}{c}\text { Muito } \\
\text { melhor } \\
\text { (1) }\end{array}$ & $\begin{array}{l}\text { Um } \\
\text { pouco } \\
\text { melhor } \\
(2)\end{array}$ & $\begin{array}{l}\text { Não } \\
\text { muito } \\
\text { alterado } \\
\text { (3) }\end{array}$ & $\begin{array}{l}\text { Um } \\
\text { pouco } \\
\text { pior } \\
(4)\end{array}$ & $\begin{array}{l}\text { Muito } \\
\text { pior } \\
\text { (5) }\end{array}$ \\
\hline \multicolumn{6}{|l|}{ 1. Reconhecer a face das pessoas amigas e da família } \\
\hline \multicolumn{6}{|l|}{ 2. Lembrar do nome de parentes e amigos } \\
\hline \multicolumn{6}{|l|}{$\begin{array}{l}\text { 3. Lembrar de coisas sobre a família e amigos (aniversários, } \\
\text { ocupaçôes, endereços...) }\end{array}$} \\
\hline \multicolumn{6}{|l|}{ 4. Lembrar de coisas que aconteceram recentemente } \\
\hline \multicolumn{6}{|l|}{ 5. Lembrar de conversas que teve nos últimos dias } \\
\hline \multicolumn{6}{|l|}{ 6. Esquecia o que queria dizer no meio de uma conversa } \\
\hline \multicolumn{6}{|l|}{ 7. lembrar-se de seu próprio endereço e telefone } \\
\hline \multicolumn{6}{|l|}{ 8. lembrar (saber) que dia e mês era } \\
\hline \multicolumn{6}{|l|}{ 9. Lembrar onde as coisas são usualmente guardadas } \\
\hline \multicolumn{6}{|l|}{$\begin{array}{l}\text { 10. Lembrar-se de onde encontrar as coisas que foram } \\
\text { colocadas em lugares fora do comum }\end{array}$} \\
\hline \multicolumn{6}{|l|}{ 11. Adaptar-se a qualquer mudança na sua rotina diária } \\
\hline \multicolumn{6}{|l|}{ 12. Saber como funcionam os eletrodomésticos } \\
\hline \multicolumn{6}{|l|}{$\begin{array}{l}\text { 13. Aprender a usar novos eletrodomésticos/ utensílios } \\
\text { domésticos }\end{array}$} \\
\hline \multicolumn{6}{|l|}{ 14. Aprender coisas novas em geral } \\
\hline \multicolumn{6}{|l|}{$\begin{array}{l}\text { 15. Lembrar-se de coisas que aconteceram em sua vida quando } \\
\text { era jovem }\end{array}$} \\
\hline \multicolumn{6}{|l|}{ 16. Lembrar-se de coisas que aprendeu quando era jovem } \\
\hline \multicolumn{6}{|l|}{ 17. Entender o significado de palavras não comuns } \\
\hline \multicolumn{6}{|l|}{$\begin{array}{l}\text { 18. Entender o significado do que está escrito em jornais e } \\
\text { revistas }\end{array}$} \\
\hline \multicolumn{6}{|l|}{ 19. Acompanhar uma estória em um livro ou pela TV } \\
\hline \multicolumn{6}{|l|}{ 20. Escrever uma carta para um amigo ou com fins de trabalho } \\
\hline \multicolumn{6}{|l|}{ 21. Saber sobre eventos históricos importantes do passado } \\
\hline \multicolumn{6}{|l|}{ 22. Tomar decisões com problemas do dia a dia } \\
\hline \multicolumn{6}{|l|}{ 23. Manusear dinheiro para compras } \\
\hline \multicolumn{6}{|l|}{$\begin{array}{l}\text { 24. Lidar com problemas financeiros (ex: pensão, conta } \\
\text { bancária) }\end{array}$} \\
\hline \multicolumn{6}{|l|}{$\begin{array}{l}\text { 25. Lidar com outros problemas matemáticos, por exemplo: } \\
\text { saber quanto comprar de comida, saber quanto tempo se } \\
\text { passou entre as visitas dos familiares/ amigos. }\end{array}$} \\
\hline $\begin{array}{l}\text { 26. Usar sua inteligência para entender o que está acontecendo } \\
\text { e o motivo pelo qual está acontecendo. }\end{array}$ & & & & & \\
\hline
\end{tabular}


ESCORE CLÍNICO DE DEMÊNCIA - FOLHA DE REGISTRO

Esta é uma entrevista semi-estruturada. Por favor, faça todas estas perguntas. Faça quaisquer questōes adicionais que sejam necessárias para determinar o CDR do sujeito. Por favor, tome nota das informaçōes das perguntas adicionais.

\section{QUESTÕES SOBRE MEMÓRIA PARA O INFORMANTE}

1. Ele/ela tem algum problema com sua memória ou seu pensamento (raciocínio)?

SIM NÄO

1a - Se sim, é um problema constante? (em oposição a eventual, raro)

SIM NÄO

2. Ele/ela pode se lembrar de eventos recentes?

Frequentemente Às vezes Raramente

3. Ele/ela pode se lembrar de uma lista curta de itens (compras)?

Frequentemente Às vezes Raramente

4. Houve algum declínio na memória durante o último ano?

SIM NÄO

5. Sua memória está comprometida a tal ponto que teria interferido em suas atividades de vida diária de alguns anos atrás?

(ou atividades pré-aposentadoria) (opinião de outros informantes)

SIM NÄO

6. Ele/ela se esquece completamente de um evento importante

(ex. viagem, festa, casamento em familia)

algumas semanas depois do evento?

Freqüentemente Às vezes Raramente

7. Ele/ela se esquece de detalhes pertinentes de um evento importante?

Frequentemente Às vezes Raramente

8. Ele/ela se esquece completamente de informaçöes importantes do passado distante (ex. data de nascimento, data de casamento, local do emprego)?

Frequentemente Às vezes Raramente

9. OBS - Questăo removida por năo ser aplicável.

\section{QUESTÕES SOBRE ORIENTAÇÃO PARA O INFORMANTE}

Com que frequência ele/ela sabe o exato:

1. Dia do Mês?

$$
\text { Frequentemente Às vezes Raramente Năo sabe }
$$

2. Mês?

Frequentemente Às vezes Raramente Năo sabe

3. $\underline{\text { Ano? }}$

Frequentemente Às vezes Raramente Não sabe

4. Dia da semana?

Frequentemente Às vezes Raramente Não sabe

5. Ele/ela tem dificuldades com relacōes temporais (quando os eventos ocorreram em relaçăo uns com os outros)?
Frequentemente
Às vezes
Raramente
Năo sabe 
6. Ele/ ela pode achar seu caminho em ruas conhecidas?

Frequentemente Às vezes Raramente Năo sabe

7. Com que frequência ele/ela sabe como ir de um lugar para o outro fora de sua vizinhança?

Frequentemente Às vezes Raramente Năo sabe

8. Com que frequência ele/ela pode encontrar seu caminho dentro de casa?

Frequentemente Às vezes Raramente Năo sabe

\section{QUESTÕES SOBRE JULGAMENTO E RESOLUÇÃO DE PROBLEMAS PARA O INFORMANTE}

1. Em geral, se você tivesse que avaliar as habilidades dele/dela para resolver problemas atualmente, você consideraria que elas săo:

Tăo boas quanto sempre foram.

Boas, mas năo tão boas quanto antes.

Regulares.

Ruins.

Năo há nenhuma habilidade.

2. Avalie sua habilidade em lidar com pequenas quantias de dinheiro (ex.: trocar dinheiro, dar gorjeta):

Năo há perda. Alguma perda. $\quad$ Perda grave

3. Avalie sua habilidade em lidar com transaçöes financeiras complicadas (ex.: pagar contas, controle de conta bancária):

Năo há perda. $\quad$ Alguma perda. $\quad$ Perda grave.

4. Ele/ela pode lidar com uma emergência doméstica (ex. vazamento nos encanamentos, pequenos incêndios):

Tåo bem quanto antes.

Pior do que antes por causa da dificuldade de pensamento (raciocínio).

Pior do que antes, por outra razăo. (qual)

5. Ele/ela pode entender situaçöes ou explicaçöes?

Frequentemente Às vezes Raramente Năo sabe

6. Ele/ela se comporta de modo apropriado* [isto é, em sua maneira usual (pré-doença)]em situaçöes sociais e em interaçăo com outras pessoas?

Frequentemente Às vezes Raramente Năo sabe

*Este item avalia comportamento, năo aparência. 


\section{QUESTÕES SOBRE ASSUNTOS COMUNITÁRIOS PARA O INFORMANTE}

\section{Ocupacional}

1. O sujeito ainda está trabalhando?

Se năo aplicável - vá para o item número 4

Se sim - vá para o item número 3

Se năo - vá para o item número 2

2. Os problemas de memória ou de pensamento (raciocínio) contribuíram para a decisăo do sujeito de se aposentar? (A questão 4 é a próxima)

3. O sujeito tem dificuldade significante em seu trabalho por causa de problemas com memória ou pensamento (raciocínio)? Raramente ou nunca Às vezes Frequentemente Năo sabe

5. Ele/ela dirige carros atualmente?

6. Se năo, é devido a problemas de memória ou pensamento (raciocínio)?

7. Se ele/ela ainda está dirigindo, há problemas ou riscos devido ao pensamento (raciocinio) pobre?

8. Ele/ela é capaz de fazer compras para suas próprias necessidades independentemente? Raramente ou nunca Às vezes

9. Ele/ela é capaz de fazer atividades independentemente fora de sua casa? Raramente ou de As vezes salăo de beleza).

10. Ele/ela é levado a eventos sociais fora da casa de familiares? Se não, por que não?

11. Um observador casual do comportamento do sujeito pensaria que ele está doente?

12. Se institucionalizado, ele/ela participa bem de atividades sociais?

SIM NÄO

IMPORTANTE:

As informaçōes coletadas săo suficientes para classificar o nivel de comprometimento do sujeito em assuntos comunitários?

Se não, por favor, investique mais.

Atividades na comunidade: tais como ir à igreja, visitar amigos ou familia, atividades políticas, organizaçöes profissionais tais como associaçöes, outros grupos profissionais, clubes sociais, organizaçăo de serviços, programas educacionais).

* Por favor, adicione notas se necessário para esclarecer o nivel de funcionamento do sujeito nesta área. 


\section{QUESTÕES SOBRE O LAR E ATIVIDADES DE LAZER PARA O INFORMANTE}

1a) Que mudanças ocorreram em suas habilidades de realizar tarefas domésticas?

1b) $\mathrm{O}$ que ele/ela ainda pode fazer bem?

2a) Que mudanças ocorreram em suas habilidades para realizar seus passatempos (hobbies)?

2b) $O$ que ele/ela ainda pode fazer bem?

3) Se institucionalizado, o que ele/ela não pode mais fazer bem (Casa e Hobbies)

Atividades da vida diária (Blessed):

Nenhuma perda
Perda grave

4. Habilidade para realizar tarefas domésticas Por favor, descreva

5. Ele/ela é capaz de realizar tarefas domésticas até o nivel de: (Escolha uma, o informante năo precisa ser perguntado diretamente)

\section{Sem funcăo significativa}

(Realiza atividades simples, tais como fazer a cama, somente com muita supervisăo)

\section{Funciona somente em atividades limitadas}

(Com alguma supervisăo, lava a louça com limpeza aceitável, coloca a mesa)

Funciona independentemente em algumas atividades

(Opera equipamentos, tal como aspirador de pó, prepara refeiçōes simples)

Funciona em atividades usuais mas não no nivel usual

Funciona normalmente em atividades usuais

IMPORTANTE:

As informaçōes coletadas săo suficientes para classificar o nivel de comprometimento do sujeito em CASA \& HOBBIES?

\section{Se não, por favor investique mais.}

Tarefas Domésticas: Tais como cozinhar, lavar, limpar, fazer compras, levar o lixo para fora, limpar o quintal, manutençăo de cuidados básicos e reparos básicos na casa

Hobbies: Costurar, pintar, artesanato, leitura, entretenimento, fotografia, jardinagem, ir ao teatro ou concerto, trabalho em madeira, participaçăo em esportes. 
QUESTÕES SOBRE O AUTOCUIDADO PARA O INFORMANTE

"Qual sua estimativa da habilidade mental dele (a) nas seguintes áreas:"

\begin{tabular}{|c|c|c|c|c|}
\hline $\begin{array}{l}\text { Vestir-se } \\
\text { (Blessed) }\end{array}$ & $\begin{array}{c}\text { Sem ajuda } \\
\text { (0) }\end{array}$ & $\begin{array}{l}\text { Às vezes não abotoa os } \\
\text { botōes corretamente,... } \\
\text { (1) }\end{array}$ & $\begin{array}{l}\text { Sequência errada- } \\
\text { esquece itens } \\
\text { comumente. } \\
\text { (2) }\end{array}$ & $\begin{array}{l}\text { Incapaz de se vestir } \\
\text { (3) }\end{array}$ \\
\hline $\begin{array}{l}\text { Lavar-se } \\
\text { (Arrumar- } \\
\text { se) }\end{array}$ & $\begin{array}{c}\text { Sem ajuda } \\
\text { (0) }\end{array}$ & $\begin{array}{l}\text { Necessita de estímulo } \\
\text { (1) }\end{array}$ & $\begin{array}{l}\text { Algumas vezes } \\
\text { precisa de ajuda } \\
\text { (2) }\end{array}$ & $\begin{array}{l}\text { Sempre-ou quase } \\
\text { sempre - precisa de } \\
\text { ajuda } \\
\text { (3) }\end{array}$ \\
\hline $\begin{array}{l}\text { Hábitos } \\
\text { À mesa }\end{array}$ & $\begin{array}{l}\text { De modo limpo; utiliza os } \\
\text { talheres adequados. } \\
\text { (0) }\end{array}$ & $\begin{array}{l}\text { De modo desorganizado; } \\
\text { utiliza apenas colher. } \\
\text { (1) }\end{array}$ & $\begin{array}{l}\text { Apenas sólidos } \\
\text { simples } \\
\text { (2) }\end{array}$ & $\begin{array}{l}\text { Tem que ser } \\
\text { alimentado } \\
\text { (3) }\end{array}$ \\
\hline $\begin{array}{l}\text { Controle } \\
\text { de } \\
\text { esfíncter }\end{array}$ & $\begin{array}{l}\text { Controle completo } \\
\text { normal } \\
\text { (0) }\end{array}$ & $\begin{array}{c}\text { Ocasionalmente molha a } \\
\text { cama } \\
\text { (1) }\end{array}$ & $\begin{array}{l}\text { Frequentemente } \\
\text { molha a cama } \\
\text { (2) }\end{array}$ & $\begin{array}{c}\text { Duplamente } \\
\text { incontinente } \\
\text { (3) }\end{array}$ \\
\hline
\end{tabular}

*Escore 1 pode ser considerado se o auto-cuidado estiver comprometido quando comparado a um estado anterior, mesmo que não receba estímulo. 
ESCORE CLÍNICO DE DEMÊNCIA (CDR)

\begin{tabular}{|l|l|l|l|l|l|}
\hline Escore Clínico de Demência (CDR) & 0 & 0,5 & 1 & 2 & 3 \\
\hline
\end{tabular}

\begin{tabular}{|c|c|c|c|c|c|}
\hline & \multicolumn{5}{|c|}{ Comprometimento } \\
\hline & $\begin{array}{c}\text { Normal } \\
0\end{array}$ & $\begin{array}{c}\text { Questionável } \\
0,5\end{array}$ & \begin{tabular}{|c|} 
Leve \\
1 \\
\end{tabular} & $\begin{array}{c}\text { Moderada } \\
2 \\
\end{array}$ & $\begin{array}{c}\text { Grave } \\
3 \\
\end{array}$ \\
\hline Memória & $\begin{array}{c}\text { Sem perda de } \\
\text { memória ou } \\
\text { esquecimento leve e } \\
\text { inconstante. }\end{array}$ & $\begin{array}{l}\text { Esquecimento leve e } \\
\text { constante (em } \\
\text { oposiçăo a eventual); } \\
\text { recordaçăa parcial de } \\
\text { eventos; } \\
\text { esquecimento } \\
\text { "benigno". } \\
\end{array}$ & $\begin{array}{c}\text { Moderada perda de } \\
\text { memória; mais marcada } \\
\text { para eventos recentes; } \\
\text { déficit interfere nas } \\
\text { atividades cotidianas. }\end{array}$ & $\begin{array}{c}\text { Perda de memória } \\
\text { grave; somente retém } \\
\text { material intensamente } \\
\text { aprendido; material } \\
\text { novo rapidamente } \\
\text { perdido. }\end{array}$ & $\begin{array}{l}\text { Perda de memória } \\
\text { grave; restam } \\
\text { apenas fragmentos. }\end{array}$ \\
\hline Orientação & $\begin{array}{l}\text { Plenamente } \\
\text { orientado. }\end{array}$ & $\begin{array}{l}\text { Plenamente orientado, } \\
\text { exceto por leve } \\
\text { dificuldade nas } \\
\text { relaçöes temporais. }\end{array}$ & $\begin{array}{c}\text { Dificuldade moderada } \\
\text { com relaçöes } \\
\text { temporais; orientado } \\
\text { para lugar do exame; } \\
\text { pode ter desorientaçăo } \\
\text { geográfica em outros } \\
\text { lugares. } \\
\end{array}$ & \begin{tabular}{|c|} 
Dificuldade grave com \\
relaçöes temporais; \\
usualmente \\
desorientado para o \\
tempo, \\
frequentemente para o \\
espaço. \\
\end{tabular} & $\begin{array}{l}\text { Orientado apenas } \\
\text { para pessoa. }\end{array}$ \\
\hline $\begin{array}{l}\text { Julgamento } \\
\text { e resolução } \\
\text { de } \\
\text { problemas }\end{array}$ & $\begin{array}{c}\text { Resolve bem } \\
\text { problemas diários e } \\
\text { administra bem } \\
\text { negócios e finanças; } \\
\text { bom julgamento em } \\
\text { relaçăo ao } \\
\text { desempenho prévio. } \\
\end{array}$ & $\begin{array}{l}\text { Leve dificuldade em } \\
\text { resolver problemas, } \\
\text { similaridades e } \\
\text { diferenças. }\end{array}$ & $\begin{array}{l}\text { Dificuldade moderada } \\
\text { para administrar } \\
\text { problemas, } \\
\text { similaridades e } \\
\text { diferenças; julgamento } \\
\text { social usualmente } \\
\text { mantido. } \\
\end{array}$ & $\begin{array}{c}\text { Grave dificuldade em } \\
\text { administrar problemas, } \\
\text { similaridades } e \\
\text { diferenças; julgamento } \\
\text { social usualmente } \\
\text { comprometido. }\end{array}$ & $\begin{array}{l}\text { Incapaz de fazer } \\
\text { julgamentos ou de } \\
\text { resolver problemas. }\end{array}$ \\
\hline $\begin{array}{l}\text { Assuntos } \\
\text { Comunitários }\end{array}$ & $\begin{array}{l}\text { Funçăo } \\
\text { independente no } \\
\text { nivel usual no } \\
\text { trabalho, em } \\
\text { compras, grupos } \\
\text { sociais ou de } \\
\text { voluntários. }\end{array}$ & $\begin{array}{l}\text { Leve dificuldade } \\
\text { nessas atividades }\end{array}$ & $\begin{array}{c}\text { Incapaz de funcionar } \\
\text { independentemente } \\
\text { nessas atividades, } \\
\text { embora ainda possa } \\
\text { engajar-se em algumas; } \\
\text { parece normal à } \\
\text { inspeçăo casual. }\end{array}$ & $\begin{array}{c}\text { Nenhuma referência a } \\
\text { funcionamento } \\
\text { independente fora de } \\
\text { casa. Parece estar } \\
\text { bem para ser levado a } \\
\text { atividades fora de } \\
\text { ambiente familiar. }\end{array}$ & $\begin{array}{l}\text { Nenhuma referéncia } \\
\text { a funcionamento } \\
\text { independente fora } \\
\text { de casa. Parece } \\
\text { estar muito doente } \\
\text { para ser levado a } \\
\text { atividades fora de } \\
\text { ambiente familiar }\end{array}$ \\
\hline $\begin{array}{l}\text { Tarefas do } \\
\text { Lar e } \\
\text { Atividades } \\
\text { de Lazer }\end{array}$ & $\begin{array}{l}\text { Vida no lar, } \\
\text { passatempos e } \\
\text { interesses } \\
\text { intelectuais bem } \\
\text { mantidos. }\end{array}$ & $\begin{array}{c}\text { Vida no lar, } \\
\text { passatempos e } \\
\text { atividades intelectuais } \\
\text { levemente } \\
\text { comprometidos. }\end{array}$ & $\begin{array}{c}\text { Dificuldade leve mas } \\
\text { evidente nas funçōes } \\
\text { do lar; tarefas mais } \\
\text { dificeis abandonadas; } \\
\text { passatempos } e \\
\text { interesses mais } \\
\text { complexos } \\
\text { abandonados. } \\
\end{array}$ & $\begin{array}{l}\text { Somente tarefas } \\
\text { simples preservadas, } \\
\text { interesses muito } \\
\text { restritos e mal } \\
\text { sustentados. }\end{array}$ & $\begin{array}{l}\text { Sem funçăo } \\
\text { significativa em } \\
\text { casa. }\end{array}$ \\
\hline Autocuidado & Plenamente capaz & para o autocuidado. & Necessita estímulo. & $\begin{array}{c}\text { Requer ajuda para } \\
\text { vestir-se, higiene e } \\
\text { cuidado com objetos } \\
\text { pessoais. }\end{array}$ & $\begin{array}{c}\text { Requer muita ajuda } \\
\text { para o cuidado } \\
\text { pessoal, } \\
\text { incontinência } \\
\text { frequente. }\end{array}$ \\
\hline
\end{tabular}




\section{Inventário Neuropsiquiátrico}

(Cummungs et al - 1994)

- Responder baseando-se nas mudanças que ocorreram desde que o paciente começou a ter problemas de memória

- Marcar sim apenas quando o sintoma estiver presente. Do contrário, marcar não.

- Responda honestamente e meticulosamente às questões

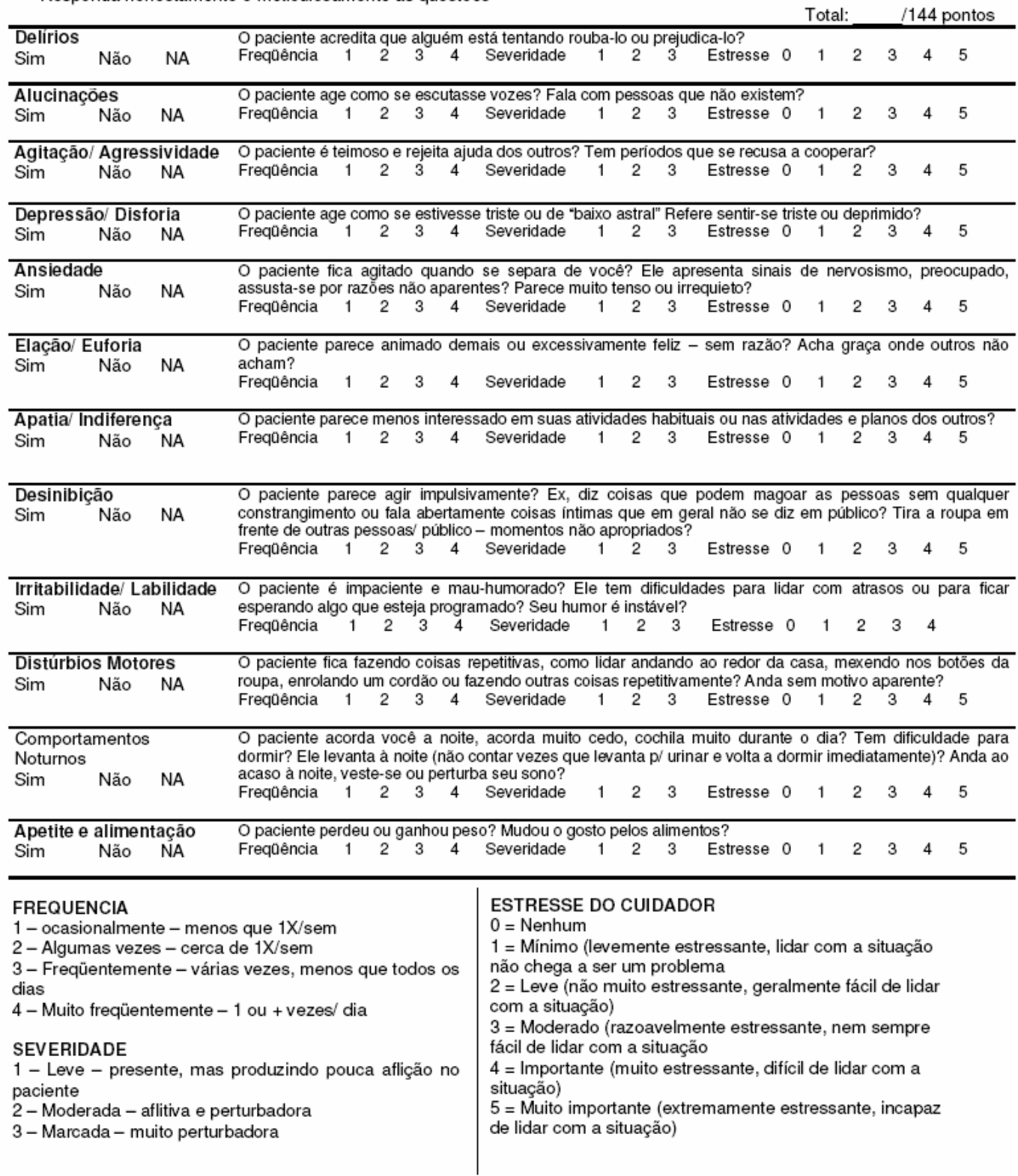


Índice de Katz para Atividades de Vida Diária

(Katz, S; Down, TD; Cash, HR et al - 1970

\begin{tabular}{|l|l|}
\hline Banho & I - Independente - não necessita de auxílio \\
& A - Auxílio - recebe assistência para banhar uma parte do corpo (dorso/pernas) \\
& D - Dependente - necessita que alguém o banhe
\end{tabular}

$\mathrm{I}=1$ ponto $\mathrm{A}=0,5$ e $\mathrm{D}=0$ ponto

TOTAL: 16

Avaliação de Parkinsonismo (Adaptado de Tanner et al, 1990)

\begin{tabular}{|l|c|c|}
\hline & SIM & NAO \\
\hline 1. Tinha dificuldade para se levantar de uma cadeira? & & \\
\hline 2. Notou se a letra (escrita) ficou pequena, se reduziu de tamanho? & & \\
\hline $\begin{array}{l}\text { 3. Notou ou alguém comentou se a sua voz estava mais baixa ou mais fraca } \\
\text { que era antes? }\end{array}$ & & \\
\hline 4. Tinha alterações do equilíbrio ao caminhar? & & \\
\hline 5. Os pés ficavam presos ou agarrados no chão ao atravessar portas? & & \\
\hline 6. Acha o seu rosto ficou mais "parado", menos expressivo do que era antes? & & \\
\hline 7. Tinha tremores nos braços ou nas pernas? & & \\
\hline 8. Tinha dificuldades de abotoar as roupas? & Não Aplicável Park: \\
\hline 9. Arrastava os pés ou dava passos curtos ao caminhar?
\end{tabular}




\section{ESCALA DE ATIVIDADES INSTRUMENTAIS DA VIDA DIÁRIA (IADL)}

(Lawton \& Brody)

\section{A - Habilidade para usa o telefone \\ 1. Utiliza o telefone por iniciativa própria \\ 2. Disca alguns números conhecidos \\ 3. Atende mas não faz ligações \\ 4. Não usa o telefone de modo algum \\ B - Compras \\ 1. Faz compras independente/e \\ 2. Faz pequenas compras independente/e \\ 3. Precisa ser acompanhado nas compras \\ 4. Incapaz de fazer compras}

\section{C - Preparo de alimentos}

1. Planeja, prepara e serve adequadamente as refeicões independentemente

2. Prepara adequadamente as refeições se alguém Ihe fornecer os ingredientes

3. Aquece, serve e prepara refeições, mas não garante uma dieta adequada

4. Necessita que alguém prepare e sirva a refeição

\section{D - Tarefas domésticas}

1. Mantem a casa sozinho ou com auxílio ocasional (p.ex: auxílio para tarefas pesadas)

2. Realiza tarefas diárias leves, como lavar louça, fazer a cama

3. Realiza tarefas diárias leves, mas não consegue fazê-las dentro dos padrões de limpeza

4. Necessita de auxílio com todas as tarefas domésticas

5. Não faz/ participa de nenhuma tarefa doméstica

\section{E - Lavanderia}

1. Lava completamente as roupas

2. Lava pequenas peças: meias, etc

\section{F - Transporte}

1. Usa independentemente transportes públicos ou dirige seu próprio carro

2. Chama de táxi, mas não usa transporte público

3. Usa transporte público se acompanhado

4. Locomove-se limitadamente de táxi ou carro 1 com auxílio de outros

5. Não sai de casa/ Não usa nenhum transporte

\section{G - Medicação}

1. É responsável por tomar sua medicação em dose e horários corretos

2. Assume responsabilidade por tomar sua medicação se separada anteriormente por outros

3. Não é capaz de tomar sua medicação

\section{H - Finanças}

1. Controla suas finanças independentemente (conta de banco, talão de cheque, preenche cheques, paga contas)

2. Controla contas no dia a dia, mas necessita de auxílio com banco, compras maiores,...

3. Incapaz de controlar finanças

Lawton,MP; Brody, EM - The instrumental activities of Daily Living Scale. Gerontologist, 1969, 9: 179 - 186

Perguntas adicionais:

Tota: / 8 pontos

Ele(a) esquece panela no fogo, torneira aberta ou ferro ligado?

Ele(a) pode ser deixado(a) em casa sozinho(a) de forma segura? 
Episódio Maior Depressivo no Passado - SCID

Critérios para classificar como depressão maior: Cinco (ou mais) dos seguintes critérios presentes durante período maior ou igual a duas semanas, sendo que um dos cinco deve ser ou (1) humor deprimido, ou (2) perda do interesse ou prazer.

1) Já houve, pelo menos uma vez na vida dele(a), algum momento em que se sentiu deprimido(a), ou na pior na maior parte do dia, quase todos os dias? (Como é que foi isso?)

SE SIM: Durou mais que duas semanas? SIM ( ) NÃO( )

Critério: $12 \quad 3$

2) Naquele tempo ou em outro momento, ele(a) perdeu o interesse ou o prazer pelas coisas que costumava gostar? (Como é que foi isso?) Isso acontecia quase todos os dias?

SE SIM: Durou mais que duas semanas? SIM ( ) NÃO ( )

Critério: $1 \quad 2 \quad 3 \quad$ ? Quando foi isso?

3) Naquele período ele(a) perdeu ou ganhou peso? Ele(a) estava tentando perder peso?

SE NÂO: Como estava o apetite dele(a)? (Tinha que forçar para comer? Comia menos/mais que o habitual? Isso acontecia quase todos os dias?)

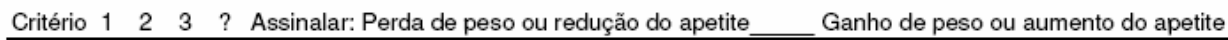

4) Como estava o sono dele(a)? (Dificuldade para dormir, acordando freqüentemente, dificuldades em ficar acordado, acordando muito cedo, ou, dormindo demais? Quantas horas por noite comparado com o habitual? Isso acontecia quase todas as noites?)

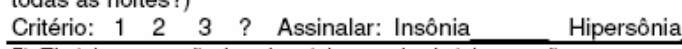

5) Ele(a) estava tão inquieto(a) ou agitado(a) que não era capaz de ficar parado(a)? (Isso acontecia todos os dias?)

SE NĀO: E o contrário: falando e se movendo mais devagar do que o normal dele(a)? (Isso acontecia todos os dias?)

Critério: $1 \quad 2 \quad 3 \quad$ ? Assinalar: agitação psicomotora retardo psicomotor

6) Como estava a energia dele(a)? (Cansado(a) o tempo inteiro? Quase todos os dias?)

Critério: 123 ?

7) Como ele se sentia em relação a si mesmo? (Inútil, sem valor?) Quase todos os dias?

SE NÃO: Ele se sentia culpado por coisas que fazia ou deixava de fazer? Quase todos os dias?

Critério: $\begin{array}{llllll}1 & 2 & 3 & \text { ? Assinalar: Sentimento de inutilidade_ Culpa inadequada }\end{array}$

8) Ele(a) tinha dificuldade para se concentrar ou pensar? (Com que tipo de coisas isso interferia?) Quase todos os dias?

SE NÄO: Era difícil para ele(a) tomar decisöes sobre coisas do dia a dia? Quase todos os dias?

Critério: $\begin{array}{llllll}1 & 2 & 3 & \text { ? Assinalar: Capacidade de pensar diminuída Indecisão }\end{array}$

9) As coisas estavam tão ruins que ele(a) pensava muito em morte ou que estaria em melhor situação se estivesse morto(a)? E quanto a se ferir?

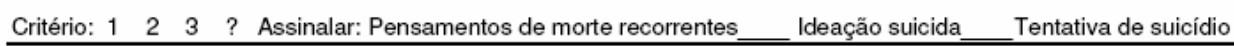

10) Durante aquele tempo ficou difícil para ele(a) trabalhar, cuidar das coisas em casa, ou se relacionar com as pessoas?

$\underline{\operatorname{SIM}()} \mathrm{NA} O()$

11) Pouco antes de tudo isso começar ele estava bebendo em excesso ou usando drogas? SIM ( ) NÃO ( )

12) Pouco antes disso começar ele estava fisicamente doente? $\operatorname{SIM}($ ) NÃO ( )

13) Isso começou logo depois de alguém próximo a ele(a) morrer? SIM ( ) NÃO ( )

Durou mais que 2 meses? $\operatorname{SIM}($ ) NÃO ( )

OBS: Houve algum outro episódio de depressão na vida do paciente? ( ) SIM （ ) NÃO

Quando ocorreu (eram)?

CONSIDERAR:

1 - ausente ou falso $\quad 2$-subliminar (duvidoso) $\quad 3$-limiar ou verdadeiro $\quad ?$-informação inadequada 
Episódio Maníaco no Passado - SCID

Critérios para classificar como mania no passado: Humor elevado e mais três dos outros sintomas, ou humor irritável e mais quatro dos outros sintomas.

HUMOR ELEVADO: Já houve algum período de tempo em ele(a) estava se sentindo tão bem, agitado(a) ou excitado(a) que vocês perceberam que ele(a) não estava no seu normal? Ou ficava tão excitado(a) que se envolvia em problemas? Critério $1 \quad 2 \quad 3 \quad$ ?

Durou pelo menos 1 semana? Ou ele(a) teve que procurar um hospital? Sim ( ) Não ( )

Quando foi isso?

HUMOR IRRITÁVEL: Houve algum período em que ele(a) estava tão irritado(a), que era pego(a) gritando com as pessoas ou começando brigas ou discussōes?

Durou mais que 1 semana? Ou ele(a) teve que procurar um hospital? Sim ( ) Não ( )

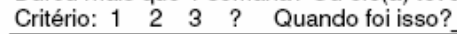

3) Naquele período como ele(a) se sentia em relação a si mesmo? (Mais confiante do que o habitual? Com algum poder ou habilidade especial?)

Critério 123 ?

4) Naquele tempo ele(a) tinha que dormir menos que o habitual? (Mesmo assim se sentia descansado?)

Critério: 1223 ?

5) Naquele tempo ele(a) estava muito mais falante que o habitual? (Vocês tinham dificuldade para interromper ou entender $o$ que ele(a) estava falando?)

Critério: 1230 ?

6) Naquele tempo os pensamentos passavam rapidamente pela cabeça dele(a)?

Critério: 1203 ?

7) Naquele tempo ele(a) era tão facilmente distraído(a) por coisas a sua volta que tinha dificuldades para se concentrar ou continuar o que estava fazendo?

Critério: $122 \quad 3 \quad$ ?

8) Naquele período, como ele(a) passava o tempo? (Ele(a) se envolvia em tantas atividades a ponto de vocês ficarem preocupados?)

SE NĀO: Ele(a) estava fisicamente inquieto(a)? (Qual a intensidade disso?)

Critério: $\begin{array}{llllll}1 & 2 & 3 & \text { ? Assinalar: aumento na atividade agitação psicomotora }\end{array}$

9) Naquele tempo, ele(a) fez alguma coisa que pudesse trazer problemas para ele(a) mesmo(a) ou para vocês

(Comprando coisas que não precisava?) (Tendo comportamento sexual inadequado?)

Critério: $1 \begin{array}{llll} & 2 & 3 & \text { ? }\end{array}$

10) Durante aquele tempo ficou difícil para ele(a) trabalhar, cuidar das coisas em casa, ou se relacionar com as pessoas?

SIM ( ) NÄO ( )

11) Pouco antes de tudo isso começar ele(a) estava bebendo em excesso ou usando drogas?

SIM ( ) NÄO ( )

12) Pouco antes disso começar, ele(a) estava fisicamente doente?

$\operatorname{SIM}() \quad$ NÄO ( )

CONSIDERAR:

1-ausente ou falso $\quad 2$-subliminar (duvidoso) 3 -limiar ou verdadeiro $\quad$ ?-informacão inadequada 
Transtorno Obsessivo-Compulsivo (TOC)

Seu parente alguma vez apresentou:

- Medos, preocupaçðes, idéias ou imagens repetitivos que causavam desconforto a ele(a)? (? 1 l 22 3)

- Comportamentos repetitivos (manias) que a pessoa tinha que fazer várias vezes e não conseguia evitar, tais como (perguntar TODOS os itens de 1 a 9 ):

1) Verificar fechaduras, fogão, se não se feriu ou feriu outros, ou perguntar se foi responsável por algo terrível que tenha acontecido (Agressão e verificação) $\left(\begin{array}{llll}? & 1 & 2 & 3\end{array}\right)$

2) Lavar excessivamente mãos e objetos, tomar banhos demorados, parecer preocupado com sujeira ou micróbios, com ficar contaminado e adoecer por isso, ter nojo de secreçōes do próprio corpo (Contaminação, limpeza e lavagem) (? $1 \quad 2 \quad 3)$

3) Guardar objetos inúteis, manter o quarto ou casa entulhados (Colecionamento) $\quad \begin{array}{lllll}\text { ? } & 1 & 2 & 3\end{array}$

4) Preocupação excessiva com: desrespeito a Deus; certo e errado; moralidade (Religião) $\quad$ (? 1 2 3 )

5) Mania de arrumação, simetria, exatidðo, perfeccionismo, ter que deixar as coisas organizadas do seu jeito $\quad\left(\begin{array}{lllllllllll} & 1 & 2 & 3\end{array}\right)$

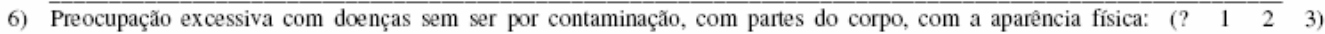

7) Compulsóes de repetição, reler ou reescrever várias vezes, repetir atividades rotineiras como entrar e sair de casa, levantar-se da cadeira, vestir roupas) $\left(\begin{array}{llll}? & 1 & 2 & 3\end{array}\right)$

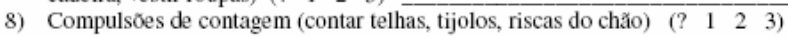

9) Comportamentos extremamente supersticiosos (medo de passar perto de cemitérios, medo de gato preto, de números ou cores que representem azar). ( $\left.\begin{array}{llll}? & 1 & 2 & 3\end{array}\right)$

Qualquer um dos itens de 1 a 9 foi positivo? ? $13 \Rightarrow \begin{aligned} & ? \text { ou } 1=\text { pule para Transtornos de tiques; } \\ & 3=\text { continue abaixo: }\end{aligned}$

Você acha que seu parente gastava muito tempo por dia com esses sintomas? $\quad\left(\begin{array}{llll}? & 1 & 2 & 3\end{array}\right)$

Quanto tempo?______ (juntando tudo chegava a 1 hora por dia?) $\quad\left(\begin{array}{llll}? & 1 & 2 & 3\end{array}\right)$

Os sintomas interferiam na vida dele? $\left(\begin{array}{llll}? & 1 & 2 & 3\end{array}\right)$

Causavam ansiedade, sofrimento? (? 12 L 3 ) Com que idade os sintomas começaram?

\section{Transtornos de tiques}

Tiques, também chamados de sestos ou cacoetes, são movimentos involuntários (que a pessoa faz sem querer), que geralmente começam na infância. Podem ser motores ou vocais. Os principais exemplos são (mostrar exemplos): piscar os olhos, fazer caretas, colocar a língua para fora, sacudir os ombros, sacudir a cabeça, fungar, pigarrear, assoviar, estalar etc.

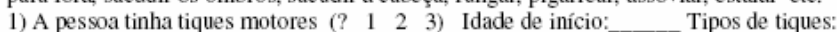

2) Tinha tiques vocais ( $\left.\begin{array}{llll}\text { ? } & 1 & 2 & 3\end{array}\right)$ Idade de início:___ tipos de tiques:

Se Nào para as respostas 1 e 2, passe para o próximo questionário. Se Sim para alguma das respostas:

Os tiques duraram mais de um ano? ( $\quad\left(\begin{array}{llll}? & 1 & 2 & 3\end{array}\right)$

Os tiques duraramentre 3 mesese um ano? $\left(\begin{array}{llll}? & 1 & 2 & 3\end{array}\right)$

A pessoa tem tiques motores e vocais? (l $\left.1 \begin{array}{lll}2 & 2 & 3\end{array}\right)$

Outras informaçóes relevantes: 


\section{CLASSIFICAÇÃO SÓCIO ECONÔMICA}

Associação Brasileira dos Institutos de Pesquisa de Mercado

(ABIPEME)

A- Em sua casa tem?

\begin{tabular}{|l|l|l|c|c|c|c|c|c|}
\hline & \multirow{2}{*}{ NÃO } & \multirow{2}{*}{ SIM } & \multicolumn{6}{|c|}{ QUANTIDADE } \\
\cline { 4 - 9 } & & & $\mathbf{1}$ & $\mathbf{2}$ & 3 & $\mathbf{4}$ & $\mathbf{5}$ & 6 ou + \\
\hline Televisão & & & 2 & 4 & 6 & 8 & 10 & 12 \\
\hline Empregada mensalista & & & 6 & 12 & 18 & 24 & 24 & 24 \\
\hline Rádio & & & 1 & 2 & 3 & 4 & 5 & 6 \\
\hline Banheiro & & & 2 & 4 & 6 & 8 & 10 & 12 \\
\hline Aspirador de pó & & & 5 & 5 & 5 & 5 & 5 & 5 \\
\hline Máquina de lavar & & & 2 & 2 & 2 & 2 & 2 & 2 \\
\hline Automóvel de passeio & & & 4 & 8 & 16 & 16 & 16 & 16 \\
\hline
\end{tabular}

TOTAL:

B- Qual a instrução do chefe de familia? (Quem é o chefe da família: )

\begin{tabular}{|l|c|}
\hline Sem Instrução/ primário incompleto & 0 \\
\hline Primário completo/ ginásio incompleto & 1 \\
\hline Ginásio completo/ colegial incompleto & 3 \\
\hline Colegial completo/superior incompleto & 5 \\
\hline Superior completo & 10 \\
\hline
\end{tabular}

TOTAL:

\begin{tabular}{|c|c|}
\hline \multicolumn{2}{|c|}{ CLASSE ABIPEME } \\
\hline CLASSE & PONTOS \\
\hline A & 35 OU + \\
\hline B & 21 a 34 \\
\hline C & 10 a 20 \\
\hline D & 05 a 09 \\
\hline E & 00 a 04 \\
\hline
\end{tabular}


8. REFERÊNCIAS 
Aguiar AR. Aplicação do método de análise por ativação com nêutrons à determinação de elementos traço em unhas humanas [tese]. São Paulo: Instituto de Pesquisas Energéticas e Nucleares; 2001.

Andrási E, Farkas E, Scheibler H, Réffy A, Bezúr L. Al, Zn, Cu, Mn and Fe levels in brain in Alzheimer's disease. Arch Gerontol Geriatr. 1995 Jul-Aug;21(1):89-97.

Andrási E, Igaz S, Szoboszlai N, Farkas É, Ajtony Z. Several methods to determine heavy metals in the human brain. Spectrochim B. 1999 May; $54(5): 819-825$.

Basun H, Forssell LG, Wetterberg L, Winblad B. Metals and trace elements in plasma and cerebrospinal fluid in normal aging and Alzheimer's disease. J Neural Transm Park Dis Dement Sect. 1991;3(4):231-58.

Bélavári C, Andrási E, Molnár Z, Bertalan É. Determination of alkali metals in control and AD brain samples by different techniques. Microchem J. 2005;79:367373.

Bélavári C, Andrási E, Molnár Z, Gawlik D. Determination of $\mathrm{Na}, \mathrm{K}, \mathrm{Rb}$ and $\mathrm{Cs}$ Distribution in Human Brain Using Neutron Activation Analysis. Microchim Acta. 2004;146 (3-4):187-191.

Bellinger FP, He QP, Bellinger MT, Lin Y, Raman AV, White LR, Berry MJ. Association of selenoprotein $\mathrm{p}$ with Alzheimer's pathology in human cortex. J Alzheimers Dis. 2008 Nov;15(3):465-72.

Bennett DA, Schneider JA, Arvanitakis Z, Kelly JF, Aggarwal NT, Shah RC, Wilson RS. Neuropathology of older persons without cognitive impairment from two community-based studies.Neurology. 2006 Jun 27;66(12):1837-44.

Berg L, Hughes CP, Coben LA, Danziger WL, Martin RL, Knesevich J. Mild senile dementia of Alzheimer type: research diagnostic criteria, recruitment, and description of a study population. J Neurol Neurosurg Psychiatry. 1982;45:962-968.

Bode P, Van Meerten TG. INAA Instrumental neutron activation analysis. Delft: Interfaculty Reactor Institute of Delft University of Technology, 1999.

Braak H, Braak E, Bohl J. Staging of Alzheimer-related cortical destruction. Eur Neurology. 1993;33(6):403-8.

Braak H, Braak E. Neuropathological stageing of Alzheimer-related changes. Acta Neuropathol. 1991;82(4):239-59. 
Braak H, Ghebremedhin E, Rüb U, Bratzke H, Del Tredici K. Stages in the development of Parkinson's disease-related pathology. Cell Tissue Res. 2004;318(1):121-34.

Bradbury MW. The effect of rubidium on the distribution and movement of potassium between blood, brain and cerebrospinal fluid in the rabbit. Brain Res. 1970 Dec 1;24(2):311-21.

Brewer GJ. Iron and copper toxicity in diseases of aging, particularly atherosclerosis and Alzheimer's disease. Exp Biol Med (Maywood). 2007 Feb;232(2):323-35.

Brown RJC, Milton MJT. Analytical techniques for trace element analysis: an overview. Trends in Analyt Chem. 2005;24(3):266-274.

Burns A. Alzheimer's disease: on the verges of treatment and prevention. Lancet Neurol. 2009 Jan;8(1):4-5.

Bush AI, Curtain CC. Twenty years of metallo-neurobiology: where to now? Eur Biophys J. 2008 Mar;37(3):241-5.

Bush AI. Metal complexing agents as therapies for Alzheimer's disease. Neurobiol Aging. 2002 Nov-Dec;23(6):1031-8.

Bush AI. Metals and neuroscience. Curr Opin Chem Biol. 2000 Apr;4(2):184-91.

Bush AI. The metallobiology of Alzheimer's disease. Trends Neurosci. 2003 Apr;26(4):207-14.

Bustamante SEZ, Bottino CMC, Lopes MA, Azevedo D, Hototian R, Litvoc J, Jacob Filho W. Instrumentos combinados na avaliação de demência em idosos: resultados preliminares. Arq Neuropsiquiatr. 2003; 61: 601-606.

Caramelli P, Barbosa MT. Como diagnosticar as quatro causas mais freqüentes de demência? Rev Bras Psiquiatr [serial on the Internet]. 2002 [citado 19 Abril 2009]. Disponível em: http://www.scielo.br/scielo.php?script=sci_arttext\&pid=S1516$44462002000500003 \& \operatorname{lng}=$ en. doi: 10.1590/S1516-44462002000500003.

Carvalho JAM, Garcia RA. O envelhecimento da população brasileira: um enfoque demográfico. Cad Saúde Pública [serial on the Internet]. 2003 June [citado 19 Abril 2009];19(3):725-733. Disponível em: http://www.scielo.br/scielo.php?script=sci_arttext\&pid=S0102311 X2003000300005\&lng=en. doi: 10.1590/S0102-311X2003000300005.

Chaves ML, Camozzato AL, Godinho C, Kochhann R, Schuh A, de Almeida VL, Kaye J. Validity of the clinical dementia rating scale for the detection and staging of dementia in Brazilian patients. Alzheimer Dis Assoc Disord. 2007;21(3):210-7. 
Citron M. Strategies for disease modification in Alzheimer's disease. Nat Rev Neurosci. 2004 Sep;5(9):677-85.

Civit T, Houdayer AJ, Kennedy G. A search for trace elements in some human intracranial tumors by instrumental neutron activation analysis. Biol Trace Elem Res. 2000 Jun;74(3): 203-10.

Cohadon F, Desbordes P. Brain water and aging. Gerontology. 1986;32 Suppl 1:469.

Comfort A. The myth of senility: Diagnosing nonspecific major illness in the elderly. Postgrad Med. 1979;65(3):130-42.

Cornett CR, Markesbery WR, Ehmann WD. Imbalances of trace elements related to oxidative damage in Alzheimer's disease brain. Neurotoxicology. 1998 Jun;19(3):339-45.

Crews DE. Senescence, aging, and disease. J Physiol Anthropol. 2007 May;26(3):365-72.

Crouch PJ, White AR, Bush AI. The modulation of metal bio-availability as a therapeutic strategy for the treatment of Alzheimer's disease. FEBS J. 2007 Aug;274(15):3775-83.

Cuajungco MP, Faget KY. Zinc takes the center stage: its paradoxical role in Alzheimer's disease. Brain Res Rev. 2003 Jan; 41(1): 44-56.

Cummings JL, Mega M, Gray $\mathrm{K}$ et al. The neuropsychiatric inventory: comprehensive assessment of psychopathology in dementia. Neurology. 1994;44:2308-2314.

Cutts DA, Spyrou NM, Maguire RP, Leenders K1. Hierarchical clustering of Alzheimer and "normal" brains using elemental concentrations and glucose metabolism determined by PIXE, INAA and PET. J. Radioanal Nucl Chem. 2001;249(2):455-60.

Danscher G, Jensen KB, Frederickson CJ, Kemp K, Andreasen A, Juhl S, Stoltenberg M, Ravid R. Increased amount of zinc in the hippocampus and amygdala of Alzheimer's diseased brains: a proton-induced X-ray emission spectroscopic analysis of cryostat sections from autopsy material. J Neurosci Methods. 1997 Sep 5;76(1):53-9.

De Silva HA, Aronson JK, Grahame-Smith DG, Jobst KA, Smith AD. Abnormal function of potassium channels in platelets of patients with Alzheimer's disease. Lancet. 1998 Nov 14;352(9140):1590-3.

De Soete D, Gibels R, Hoste J. Neutron activation analysis. London: WileyInterscience; 1972. 
Deibel MA, Ehmann WD, Markesbery WR. Copper, iron, and zinc imbalances in severely degenerated brain regions in Alzheimer's disease: possible relation to oxidative stress. J Neurol Sci. 1996 Nov;143(1-2):137-42.

Dickson DW, Crystal HA, Mattiace LA, Masur DM, Blau AD, Davies P, Yen SH, Aronson MK. Identification of normal and pathological aging in prospectively studied nondemented elderly humans. Neurobiol Aging. 1992 Jan-Feb;13(1):17989.

Donnelly PS, Xiao Z, Wedd AG. Copper and Alzheimer's disease. Curr Opin Chem Biol. 2007 Apr;11(2):128-33.

Dovey HF, John V, Anderson JP, Chen LZ, de Saint Andrieu P, Fang LY, Freedman SB, Folmer B, Goldbach E, Holsztynska EJ, Hu KL, Johnson-Wood KL, Kennedy SL, Kholodenko D, Knops JE, Latimer LH, Lee M, Liao Z, Lieberburg IM, Motter RN, Mutter LC, Nietz J, Quinn KP, Sacchi KL, Seubert PA, Shopp GM, Thorsett ED, Tung JS, Wu J, Yang S, Yin CT, Schenk DB, May PC, Altstiel LD, Bender MH, Boggs LN, Britton TC, Clemens JC, Czilli DL, Dieckman-McGinty DK, Droste JJ, Fuson KS, Gitter BD, Hyslop PA, Johnstone EM, Li WY, Little SP, Mabry TE, Miller FD, Audia JE. Functional gamma-secretase inhibitors reduce beta-amyloid peptide levels in brain. J Neurochem. 2001 Jan;76(1):173-81.

Ehmann WD, Markesbery WR, Alauddin M, Hossain TI, Brubaker EH. Brain trace elements in Alzheimer's disease. Neurotoxicology. 1986 Spring;7(1):195-206.

Farfel, JM. Fatores relacionados à senescência e à senilidade cerebral em indivíduos muito idosos: um estudo de correlação clínicopatológica [tese]. São Paulo: Faculdade de Medicina, Universidade de São Paulo; 2008.

Ferretti REL. Fatores associados às alterações morfométricas crânio-encefálicas no envelhecimento [tese]. São Paulo: Faculdade de Medicina, Universidade de São Paulo; 2008.

Ferri CP, Prince M, Brayne C, Brodaty H, Fratiglioni L, Ganguli M, Hall K, Hasegawa K, Hendrie H, Huang Y, Jorm A, Mathers C, Menezes PR, Rimmer E, Scazufca M, Alzheimer's Disease International. Global prevalence of dementia: a Delphi consensus study. Lancet. 2005 Dec 17;366(9503):2112-7.

Finefrock AE, Bush AI, Doraiswamy PM. Current status of metals as therapeutic targets in Alzheimer's disease. J Am Geriatr Soc. 2003 Aug;51(8):1143-8.

Fraser SP, Suh YH, Djamgoz MB. Ionic effects of the Alzheimer's disease betaamyloid precursor protein and its metabolic fragments. Trends Neurosci. 1997 Feb;20(2):67-72.

Gambarana C, Ghiglieri O, Masi F, Scheggi S, Tagliamonte A, De Montis MG. The effects of long-term administration of rubidium or lithium on reactivity to stress and 
on dopamine output in the nucleus accumbens in rats. Brain Res. 1999 May $1 ; 826(2): 200-9$.

Gao S, Jin Y, Hall KS, Liang C, Unverzagt FW, Ji R, Murrell JR, Cao J, Shen J, Ma F, Matesan J, Ying B, Cheng Y, Bian J, Li P, Hendrie HC. Selenium level and cognitive function in rural elderly Chinese. Am J Epidemiol. 2007 Apr $15 ; 165(8): 955-65$.

Gao S, Jin Y, Unverzagt FW, Ma F, Hall KS, Murrell JR, Cheng Y, Shen J, Ying B, Ji R, Matesan J, Liang C, Hendrie HC. Trace element levels and cognitive function in rural elderly Chinese. J Gerontol A Biol Sci Med Sci. 2008 Jun;63(6):635-41.

Garrido R, Menezes PR. O Brasil está envelhecendo: boas e más notícias por uma perspectiva epidemiológica. Rev Bras Psiquiatr. [serial on the Internet]. 2002 [citado 19 Abril 2009]. Disponível em: http://www.scielo.br/scielo.php?script=sci_arttext\&pid=S1516$44462002000500002 \& \operatorname{lng}=$ en. doi: 10.1590/S1516-44462002000500002.

Geerlings MI, Schmand B, Braam AW, Jonker C, Bouter LM, van Tilburg W. Depressive symptoms and risk of Alzheimer's disease in more highly educated older people. J Am Geriatr Soc. 2000 Sep;48(9):1092-7.

Giatti L, Barreto SM. Saúde, trabalho e envelhecimento no Brasil. Cad Saúde Pública [serial on the Internet]. 2003 June [citado 19 Abril 2009];19(3):759-771. Disponível em: http://www.scielo.br/scielo.php?script=sci_arttext\&pid=S0102311X2003000300008\&lng=en. doi: 10.1590/S0102-311X2003000300008.

Glascock MD. An Overview of Neutron Activation Analysis [Citado em 14 de abril de 2009]. Disponível em: http://ecow.engr.wisc.edu/cgibin/get/ne/427/edwards/naaoverview.pdf

Goedert M, Spillantini MG. A century of Alzheimer's disease. Science. 2006 Nov;3;314(5800):777-81.

Grinberg LT, Ferretti RE, Farfel JM, Leite R, Pasqualucci CA, Rosemberg S, Nitrini R, Saldiva PH, Filho WJ, Brazilian Aging Brain Study Group. Brain bank of the Brazilian aging brain study group - a milestone reached and more than 1,600 collected brains. Cell Tissue Bank. 2007;8(2):151-62.

Guidotti TL, McNamara J, Moses MS. The interpretation of trace element analysis in body fluids. Indian J Med Res. 2008 Oct;128(4):524-32.

Hardy J. A hundred years of Alzheimer's disease research. Neuron. 2006 Oct; 5;52(1):3-13.

Hebbrecht G, Maenhaut W, Reuck J. Brain trace elements and aging. Nucl Instr Meth Phys Res. 1999:208-13. 
Hendrix P, Van Cauwenbergh R, Robberecht H, Deelstra H. Daily dietary rubidium intake in Belgium using duplicate portion sampling. Z Lebensm Unters Forsch A. 1997;204:165-167.

Herz J. Overview: the long and winding road to understanding Alzheimer's disease. Neuron. 2007 Feb;15;53(4):477-9.

Huang X, Cuajungco MP, Atwood CS, Moir RD, Tanzi RE, Bush AI. Alzheimer's disease, beta-amyloid protein and zinc. J Nutr. 2000 May;130(5S Suppl):1488S$92 \mathrm{~S}$.

Instituto Brasileiro de Geografia e Estatística (IBGE). Perfil dos idosos responsáveis pelo domicílio no Brasil - 2000. Estudos e Pesquisas - Informação Demográfica e Socioeconômica. Rio de Janeiro: IBGE; 2002.

Instituto Brasileiro de Geografia e Estatística (IBGE). Pesquisa Nacional por Amostra de Domicílios; 2007 [citado 19 Abril 2009]. Disponível em: http://www.ibge.gov.br/home/estatistica/populacao/trabalhoerendimento/pnad2007/ default.shtm.

Instituto de Pesquisas Enrgéticas e Nucleares. Centro de Reator de Pesquisa [Citado em 14 de abril de 2009]. Disponível em: http://www.ipen.br.

International Atomic Energy Agency [Citado em 14 de abril de 2009]. Disponível em: http://www.iaea.org/

Jellinger KA. Alzheimer 100 - highlights in the history of Alzheimer research. J Neural Transm. 2006 Nov;113(11):1603-23.

Jorm AF, Jacomb PA. The Informant Questionnaire on Cognitive Decline in the Elderly (IQCODE): socio-demographic correlates, reliability, validity and some norms. Psychol Med. 1989;19(4):1015-22.

Jorm AF. A short form of the informant questionnaire on cognitive decline in the elderly (IQCODE): development and cross-validation. Psychol Med. 1994;24:145153.

Jorm AF. The Informant Questionnaire on cognitive decline in the elderly (IQCODE): a review. Int Psychogeriatr. 2004;16(3):275-93.

Kalache A. Envelhecimento populacional no Brasil: uma realidade nova. Cad. Saúde Pública [serial on the Internet]. 1987 Sep [citado 19 Abril 2009]; 3(3):217220. Disponível em: http://www.scielo.br/scielo.php?script=sci_arttext\&pid=S0102311 X1987000300001\&lng=en. doi: 10.1590/S0102-311X1987000300001.

Katz S, Downs TD, Cash HR, Grotz RC. Progress in development of the index of ADL. Gerontologist. 1970;10(1):20-30. 
Knopman DS, Parisi JE, Salviati A, Floriach-Robert M, Boeve BF, Ivnik RJ, Smith GE, Dickson DW, Johnson KA, Petersen LE, McDonald WC, Braak H, Petersen RC. Neuropathology of cognitively normal elderly. J Neuropathol Exp Neurol. 2003 Nov;62(11):1087-95.

Lannfelt L, Blennow K, Zetterberg H, Batsman S, AmesD, Harrison J, Masters CL, Targum S, Bush AI, Murdoch R, Wilson J, Ritchie CW, on behalf of the PBT2-201EURO study group. Safety, efficacy, and biomarker findings of PBT2 in targeting $\mathrm{A} \beta$ as a modifying therapy for Alzheimer's disease: a phase IIa, double-blind, randomised, placebo-controlled trial. Lancet Neurol. 2008;7:779-86.

Lawton MP, Brody EM. Assessment of older people: self-maintaining and instrumental activities of daily living. Gerontologist. 1969;9:179-186.

Leite REP, Jacob-Filho W, Saiki M, Grinberg LT, Ferretti REL. Determination of trace elements in human brain tissues using neutron activation analysis. J Radioanal Nucl Chem. 2008;278(3):581-584.

Lim WS, Chin JJ, Lam CK, Lim PP, Sahadevan S. Clinical Dementia Rating: Experience of a Multi-Racial Asian Population. Alzheimer Dis Assoc Disord. 2005;19(3):135-142.

Lopes MA, Bottino CMC. Prevalência de demência em diversas regiões do mundo: Análise dos estudos epidemiológicos de 1994 a 2000. Arq Neuro-Psiquiatr. [serial on the Internet]. 2002 Mar [citado 19 Abril 2009];60(1):61-69. Disponível em: http://www.scielo.br/scielo.php?script=sci_arttext\&pid=S0004282X2002000100012\&lng=en. doi: 10.1590/S0004-282X2002000100012.

Lovell MA, Robertson JD, Teesdale WJ, Campbell JL, Markesbery WR. Copper, iron and zinc in Alzheimer's disease senile plaques. J Neurol Sci. 1998 Jun $11 ; 158(1): 47-52$.

McCulla MM, Coats M, Van Fleet N, Duchek J, Grant E, Morris JC. Reliability of clinical nurse specialists in the staging of dementia. Arch Neurol. 1989;46(11):1210-1.

McKeith IG, Dickson DW, Lowe J, Emre M, O'Brien JT, Feldman H, Cummings J, Duda JE, Lippa C, Perry EK, Aarsland D, Arai H, Ballard CG, Boeve B, Burn DJ, Costa D, Del Ser T, Dubois B, Galasko D, Gauthier S, Goetz CG, Gomez-Tortosa E, Halliday G, Hansen LA, Hardy J, Iwatsubo T, Kalaria RN, Kaufer D, Kenny RA, Korczyn A, Kosaka K, Lee VM, Lees A, Litvan I, Londos E, Lopez OL, Minoshima S, Mizuno Y, Molina JA, Mukaetova-Ladinska EB, Pasquier F, Perry RH, Schulz JB, Trojanowski JQ, Yamada M; Consortium on DLB. Diagnosis and management of dementia with Lewy bodies: third report of the DLB consortium. Neurology. 2005;65:1863-1872.

McKeith IG, Galasko D, Kosaka K, Perry EK, Dickson DW, Hansen LA, Salmon DP, Lowe J, Mirra SS, Byrne EJ, Lennox G, Quinn NP, Edwardson JA, Ince PG, 
Bergeron C, Burns A, Miller BL, Lovestone S, Collerton D, Jansen EN, Ballard C, de Vos RA, Wilcock GK, Jellinger KA, Perry RH. Consensus guidelines for the clinical and pathologic diagnosis of dementia with Lewy bodies (DLB): report of the consortium on DLB international workshop. Neurology. 1996;47(5):1113-24.

McKhann GM, Albert MS, Grossman M, Miller B, Dickson D, Trojanowski JQ, Work Group on Frontotemporal Dementia and Pick's Disease. Clinical and pathological diagnosis of frontotemporal dementia: report of the Work Group on Frontotemporal Dementia and Pick's Disease. Arch Neurol. 2001;58(11):1803-9.

Meseguer I, Molina JA, Jiménez-Jiménez FJ, Aguilar MV, Mateos-Vega CJ, González-Muñoz MJ, de Bustos F, Ortí-Pareja M, Zurdo M, Berbel A, Barrios E, Martínez-Para MC. Cerebrospinal fluid levels of selenium in patients with Alzheimer's disease. J Neural Transm. 1999;106(3-4):309-15.

Mirra SS, Heyman A, McKeel D, Sumi SM, Crain BJ, Brownlee LM, Vogel FS, Hughes JP, van Belle G, Berg L. The Consortium to Establish a Registry for Alzheimer's Disease (CERAD). Part II. Standardization of the neuropathologic assessment of Alzheimer's disease. Neurology. 1991;41(4):479-86.

Montaño MB, Ramos LR. Validity of the Portuguese version of Clinical Dementia Rating. Rev Saúde Pública. 2005;39(6):912-7.

Morris JC. The clinical dementia rating (CDR):current version and scoring rules. Neurology. 1993;43:2412-2414.

Nakagawa N. Studies on changes in trace elements of the brain related to aging. Hokkaido Igaku Zasshi. 1998 Mar;73(2):181-99.

National Institute of Standards and Technology, Certificate of Analysis: SRM 1566b Oyster Tissue, Gaithersburg, 2001.

National Institute of Standards and Technology, Certificate of Analysis: SRM 1577b Bovine Liver, Gaithersburg, 1991.

Nestor PJ, Scheltens P, Hodges JR. Advances in the early detection of Alzheimer's disease. Nat. Med. 2004 Jul;10 Suppl: S34-41.

Neter J, Kutner MH, Nachtsheim CJ, Li W. Applied Linear Statistical Models. 5th ed. Chicago: Irwin; 2005.

Nitrini R, Caramelli P, Bottino CM, Damasceno BP, Brucki SM, Anghinah R, Academia Brasileira de Neurologia. Diagnosis of Alzheimer's disease in Brazil: cognitive and functional evaluation. Recommendations of the Scientific Department of Cognitive Neurology and Aging of the Brazilian Academy of Neurology. Arq Neuropsiquiatr. 2005;63(3A):720-7. 
Nitrini R, Caramelli P, Herrera E Jr, Bahia VS, Caixeta LF, Radanovic M, Anghinah R, Charchat-Fichman H, Porto CS, Carthery MT, Hartmann AP, Huang $\mathrm{N}$, Smid J, Lima EP, Takada LT, Takahashi DY. Incidence of dementia in a community-dwelling Brazilian population. Alzheimer Dis Assoc Disord. 2004 OctDec;18(4):241-6.

Nunomura A, Perry G, Aliev G, Hirai K, Takeda A, Balraj EK, Jones PK, Ghanbari H, Wataya T, Shimohama S, Chiba S, Atwood CS, Petersen RB, Smith MA. Oxidative damage is the earliest event in Alzheimer disease. J Neuropathol Exp Neurol. 2001 Aug;60(8):759-67.

Organização Mundial de Saúde (OMS). Envelhecimento ativo: uma política de saúde. Brasília: Organização Pan-Americana da Saúde; 2005.

Panayi AE, Spyrou NM, Iversen BS, White MA, Part P. Determination of cadmium and zinc in Alzheimer's brain tissue using inductively coupled plasma mass spectrometry. J Neurol Sci. 2002 Mar 15; 195(1): 1-10.

Panayi AE, Spyrou NM, Part P. Differences in trace element between Alzheimer and "normal" human brain tissue using instrumental neutron activation analysis (INAA). J Radioanal Nucl Chem. 2001;249(2):437-41.

Panayi AE, Spyrou NM, Ubertalii LC, Akanle OA, Part P. Differences in trace element concentration between the right and left hemispheres of human brain using INAA. J Radioanal Nucl Chem. 2000;244(1):205-207.

Papaléo-Netto, M. O estudo da velhice no século XX: histórico, definição do campo e termos básicos. In: Freitas EV e colaboradores. Tratado de Geriatria e Gerontologia. $2^{\mathrm{a}}$ edição. Rio de Janeiro: Guanabara Koogan, 2006.

Petrini M, Vaglini F, Carulli G, Azzarà A, Ambrogi F, Grassi B. Rubidium is a possible supporting element for bone marrow leukocyte differentiation. Haematologica. 1990 Jan-Feb;75(1):27-31.

Religa D, Strozyk D, Cherny RA, Volitakis I, Haroutunian V, Winblad B, Naslund J, Bush AI. Elevated cortical zinc in Alzheimer disease. Neurology. 2006 Jul $11 ; 67(1): 69-75$.

Roskams AJ, Connor JR. Iron, transferrin, and ferritin in the rat brain during development and aging. J Neurochem. 1994 Aug;63(2):709-16.

Saiki M, Jaluul O, Sumita NM, Vasconcellos MB, Jacob Filho W. Trace element contents in serum of healthy elderly population of metropolitan São Paulo area in Brazil. Trace Elem Med Biol. 2007;21 Suppl 1:70-3.

Saito Y, Ruberu NN, Sawabe M, Arai T, Tanaka N, Kakuta Y, Yamanouchi H, Murayama S. Staging of argyrophilic grains: an age-associated tauopathy. J Neuropathol Exp Neurol. 2004;63(9):911-8. 
Schenk D, Barbour R, Dunn W, Gordon G, Grajeda H, Guido T, Hu K, Huang J, Johnson-Wood K, Khan K, Kholodenko D, Lee M, Liao Z, Lieberburg I, Motter R, Mutter L, Soriano F, Shopp G, Vasquez N, Vandevert C, Walker S, Wogulis M, Yednock T, Games D, Seubert P. Immunization with amyloid-beta attenuates Alzheimer-disease-like pathology in the PDAPP mouse. Nature. 1999 Jul 8;400(6740):173-7.

Schmitt FA, Davis DG, Wekstein DR, Smith CD, Ashford JW, Markesbery WR. "Preclinical" AD revisited: neuropathology of cognitively normal older adults. Neurology. 2000 Aug 8;55(3):370-6.

Schweizer U, Bräuer AU, Köhrle J, Nitsch R, Savaskan NE. Selenium and brain function: a poorly recognized liaison. Brain Res Brain Res Rev. 2004 Jul;45(3):16478 .

Serviço de Verificação de Óbitos da Capital - USP [Citado em 14 de abril de 2009]. Disponível em: http://www.svoc.usp.br.

Small DH, Cappai R. Alois Alzheimer and Alzheimer's disease: a centennial perspective. J Neurochem. 2006 Nov;99(3):708-10.

Smith MA, Perry G. What are the facts and artifacts of the pathogenesis and etiology of Alzheimer disease? J Chem Neuroanat. 1998 Dec;16(1):35-41.

Spyrou NM. Neutron activation analysis challenges: Problems and applications in biomedical and other areas. J Radioanal Nucl Chem. 1999 Jan; 239(1):59-70.

Stern Y. What is cognitive reserve? Theory and research application of the reserve concept. J Int Neuropsychol Soc. 2002 Mar;8(3):448-60.

Tamano H, Enomoto S, Oku N, Takeda A. Preferential uptake of zinc, manganese, and rubidium in rat brain tumor. Nucl Med Biol. 2002 May;29(4):505-8.

Tanner C, Gilley D, Goetz C. A brief screening questionnaire for Parkinsonism. Ann Neurol. 1990;28:267-268.

The National Institute on Aging, Reagan Institute Working Group on Diagnostic Criteria for the Neuropathological Assessment of Alzheimer's Disease. Consensus recommendations for the postmortem diagnosis of Alzheimer's disease. Neurobiol Aging. 1997;18(4 Suppl):S1-2.

Thompson CM, Markesbery WR, Ehmann WD, Mao YX, Vance DE. Regional brain trace-element studies in Alzheimer's disease. Neurotoxicology. 1988 Spring;9(1):1-7.

Tõugu V, Karafin A, Palumaa P. Binding of zinc(II) and copper(II) to the fulllength Alzheimer's amyloid-beta peptide. J Neurochem. 2008 Mar;104(5):1249-59. 
Troulinaki K, Tavernarakis N. Neurodegenerative conditions associated with ageing: a molecular interplay? Mech Ageing Dev. 2005 Jan;126(1):23-33.

Vance DE, Ehmann WD, Markesbery WR. A search for longitudinal variations in trace element levels in nails of Alzheimer's disease patients. Biol Trace Elem Res. 1990 Jul-Dec;26-27:461-70.

Versieck J, Hoste J, Barbier F, Michels H, De Rudder J. Simultaneous determination of iron, zinc, selenium, rubidium, and cesium in serum and packed blood cells by neutron activation analysis. Clin Chem. 1977 Jul;23(7):1301-5.

Vilela LP, Caramelli P. A doença de Alzheimer na visão de familiares de pacientes. Rev Assoc Med Bras [serial on the Internet]. 2006 June [citado 19 Abril 2009]; 52(3):148-152. Disponível em: http://www.scielo.br/scielo.php?script=sci_arttext\&pid=S0104$42302006000300014 \& \operatorname{lng}=$ en. doi: 10.1590/S0104-42302006000300014.

Welsh-Bohmer KA, White CL 3rd. Alzheimer disease: what changes in the brain cause dementia? Neurology. 2009 Jan 27;72(4):e21.

Wenstrup D, Ehmann WD, Markesbery WR. Trace element imbalances in isolated subcellular fractions of Alzheimer's disease brains. Brain Res. 1990 Nov 12;533(1):125-31.

Williams RH, Maturen A, Sky-Peck HH. Pharmacologic role of rubidium in psychiatric research. Compr Ther. 1987 Sep;13(9):46-54.

Yushmanov VE, Kharlamov A, Boada FE, Jones SC. Monitoring of brain potassium with rubidium flame photometry and MRI. Magn Reson Med. 2007 Mar;57(3):494-500. 